\title{
Enzymatic reactions involving the heteroatoms from organic substrates
}

\author{
CATERINA G.C. MARQUES NETTO ${ }^{1,2}$, DAYVSON J. PALMEIRA ${ }^{1}$, \\ PATRÍCIA B. BRONDANI ${ }^{3}$ and LEANDRO H. ANDRADE ${ }^{1}$
}

\author{
${ }^{1}$ Departamento de Química Fundamental, Universidade de São Paulo, Avenida \\ Prof. Lineu Prestes, 748, 05508-000 São Paulo, SP, Brazil \\ ${ }^{2}$ Departamento de Química, Universidade Federal de São Carlos, Rodovia \\ Washington Luis, s/n, Km 235, 13565-905 São Carlos, SP, Brazil \\ ${ }^{3}$ Departamento de Ciências Exatas e Educação, Universidade Federal de Santa \\ Catarina, Rua João Pessoa, 2750, 89036-256 Blumenau, SC, Brazil
}

Manuscript received on September 20, 2017; accepted for publication on January 1, 2018

\begin{abstract}
Several enzymatic reactions of heteroatom-containing compounds have been explored as unnatural substrates. Considerable advances related to the search for efficient enzymatic systems able to support a broader substrate scope with high catalytic performance are described in the literature. These reports include mainly native and mutated enzymes and whole cells biocatalysis. Herein, we describe the historical background along with the progress of biocatalyzed reactions involving the heteroatom( $\mathrm{S}, \mathrm{Se}, \mathrm{B}, \mathrm{P}$ and $\mathrm{Si})$ from hetero-organic substrates.
\end{abstract}

Key words: heteroatom, biocatalysis, enzymes, biotransformation.

\section{INTRODUCTION}

Enzymes act as Nature's machinery to obtain new molecules through energetically favorable reactions. This feature led chemists to incorporate enzymes in synthetic protocols to produce natural and unnatural heteroatom-containing organic molecules in an easier way for different purposes. Synthetic procedures involving the assimilation or transformation of heteroatom-containing molecules into organic compounds are common reactions employed in several organic (For recent reviews

Correspondence to: Leandro Helgueira Andrade

E-mail: leandroh@iq.usp.br

* Contribution to the centenary of the Brazilian Academy of Sciences. see: Gao et al. 2015, Applegate and Berkowitz 2015, Guan et al. 2015, Wallace and Balskus 2014, Anobom et al. 2014, Fesko and Gruber-Khadjawi 2013, Matsuda 2013) or organometallic protocols (Bergbreiter and Momongan 1992, Gnedenkot and Ryabov 1994, Howell and Palin 1996, Rigby and Sugathapala 1996 and Ryabov et al. 1998). Therefore, it is evident that there is a demand for the synthesis of relevant hetero-organic derivatives, with special attention to environmental-friendly reactions, such as the biocatalyzed-transformations.

The most common organic substrates for enzymes are alcohols (Goswami et al. 2013 and Somers et al. 1999), carbonylic compounds (Chang and Shaw 2009, Liederer and Borchardt 2006), phosphates (Konietzny and Greigner 2002, Servi 
1999), amines (Höhne and Bornscheuer 2009, Kohls et al. 2014) and amides (Boeriu et al. 2010, Gotor 1999). Considering the wide range of other elements present in Nature, only a modest number of biocatalytic applications have been developed (Schoemaker et al. 2003). In the field of catalysis, a high selectivity is not the sole target since a broad scope of substrates suitable for industrial application is often necessary (Lindbäck et al. 2014). In several cases, enzymes have high substrate specificity and catalytic efficiency (Demetrius 1998), which can give us an excellent opportunity in the search of new substrates for enzymatic catalysis.

Enzymatic reaction of hetero-organic substrates can be subdivided in two main categories: the enzymatic transformation occurring at the heteroatom, and the enzymatic transformation occurring in any other functional group of the organic substrate. In general, the prior reaction involves oxidation/reduction of the heteroatom or change in bonding between the heteroatom and the organic moiety. In this review, enzymatic reactions involving the heteroatom from hetero-organic substrates are discussed.

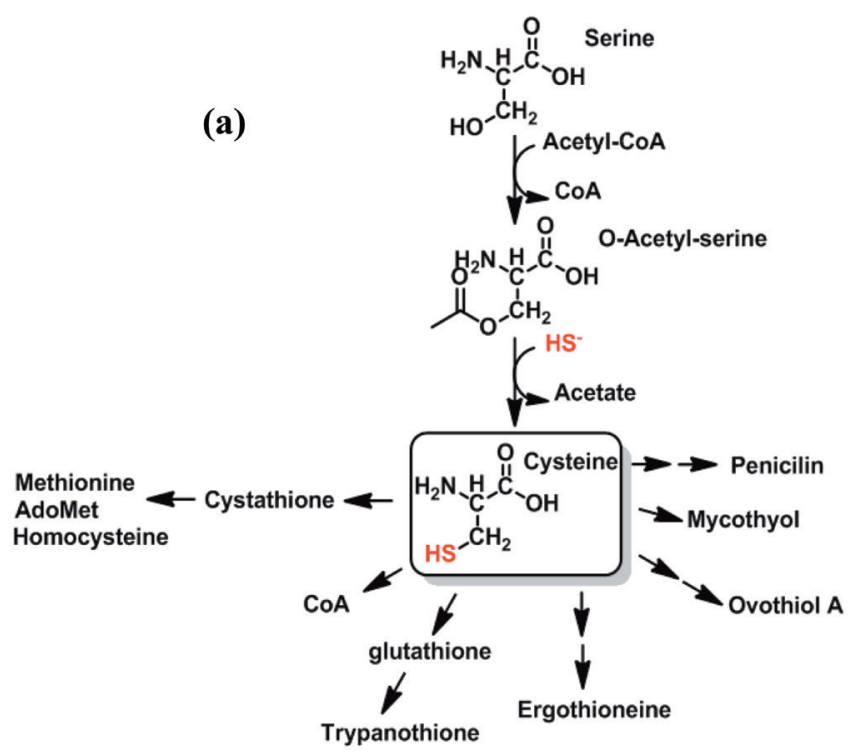

Figure 1 - Sulfur pathway in the metabolism of several organisms.

\section{SULFUR}

Life depends on sulfur's active redox chemistry. Therefore, sulfur constitutes an essential element found in amino acids and protein structures (Faloona 2009). The mechanism of its incorporation to organic molecules by several microorganisms and animals involves a prior reduction of sulfate to sulfide, followed by condensation with $\mathrm{L}$-serine to produce L-cysteine (Ellis 1953). Particularly, L-cysteine is used for the production of methionine, coenzyme A and several other important thiols as shown in Figure 1a. Persulfidic sulfur (R-S-SH) is another sulfur species that also play an important role in life's chemistry. These compounds provide an "active sulfur" able to undergo desulfuration reactions and to be transformed into FeS clusters, biotin, lipoic acid, thiamin, molybdopterin and thionucleosides, as shown in Figure 1b (Kessler 2006).

The production of these important metabolic thiols and persulfidic species demands the action of enzymes. For example, penicillin biosynthesis requires condensation of cysteine, aminoadipic acid and valine. This process occurs in the

(b)

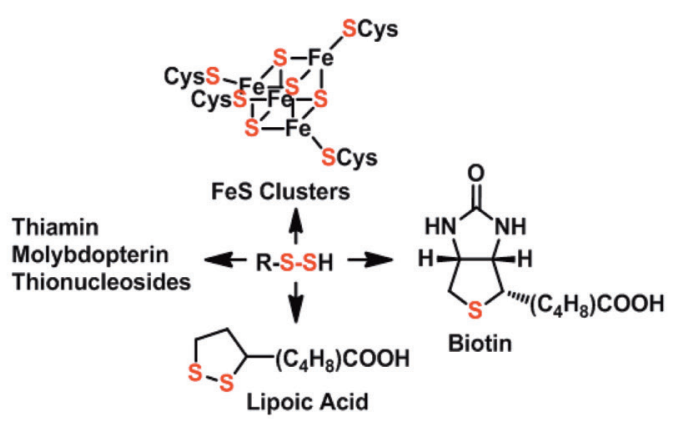


presence of isopenicillin $\mathrm{N}$-synthase (Baldwin and Abraham 1988) with complete retention of configuration. In fact, such specific reactions normally compel unique catalysts and fortunately, metabolic proteins are found in all different classes of enzymes, such as oxidoreductases (Sellmann and Sutter 1996), hydrolases (Kiełbasiński 2011), transferases (Papenbrock et al. 2011), lyases (Broderick et al. 2014), isomerases (Lillig and Berndt 2013) and ligases (Hicks et al. 2007). Examples of these enzymes are everywhere in nature (Oae and Okuyama 1992) and chemists can seize these catalysts to perform an unlimited number of reactions, including oxidations, reductions, hydrolysis and the addition of new functional groups to a certain molecule. Here, we present some of the important contributions on organosulfur biocatalytic proccess. Other important aspects of sulfur biotransformation is described elsewhere (Colonna 1994, Deasy and Maguire 2014, Fernández and Khia 2003, Holland 1992, 2001, 1988, Kiełbasiński 2011, Matsui et al. 2014, O’Mahony et al. 2011).

\section{OXIDOREDUCTASES}

As previously stated, nature performs the conversion of sulfur containing molecules to produce important metabolites. An example of oxidoreductase acting on sulfur chemistry is $\mathrm{NAD}(\mathrm{P}) \mathrm{H}$ elemental sulfur oxidoreductase (NSR). This enzyme is able to reduce elemental sulfur to $\mathrm{H}_{2} \mathrm{~S}$ (Schut et al. 2007). The mechanism of $\mathrm{H}_{2} \mathrm{~S}$ synthesis involves the formation of di-, per-, and polysulfide derivatives of coenzyme A, as shown in Figure 2 (Herwald et al. 2013). This type of enzyme is responsible for the anti-oxidative stress in certain microorganisms, indicating its essential role in the metabolism of species in environments with low levels of oxygen.

The detection of oxidoreductase enzymes in whole cells permits the discovery and isolation of new enzymes that can be applied in

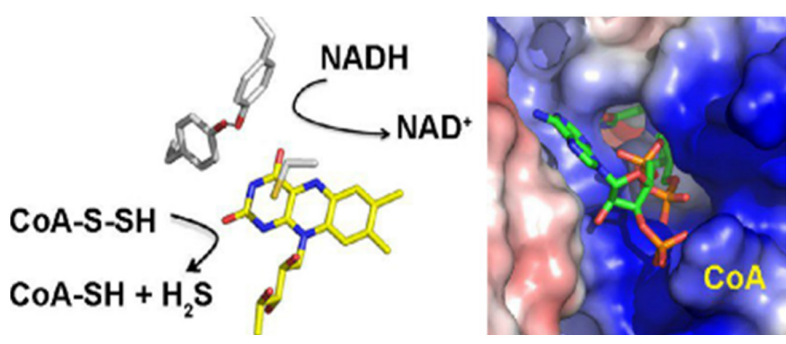

Figure 2 - Possible mechanism for disulfide reductase. Reprinted with permission from American Chemical Society. (Herwald et al. 2013). Copyright 2015 American Chemical Society.

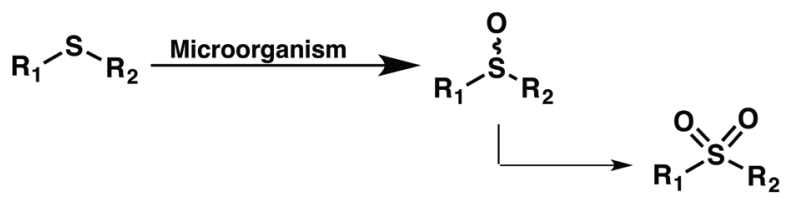

Figure 3 - Oxidation of a sulfide to sulfoxides and sulfone.

biotransformations with synthetic targets. The presence of these enzymes can be simply detected in vivo by $\mathrm{PbS}$ formation on a paper embedded with $\mathrm{Pb}(\mathrm{OAc})_{2}$ (Zhang and Weiner 2014). Isolated NSR enzymes have not yet been used in biotransformations, however, whole cells and other oxidoreductases have been used for the oxidation/ reduction of organosulfur compounds as will be evident from this review.

\section{OXIDATION REACTIONS}

Most of the contributions on biotransformation of organosulfur compounds are based on the oxidation of a sulfide to a sulfoxide, as shown in Figure 3 (Holland 2001, Benoit et al. 1993, Chen et al. 1999, Fang et al. 1995). The main concern with this reaction is to avoid sulfone formation, which is a product from sulfoxide over oxidation. Sulfoxides possess enantiomers due to the sulfur atom as a stereocenter in a pyramidal structure (Alphand and Wohlgemuth 2010, Bzhezovsky et al. 2004, Reed and Schleyer 1990, Bzhezovskii et al. 2005).

The synthesis of chiral organic sulfoxides gained its reputation due to their usefulness as synthons (Alwedi et al. 2014) and as chiral 
auxiliaries in asymmetric reactions (Matsui et al. 2014, Pellissier 2006). There are several methods to pursue the synthesis of chiral sulfoxides (Pellissier 2006): for instance, transformation of a pure sulfonate, kinetic resolution of a racemic mixture, enantioselective oxidation of prochiral sulfides and modification of the structure of some chiral sulfoxides without any loss of stereochemistry (Kagan 2009).

The pioneer studies on biotransformations of organosulfur compounds were based on fermentation by certain microorganisms (Holland 1988, Holland et al. 1994b, Tang et al. 1995). The initial steps of discovering S-oxygenation were performed by Wright et al. (1954a, b). In these studies, $l$-sulfoxide biotin was synthesized from biotin oxidation when pimelic acid was added to cultures of Aspergillus niger Figure 4. Curiously, fermentation using Neurospora crassa resulted in both biotin sulfoxides enantiomers, whereas, the oxidation by Aspergillus niger yielded predominantly the levo form. In order to prove that the levo form was not produced by a nonenzymatic reaction, an assay was performed by Wright et al. (1954a), in which they observed that the dextro-form was the predominant product in the absence of an organism, suggesting a product from chemical oxidation by air. Based on these results, the authors concluded that the opposite form ( $l$-sulfoxide biotin) was obtained by an enzymatic system of Aspergillus niger.

Aspergillus niger has also shown an $(R)$ stereoselectivity in microbiological oxidations ranging from 4 to $98 \%$ of enantiomeric excess for different substrates (Auret et al. 1966). The best substrate was $t$-butyl- $p$-tolyl sulfide (24\% yield, $98 \%$ ee), presumably due to a better fit in the enzyme active site (Auret et al. 1966). By introducing a $p$-methyl substituent into the phenyl group, an increase from $5 \%$ to $77 \%$ of stereoselectivity (R-configuration) was observed. Therefore, high yields and optical purity are expected with a

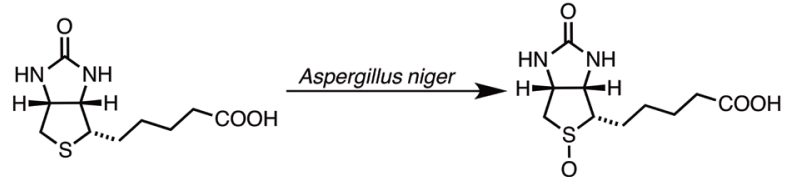

Figure 4 - Biotin-1-sulfoxide formation from the fermentation using A. niger (Wright et al. 1954b).

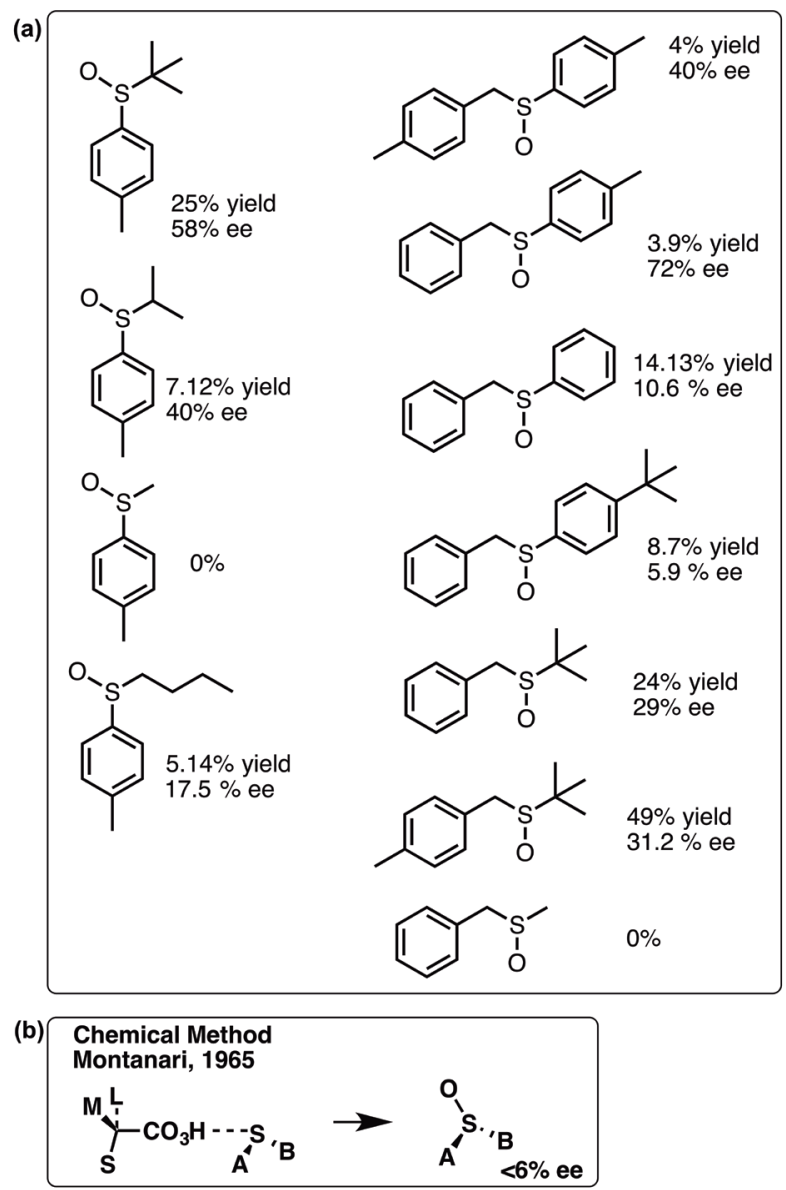

Figure 5 - Sulfoxides studied by Auret et al. (Auret et al. 1966) (a) and the chemical oxidation with $(+)$-percamphoric acid described by Montanari (1965) (b).

more efficient fit of the substrates in the enzyme active site. Auret et al. (1968), for example, have shown that the biooxidation of unsymmetrical sulfides resulted in products with higher optical activities (Figure 5a) than the available chemical method at that time, which was an oxidation via $(+)$-percamphoric acid, as seen in Figure 5b (Auret et al. 1968, Montanari 1965). 
The oxidation of methyl thiosteroids with strains of Calonectria decora was another mark in the history of sulfur-containing organic molecules. In this contribution, Holmlund et al. (1962) described the first stereoselective sulfur oxidation of steroids mediated by microorganisms.

Later on, oxidations of thioethers were performed with several strains of Rhizopus and Aspergillus by Auret et al. (1974). Reactions with Rhizopus species showed very low $(S)$ enantioselectivity (5-25\%) but in contrast, $A$. niger lead to moderate yields (20-30\%) and moderate to high ee for the $(R)$-sulfoxide (65-87\%) using aromatic thioethers as substrates, as shown in Table I . The oxidation of $t$-butyl benzyl thioether was also evaluated and the preferential formation of the (S)-t-butyl benzyl sulfoxide was observed for all strains of $A$. niger with a range of 6 to $77 \% \mathrm{ee}_{\mathrm{p}}$ and 10 to $46 \%$ yield. The enantiopreference for different substrates ( $t$-butyl benzyl thioether and the aromatic substrates) was not discussed further on by the authors. However, a discussion around the lower ee $(6 \%)$ and higher ee $(77 \%)$ is stated in the study, since both enantioselectivities came from the same $A$. niger strain NRRL 337. The main difference between these two cultures was the time interval in which the organisms were subcultured, one being subcultured over a 1-year period, while the other over a 9-year period. Therefore, since the 9 -year subcultured strain was the one presenting the lower ee, it was stated that possibly a spontaneous mutation occurred during the 9-year period and changed the enzyme activity, yielding to the formation of products in low enantioselectivities.

By changing the microorganism, Abushanab et al. (1978) were able to obtain both sulfoxide
TABLE I

Oxidation of several thioethers by $A$. niger strain NRRL 382.

\begin{tabular}{|c|c|c|c|c|}
\hline \multirow[b]{2}{*}{ Thioether } & \multicolumn{3}{|c|}{ Sulfoxide } & \multirow[b]{2}{*}{$\begin{array}{l}\text { Sulfone } \\
\text { Yield } \\
(\%)\end{array}$} \\
\hline & $\begin{array}{c}\text { Yield } \\
(\%)\end{array}$ & $\begin{array}{c}\text { Optical } \\
\text { purity } \\
(\%)\end{array}$ & $\begin{array}{l}\text { Config- } \\
\text { uration }\end{array}$ & \\
\hline & 30 & 86 & $R$ & 20 \\
\hline & 27 & 10 & $S$ & 5 \\
\hline & 30 & 65 & $R$ & 7 \\
\hline & 36 & 67 & $R$ & 4 \\
\hline & 23 & 4 & $R$ & 4 \\
\hline
\end{tabular}

enantiomers from methyl $p$-tolyl sulfide, as shown in Figure 6. In their work, Mortierella isabellina strain NRRL 1757 was able to convert methyl $p$-tolyl sulfide into the $(+)-(R)$-sulfoxide in $60 \%$ yield and $100 \%$ optical purity, while Helminthosporium $w$. NRRL 4671 produced the $(-)-(S)$-sulfoxide in $50 \%$ yield and $100 \%$ optical purity. These sulfoxides were used for the synthesis of $(R)$-mevalonolactone, which was obtained with only $17 \%$ optical purity (Abushanab et al. 1978).

Other substrates were also a matter of study in these initial years of sulfide oxidation. For example, a cyclic thioacetal, 1,3-dithian, was used as a substrate for biotransformation reactions (Auret et al. 1981). These reactions were performed in the presence of Mortierella isabellina, Aspergillus foetidus and Helminthosporium species, obtaining 1,3-dithian 1-oxide, Figure 7. The enantiomeric excess for the

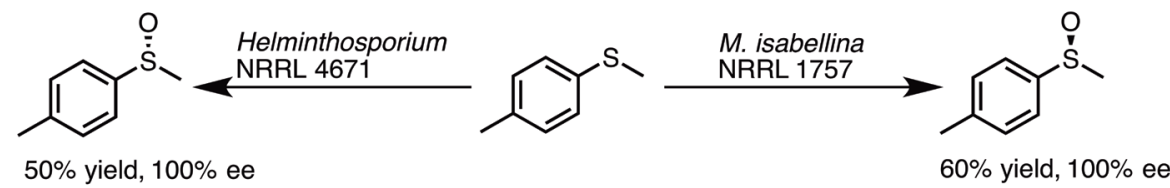

Figure 6 - Production of optical pure sulfoxides with different microorganisms. 
cyclic thioacetal was relatively low (0-20\%). In the same study, Auret et al. (1981) also performed the reduction of 1,3-dithian 1-oxide, 1,3,5-trithian 1-oxide, and cis-1,3-dithian 1,3-dioxide with $M$. isabellina, showing a preferential reduction of the $(S)$-sulfoxide to the corresponding thiane, but with very low ee (1-16\%) (Auret et al. 1981). This study indicated that cyclic thioacetals and sulfoxides are poor substrates for biotransformation using the selected fungi.

Searching for new microorganisms able to perform sulfide oxidation, Ohta et al. have found that Corynebacterium equi IFO 3730 was able to oxidize alkyl aryl sulfides to optically active $(R)$ sulfoxides and sulfones (Ohta et al. 1985). The enzyme activity was dependent on the growth phase, with oxidation reactions occurring only at the logarithmic phase. Therefore, Ohta et al. (1985)

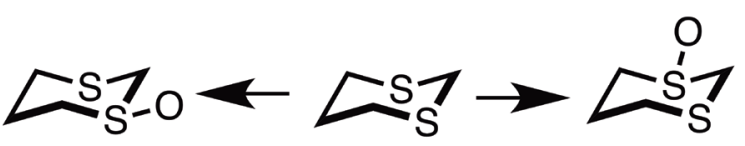

(S)

$(R)$

$15-20 \%$ ee

$3-22 \%$ ee

Figure 7 - Oxidation of 1,3-dithian in the presence of different fungi. found out that sulfide should be added at the same time as inoculation of the seed culture in order to obtain sulfoxides. In this work, sulfones synthesis was suppressed (from $88 \%$ to $0 \%$ ) by the decrease of the carbon chain size next to the sulfur atom, as shown in Table II. These results indicate that perfect substrates should have larger and bulkier substituent at the aryl moiety. The enantioselectivity found for Corynebacterium equi IFO 3730 demonstrated that Ohta et al. (1985) method was favorable for $(R)$ alkyl aryl sulfides oxidation.

After analyzing these initial contributions on sulfide oxidation to sulfoxides, it is evident that while some sulfoxides were interesting due to their metabolic action (Casida et al. 1975, Wright and Cresson 1954), others were targeted or used for the synthesis of more complex compounds. Historically, the search for novel enzymes to achieve high optical purity and yields was always an important goal. As shown previously, the first $100 \%$ optical purity was reported in 1978 (Abushanab et al. 1978) with two different microorganisms, Mortierella isabellina strain NRRL 17578 and Helminthosporium w. NRRL 4671. Nevertheless, most of the examples described until 1985 presented low selectivity and/ or low yield of sulfoxide synthesis.

TABLE II

Oxidation of the alkyl-aryl sulfides by Corynebacterium equi IFO 3730 (Ohta et al. 1985).

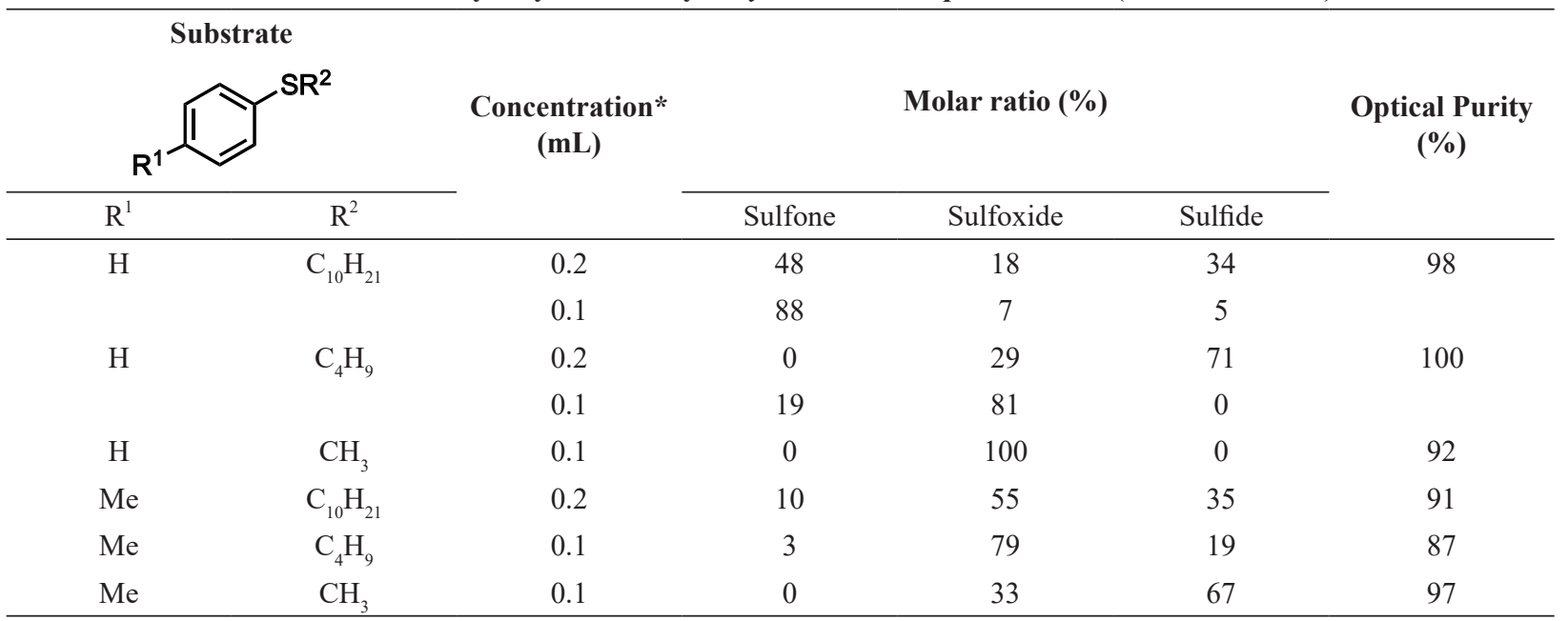

* Substrate: Sulfide was added to a $50 \mathrm{~mL}$ of the reaction medium. 


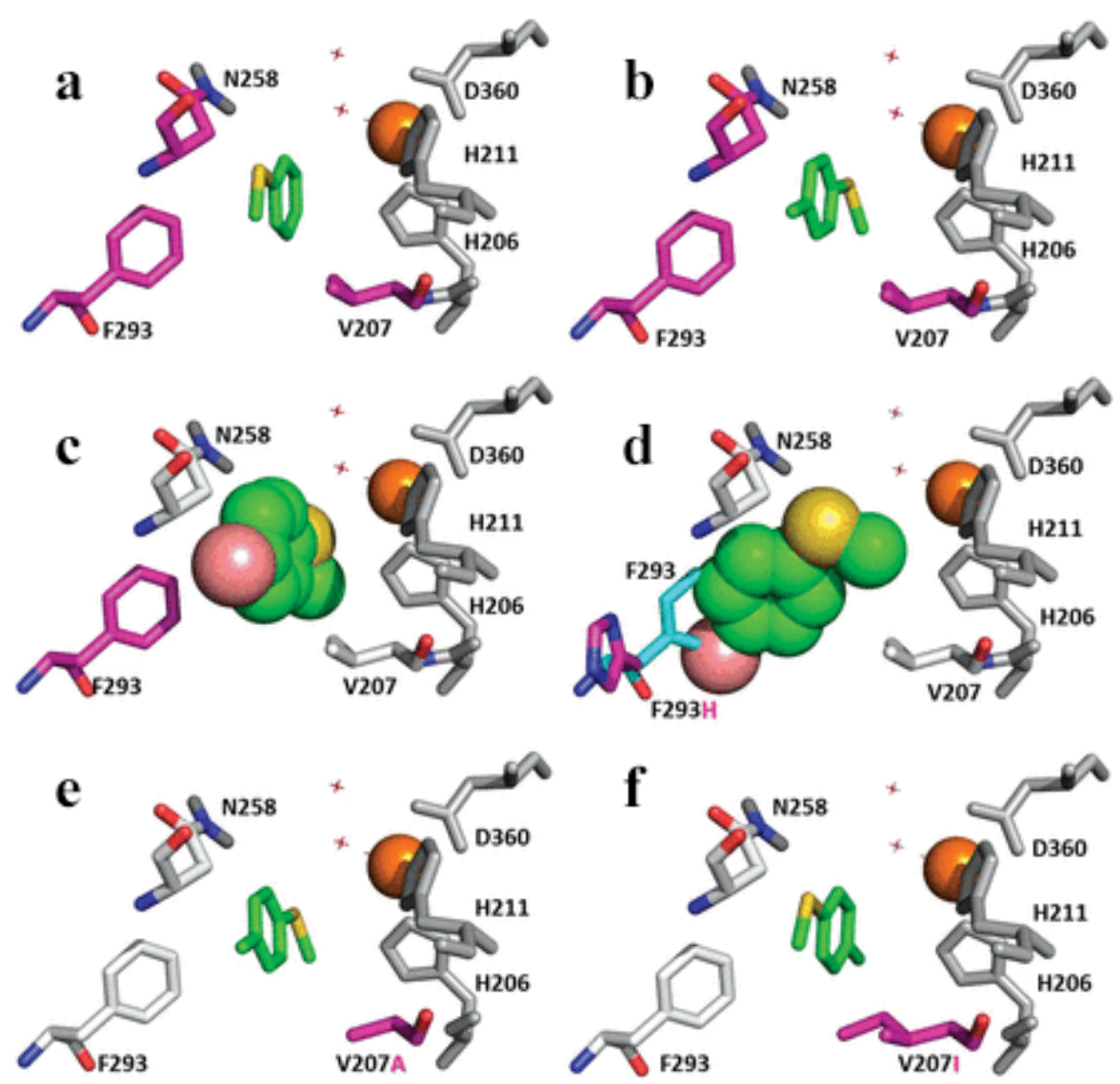

Figure 8 - Molecular models of thioanisole, Br-thioanisole and Me-thioanisole in the active site. The amino acid residues that were subjected to mutagenesis are presented in magenta color (V207, F293 and N258). (a) Thioanisole in wild type active site; (b) p-tolyl in wild type active site, (c) Br-thioanisole in wild-type active site, (d) Br-thioanisole in F293H, (e) p-tolyl in V207A modified enzyme and (f) p-tolyl in V207I modified enzyme. Reprinted with permission from Oxoford University Press. (Shainsky et al. 2013) Copyright 2015 Oxford University Press.

Protein engineering is one option to obtain the desired specificity and activity of a particular enzyme and can facilitate the use of less common substrates (Krishna 2002, Prabhulkar et al. 2012). The influence of some mutations on the selectivity of a redox enzyme was described by Shainsky et al. (2013), who studied the oxidation of thioanisole derivatives. In the oxidation by wild-type cells, the selectivity decreases in the following order: thioanisole $>$ Me-thioanisole $>$ Cl-thioanisole $>\mathrm{Br}$ thioanisole, while the N258 variants showed an increase in ee (from zero to up to $80 \%$ ), yielding the $(R)$-enantiomer for all substrates. Cell variant
V207I had improved the original pro- $(R)$ enantioselectivity. The authors suggested that the main influence on the enzyme activity and selectivity is the substrate size and its coordination in the active site which can be influenced by hydrophobic interactions and steric factors, as seen by an in silico docking (Figure 8).

Nikodinovic-Runic et al. (2013) also used engineered enzymes. Styrene monooxygenase (SMO) from P. putida CA-3 was employed in the native and mutated forms for the oxygenation of several substituted thioanisoles. The engineered SMO (R3-11) proved to produce chiral sulfoxides 
with similar ee when compared to the native SMO with preferential $(R)$-configuration $(0-84 \%$ ee). However, the mutated SMO converted the substrates much faster when compared to the native enzyme, as can be seen in Table III. The lower reaction rate of benzo[b]thiophene and 2-substituted thioanisoles compared to thioanisole in the wildtype enzyme could be due to the presence of a more rigid and bulkier heterocyclic ring structure in benzo[b]thiophene and 2-substituted moieties. In the engineered enzyme, the $\beta 4$ strand has subtle but significant changes in enzyme conformation, affecting its active site, widening the binding pocket, therefore, and increasing the reaction rates.

As previously shown by Auret et al. (1966), the introduction of a $p$-methyl substituent into the S-phenyl group gave an increase of $5 \%$ to $77 \%$ in the stereoselectivity of the sulfide oxidation, which suggested the existence of a hydrophobic pocket in the enzyme and, consequently, a better fit of these substrates in the active site. However, only after 29 years, the initial ideas of an active site model for the oxidation reaction of sulfides were developed. Nowadays, in silico docking calculations can be used to determine the best substrate fit in an enzyme active site (Damborsky and Brezovsk 2014, Konc et al. 2015), but these calculations are strongly dependent on the existence of an enzyme crystal structure, whereas the older methodologies can guide scientists to the development of a substrateenzyme theory on non-crystallized enzymes.

Ottolina et al. $(1995,1996)$ described a cubic model and the possible orientation of the substrates in the active site as an attempt to give a more comprehensive view of enzyme catalysis. For example, the S-oxygenation by Mortierella isabellina and Helminthosporium sp., in which Huang et al. (2002) demonstrated substrates with low conversions were crucial for defining a model of active site. In this study, even though some substrates exhibited a slow rate of S-oxygenation, the opposite orientation adopted by these sulfides
TABLE III

Reaction rates for different substrates $(\mu \mathrm{mol} / \mathrm{min} / \mathrm{g})$ with wild type (native SMO) and engineered SMO enzymes (Eng. SMO).

\begin{tabular}{|c|c|c|c|c|}
\hline \multirow[b]{2}{*}{ Substrate } & \multirow{2}{*}{$\begin{array}{l}\text { Native } \\
\text { SMO }\end{array}$} & \multirow{2}{*}{$\begin{array}{l}\text { Eng. } \\
\text { SMO }\end{array}$} & \multicolumn{2}{|c|}{ Sulfoxide } \\
\hline & & & ee & $\begin{array}{l}\text { Abs. } \\
\text { Conf }\end{array}$ \\
\hline Thioanisole & $83.3 \pm 0.9$ & $98.1 \pm 0.4$ & $45 \%$ & $R$ \\
\hline 2-Methylthioanisole & $34.5 \pm 0.5$ & $64.8 \pm 0.5$ & $84 \%$ & $S$ \\
\hline 2-Chlorothioanisole & $33.4 \pm 0.4$ & $93.4 \pm 0.4$ & $6 \%$ & $R$ \\
\hline 2-Bromothioanisole & $40.2 \pm 0.3$ & $83.1 \pm 0.9$ & $50 \%$ & $R$ \\
\hline 4-Methylthioanisole & $47.8 \pm 0.6$ & $58.9 \pm 0.5$ & $12 \%$ & $R$ \\
\hline 4-Chlorothioanisole & $78.6 \pm 0.8$ & $92.5 \pm 0.6$ & $10 \%$ & $S$ \\
\hline 4-Bromothioanisole & $70.8 \pm 0.5$ & $88.9 \pm 0.9$ & $23 \%$ & $R$ \\
\hline Benzo[b]thiophene & $8.8 \pm 0.5$ & $89.0 \pm 0.8$ & nd & $R$ \\
\hline $\begin{array}{l}\text { 2-Methylbenzo[b] } \\
\text { thiophene }\end{array}$ & $7.2 \pm 0.4$ & $40.1 \pm 0.8$ & $3 \%$ & $S$ \\
\hline
\end{tabular}

when compared to the well-accepted substrates, suggested that geometric and/or electrostatic features of the enzymes are involved in the regioand stereo-specificities of the reaction. In another report, the proposed model for the active site of cyclohexanone monooxygenase is described as having three hydrophobic pockets: the main pocket $(\mathrm{M})$ as well as a small $\left(\mathrm{H}_{\mathrm{S}}\right)$ and a large $\left(\mathrm{H}_{\mathrm{L}}\right)$ pocket, Figure 4. In this model, the circled area locates the position of sulfur (or $\mathrm{S}=\mathrm{O}$ for products) in the molecule. Even though the small pocket has a hydrophobic character, it is also known that $\mathrm{H}_{\mathrm{S}}$ is probably the natural pocket for hydroxyl group in Baeyer-Villiger oxidation of cyclic ketones. This suggests the existence of a polar-site directing the substrate orientation. For this reason an increase in hydrophobicity in this site decreases the ee (from 99\% to 12\%) (Ottolina et al. 1995), Figure 9.

It is reasonable to say that sulfide structures dramatically influence not only the enantioselectivity, but also the profile of an oxidation reaction with cyclohexanone monooxygenase. This biotransformation can yield sulfoxides in high enantiomeric excesses, achieving 99\% ee ( $R$-configuration) and 93\% ee ( $S$-configuration) (Ottolina and Carrea 2002) . 

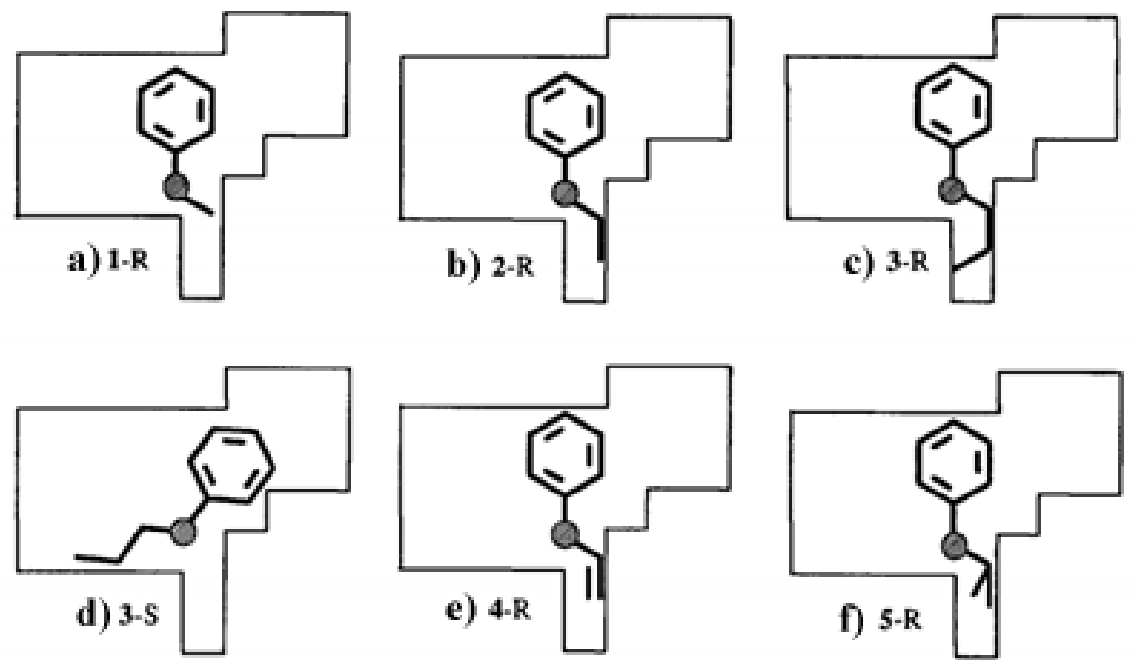

Figure 9 - Top perspective view of the active site model showing the preferred binding modes for phenyl alkyl sulfides. Reprinted with permission from Elsevier (Ottolina et al. 1995). Copyright 2015 Elsevier.

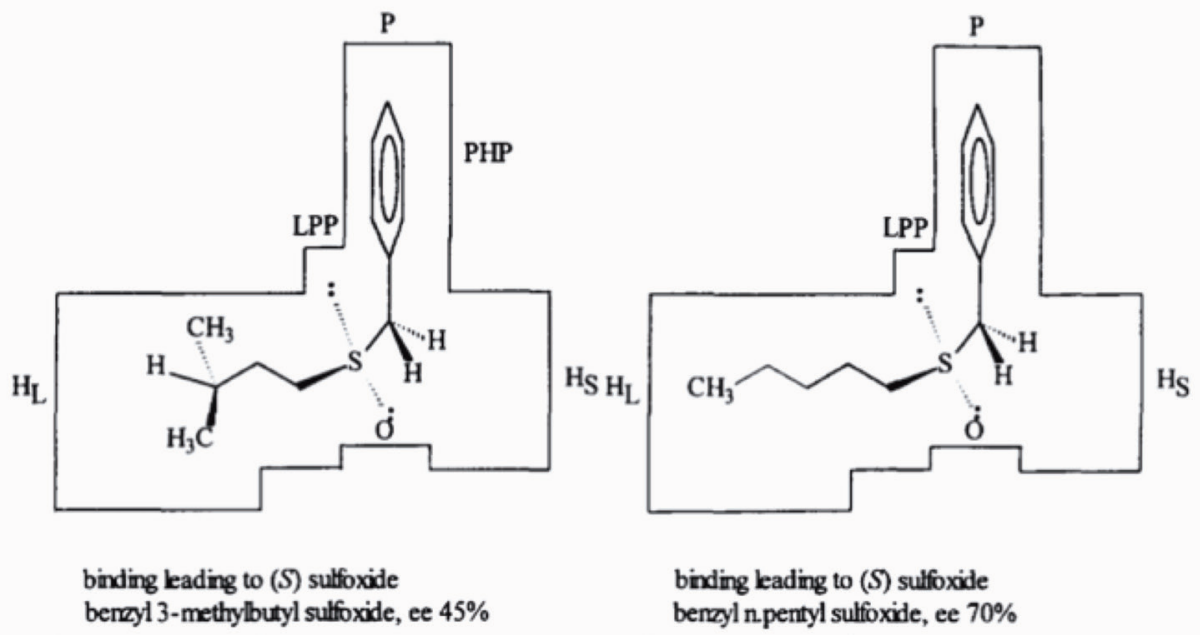

Figure 10 - Binding model for substrates bearing large alkyl groups. (Holland et al. 1997b) Reprinted with permission from Elsevier (Holland et al. 1997b). Copyright 2015 Elsevier.

The proposed "cubic model" had been examined for other substrates, demonstrating that the orientation inside the active-site model is dominated by hydrophobic interactions and steric hindrances. Based on the stereochemical outcome of over 90 biooxidations of organic sulfides, Holland et al. (1997a, b, 1999b) elegantly proposed a model which explains the enantioselectivity of the biotransformation depending on the substrate structure and its orientation inside the active site.
For instance, large alkyl groups predominantly bind at the large hydrophobic pocket $\left(\mathrm{H}_{\mathrm{L}}\right)$ while the benzylic methylene is accommodated in the small pocket, thus leading to high ee (45 and $70 \%$ ), Figure 10. On the other hand, the smaller alkyl groups can fit either in the small hydrophobic pocket $\left(\mathrm{H}_{\mathrm{S}}\right)$ or in the $\mathrm{H}_{\mathrm{L}}$, decreasing the enantioselectivity of the transformation (ee $=0 \%$ ), Figure 11, (Holland et al. 1997b). 


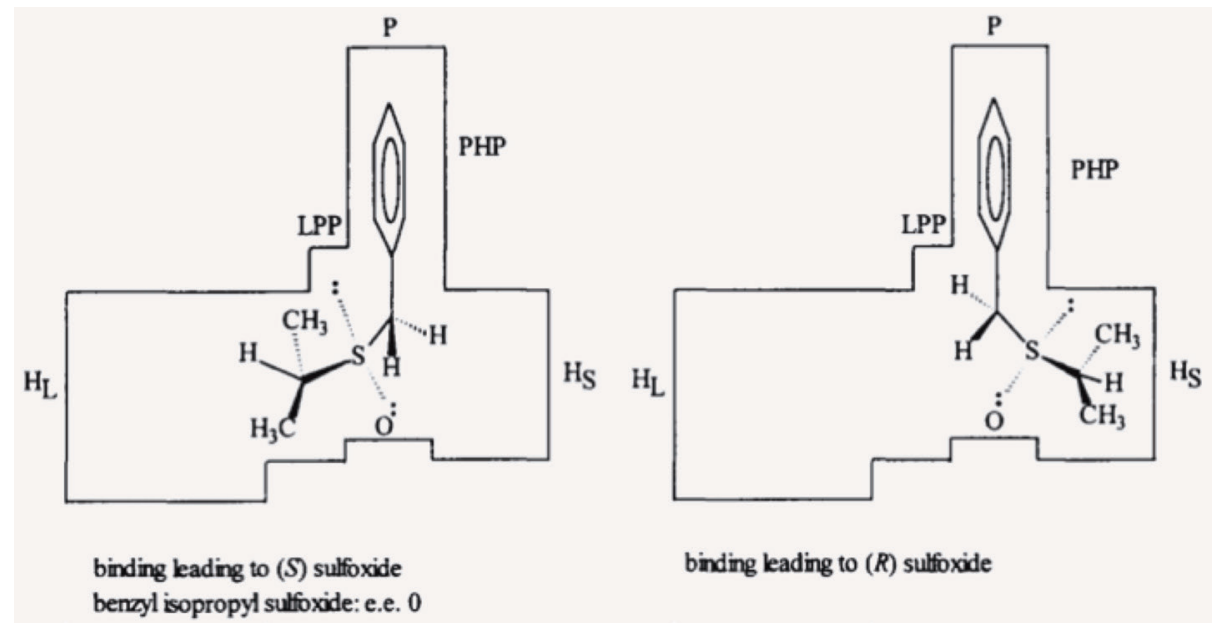

Figure 11 - Binding model for substrates bearing small alkyl groups (Holland et al. 1997b). Reprinted with permission from Elsevier (Holland et al. 1997b). Copyright 2015 Elsevier.

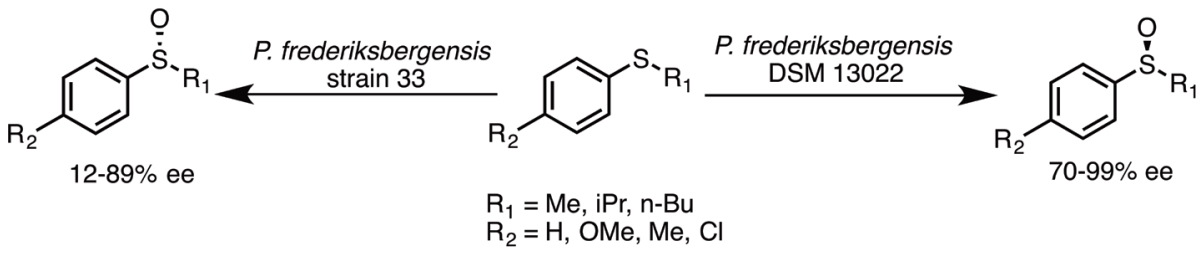

Figure 12 - Sulfide oxidation using P. frederiksbergensis strains.

In general, pure enzymes and bacterial whole-cells can be used to produce only one enantiomer ( $R$ or $S$ ). However, a challenging goal is to find bacteria exhibiting enzymes with different enantiopreference and high substrate affinity to yield both enantiomers. Pseudomonas frederiksbergensis (Adam et al. 2004, 2005) have been found to exhibit this feature with $(S)$ enantioselectivity for strain DSM 13022 and $(R)$ enantioselectivity for strain 33. No mechanism considering the difference in enantioselectivity has been suggested by the authors, Figure 12 . However, Adam et al. $(2004,2005)$ have shown that introduction of substituent (-Me, $\mathrm{OMe}$ and $\mathrm{Cl}$ ) in para-position of phenyl methyl sulfide increased the enantioselectivity (up to $>99 \%$ ee). The effect of the side-chain next to the sulfur atom was also studied. The increase in branching or length of the carbon chain has caused a strong decrease on the enantioselectivity of sulfoxidation by both $P$. frederiksbergensis strains (from $91 \%$ to $<5 \%$ ).

The $(S)-(+)$-methyl phenyl sulfoxide was obtained from methyl phenyl sulfide with a different bacterium, $P$. putida strain HKT554. Ramadhan et al. described that the addition of a hydrophobic solvent, such as $n$-hexadecane, to the fermentation can enhance the sulfide conversion from 12 to $100 \%$ (Ramadhan et al. 2013).

Another specie of Pseudomonas, Pseudomonas monteilii, was recently used by Chen et al. (2014) for oxidation of sulfides. All strains ( $P$. monteilii TB-4, P. monteilii TA-2, P. monteilii EBV2- 1, . monteilii TA-5 and P. monteilii CCTCC M2013683) could oxidize thioanisole to the corresponding $(R)$ sulfoxide with $99 \%$ yield and $99 \%$ ee. However, only strain P. monteilii CCTCC M2013683 performed the oxidation under high loadings of substrate (30 mM). Other sulfides were also evaluated and thioanisole was the best substrate. When $m$-chloro 
TABLE IV

Oxidation of alkyl-aryl sulfides by Pseudomonas monteilii.

\begin{tabular}{|c|c|c|c|}
\hline $\mathbf{R}_{1}$ & $\mathbf{R}_{2}$ & Yield (\%) & $\begin{array}{c}\text { ee }(\%) \\
\text { configuration }\end{array}$ \\
\hline$-\mathrm{Ph}$ & $-\mathrm{CH}_{3}$ & 99 & $99(R)$ \\
\hline$-\mathrm{Ph}$ & $-\mathrm{CH}_{2} \mathrm{CH}_{2} \mathrm{Cl}$ & 69 & $92(R)$ \\
\hline$-\mathrm{Ph}$ & $-\mathrm{CH}=\mathrm{CH}_{2}$ & 99 & $64(R)$ \\
\hline 2-Naphthyl & $-\mathrm{CH}_{3}$ & 99 & $99(R)$ \\
\hline$m-\mathrm{ClC}_{6} \mathrm{H}_{4}$ & $-\mathrm{CH}_{3}$ & 54 & $63(R)$ \\
\hline
\end{tabular}

thioanisole was used, a drastic decrease in the enantioselectivity was observed (64\%). However, sulfoxidation of a substrate bearing a 2-naphthyl moiety was accomplished in high yield and ee $(99 \%$ in both cases). The replacement of methyl group from thioanisole for other groups decreased the selectivity, as can be seen in Table IV. The authors have used water as solvent in all of their studies, but they also observed that the addition of $n$-hexane to the culture reduces the substrate and products toxicities on the living organism. Therefore, the addition of a hydrophobic solvent to the culture improves the reaction performance, as observed by Ramadhan et al. (2013).

Mascotti et al. (2012) employed filamentous fungi to selectively oxidize sulfur-containing compounds. Nine different fungi from Aspergillus family were used for the oxidation of cyclohexyl(methyl)sulfide and alkyl aryl sulfide. In the screening study, the best results, considering conversion and enantioselectivity, were obtained with Aspergillus fumigatus for the aromatic sulfide (100\% conversion, $72 \%$ of ee in favor of (R)-enantiomer) and with Aspergillus japonicus for the cyclic alkyl sulfide $(90 \%$ conversion, $97 \%$ of ee in favor of $(R)$-enantiomer). All the other strains exhibited moderate to low conversions and selectivities. Cyclohexyl(methyl) sulfide was hence chosen as a model substrate and its biooxidation was optimized, including the availability of oxygen, the use of resting cells, the substrate/biocatalyst ratio and the use of cosolvents. When isopropanol was applied as cosolvent $(0.5 \%, \mathrm{v} / \mathrm{v})$ and Aspergillus japonicus as biocatalyst, it was observed full conversion in favor of the corresponding $(R)$-sulfoxide with $99 \%$ ee. This method was selective and did not afford any sulfone. Aspergillus japonicus have also been proved to be more selective (Mascotti et al. 2012) than Botrytis cinerea, Eutypa lata and Trichoderma viride, (Pinedo-Rivilla et al. 2007) Figure 13.

The sulfoxidation of thioanisole can also be performed by an immobilized microperoxidase-11 (MP-11). The immobilization protocol included an encapsulation into sol-gel silica glass whereas the physisorption and covalent attachment were performed on silica gel (Kadnikova and Kostic 2003). Upon immobilization, the oligomerization of Microperoxidase-11 is suppressed. Therefore, the heme-group becomes more accessible, increasing the sulfoxidation yield from $15 \%$ to $95 \%$, while the $(S)$-enantioselectivity is also enhanced, going from $33 \%$ to $46 \%$. The encapsulation into sol-gel silica provided a 3 -fold increase in sulfoxide yield. On the other hand, MP-11 which was covalently attached, physisorbed, and chemisorbed has shown an even higher increase of sulfoxidation with a

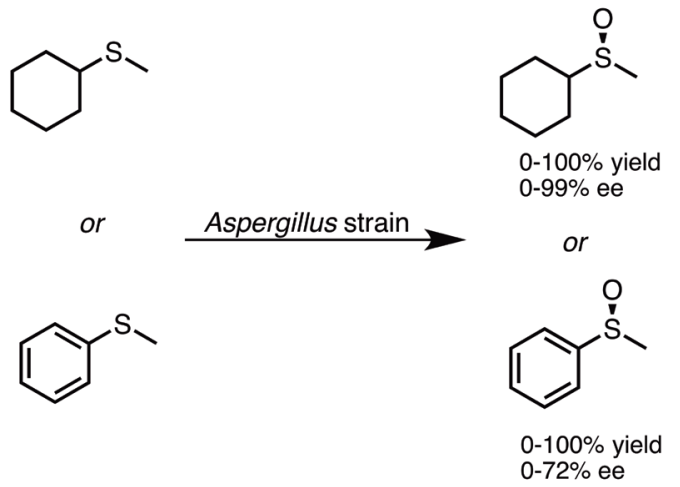

Figure 13 - Use of several Aspergillus strains as biocatalysts for the oxidation of cyclohexyl(methyl)sulfide and alkyl aryl sulfide. 
yield 6-fold higher than free MP-11. The authors also stated that despite of the catalytic effect of silica on sulfoxidation reactions, it did not affect negatively the enantioselectivity since the high enzyme loadings on the surface of the silica gel provides limited silica surface exposure to the reaction medium.

Other enzymes, such as Baeyer-Villiger Monooxygenases (BVMO) also have a very important role in sulfur oxidation, since they can catalyze the insertion of one oxygen atom into an organic substrate. The reaction proceeds after oxygen activation, otherwise no oxidation will occur due to the oxygen spin-state. Hence, the incorporation of $\mathrm{O}_{2}$ via electron donation from the enzyme-cofactor complex generates peroxyflavin (oxidant specie), then the oxygen atom can be inserted in the substrate (Leisch et al. 2011). Essentially, they are used for oxidations in which carbonylic compounds are converted into their corresponding esters or lactones (in a BaeyerVilliger reaction) (Pazmino et al. 2010). However, they display a broad substrate acceptance profile, which enables their use in sulfide oxidations. BVMO enzymes are well described for the oxidation of sulfides (Alphand and Wohlgemuth 2010, Beecher et al. 1994, Colonna et al. 1996, 1997, Pasta et al. 1995, Wojaczynska and Wojaczynsk 2010) and the latest developments will be discussed here.

Directed evolution was chosen by Reetz et al. (2004) to enhance the enantioselectivity of CHMO (cyclohexanone monooxygenase) from Acinetobacter sp. NCIMB 9871, since the wildtype enzyme showed low ee values. Using methylp-methylbenzyl sulfide as a substrate for CHMO from Acinetobacter sp. NCIMB 9871, Reetz et al. (2004) observed a 75\% conversion, however, the ee was only $14 \%$ in favor of the $(R)$-enantiomer. Thus, mutants of this enzyme were obtained and used in the same reaction for comparison. The replacement of an aspartic acid residue for a histidine (D384H) resulted in the same conversion $(75 \%)$, but with

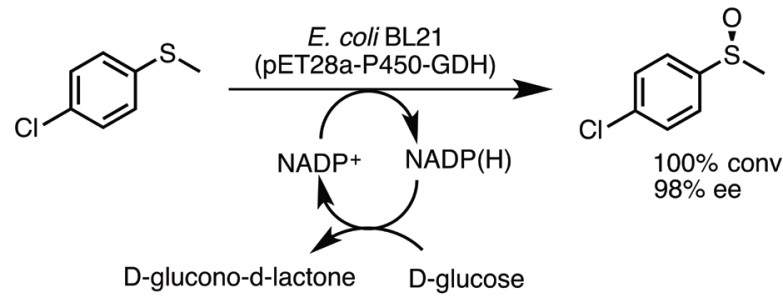

Figure 14 - NADPH regeneration system in the oxidation of para-chloro-thioanisole by recombinant $E$. coli BL21 (pET28aP450-GDH).

a much higher enantioselectivity $((R)$-enantiomer, $98.9 \%$ ee). However, if a phenylalanine is swapped for a serine (F432S) the conversion decays to $55 \%$ $((R)$-enantiomer, $98.7 \%$ ee). When two or more amino acids are swapped, the $(S)$-enantiomer was preferential with reasonable yields (52-84\%) and high enantioselectivities (95-99.7\%). The authors concluded that directed evolution provides mutants that would hardly be obtained by a rational design of a mutagenesis, especially since the crystal structure of this enzyme was still not available.

After the observation that whole cells containing monooxygenases had the drawback of using NADPH as an expensive cofactor (Zhang et al. 2010, 2011) co-expressed the P450SMO gene from Rhodococcus sp. and the GDH gene from Bacillus subtilis in a recombinant $E$. coli cell. In this way, a recombinant E. coli BL21 (pET28aP450-GDH) has both P450 monooxygenase and a NADPH regeneration system, which improves the sulfide oxidation performance. Employing this strategy, they achieved $100 \%$ conversion in the oxidation obtaining the $(S)$-sulfoxide with ee higher than $98 \%$, Figure 14 . However, due to the high sulfide cytotoxicity, the reaction efficiency decreased when the initial sulfide concentration was increased from $2 \mathrm{mM}$ to $5 \mathrm{mM}$.

Similarly to Zhang et al. (2010), a selfsufficient monooxygenase with a NADPH regenerating phosphite dehydrogenase $(\mathrm{PTDH})$ from Pseudomonas stutzeri system was described by Rioz-Martínez et al. (2011). The enzymatic 


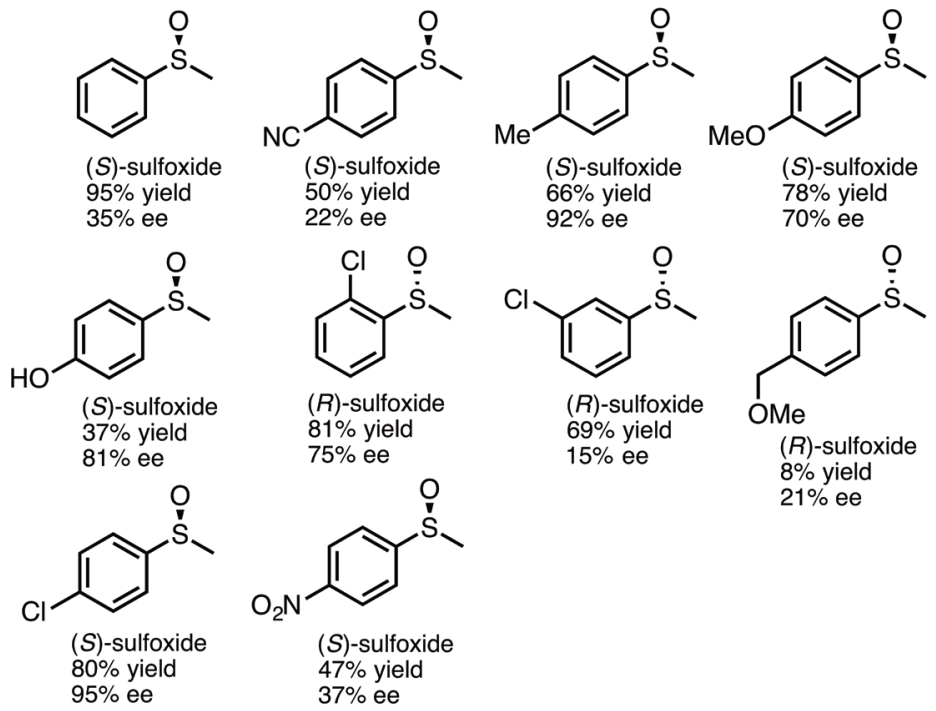

Figure 15 - Sulfoxides prepared from reactions with flavin-containing monooxygenase (FMO), fused to phosphite dehydrogenase (RiozMartinez et al. 2011).

system (PTDH-mFMO) consisted of flavin containing monooxygenase (mFMO) and PTDH, which employs phosphite as a cheap substrate for recycling NADPH. Initially, the authors explored the ability of PTDH-mFMO to convert indole derivatives into indigoid dyes, and a variety of colors evidenced products formation. After the initial tests, their bifunctional system was also explored on sulfides oxidation. PTDH-mFMO showed a preferential production of $(S)$-sulfoxides in low to high conversions (14-91\%) and ee (15-85\%), as shown in Figure 15. The influence of organic cosolvents on the oxidation of thioanisole by PTDHmFMO was also evaluated by Rioz-Martínez et al. (2011). Among the co-solvents (DMSO, hexane and octylamine), an activating effect was exclusively observed with $5 \%$ of n-hexane. The oxidation of both, thioanisole and its corresponding racemic sulfoxide, was increased (from $48 \%$ to $90 \%$ ) and an enhancement in the enantioselectivity was also observed (from $33 \%$ to $48 \%$ ).

Another co-factor regeneration system was developed by Zhai et al. (2013), which includes whole-cell biocatalyst co-expressing in E. Coli
BL21 genes from CHMO (originally from Acinetobacter calcoaceticus NCIMB 9871) and FDH (formate dehydrogenase - cofactor regenerating enzyme - originally from Candida boidinii). The sulfoxidation was performed with an efficient conversion of thioanisole (100\%) into its sulfoxide, however, as a drawback, there was the enzyme inhibition in the presence of high substrate concentrations $(80 \mathrm{mM})$. In reactions with $E$. coli BL21 (DE3)-pMM4 strain expressing only CHMO, low oxidation efficiencies were observed, due to a slow $\mathrm{NADP}^{+}$reduction to NADPH by the enzyme. As a comparison, NADPH cofactor was efficiently recycled with coexpressed CHMO and FDH, confirming the ability of the recombinant FDH to regenerate NADPH.

The employment of three different BVMO enzymes for the oxidation of several cyclohexyl alkyl sulfides, heteroaryl alkyl sulfides and cyclic and linear aliphatic sulfides were described by Rioz-Martínez et al. (2010). In an initial study, the synthesis of pyridine methyl sulfoxides containing the nitrogen atom at the 2-, 3-, or 4-position was evaluated. The nitrogen atom position proved to be 


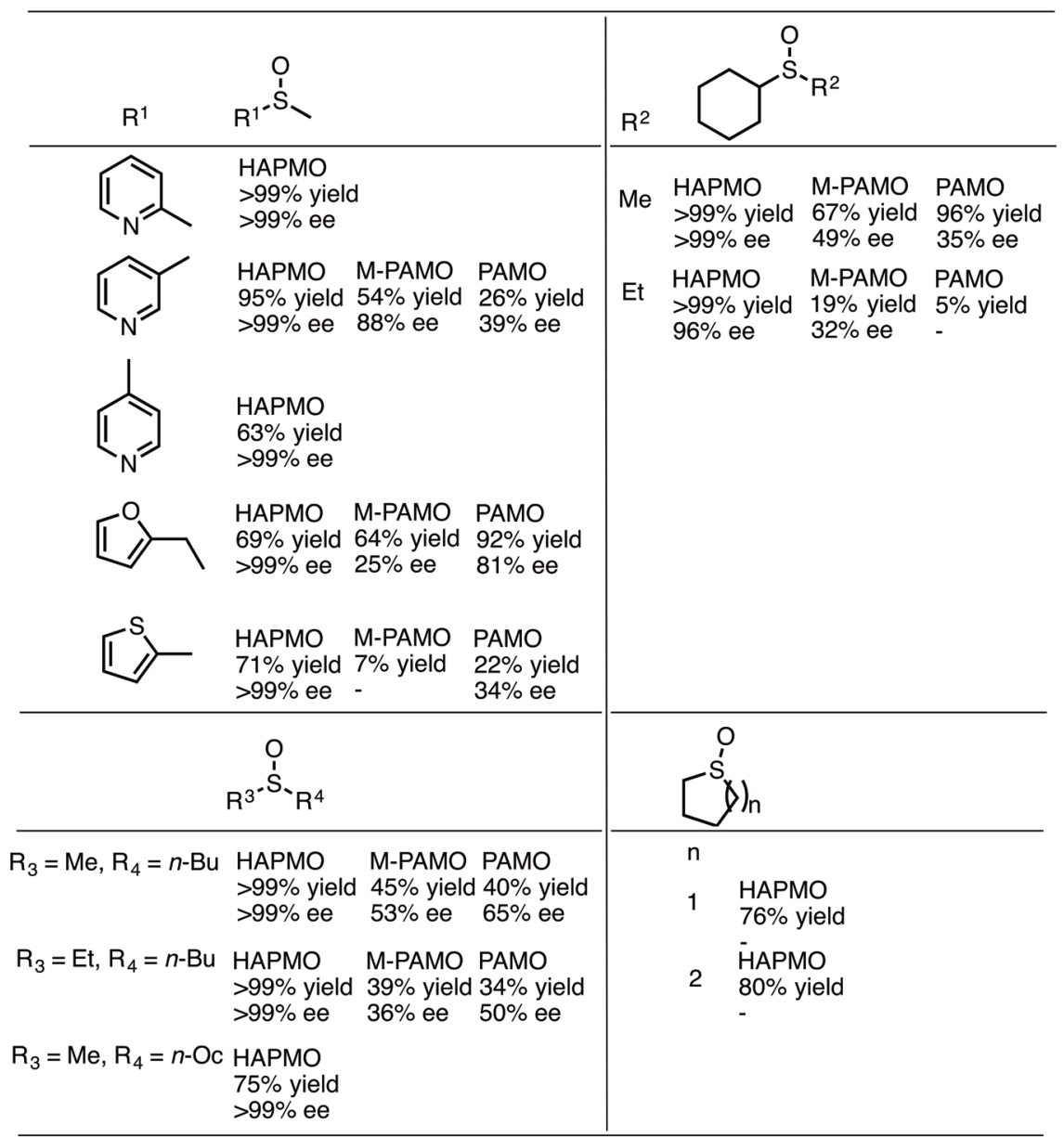

Figure 16 - Use of BVMOs (HAPMO, M-PAMO and PAMO) described by Rioz-Martínez et al. (2010) to produce sulfoxides.

essential for conversion, with consequent decrease when nitrogen was at 3-, or 4- position in pyridine ring. In the case of heteroaryl alkyl sulfides, HAPMO was able to catalyze the enzymatic sulfoxidation of 6 derivatives with moderate to high conversions $(63->99 \%)$ and excellent enantiomeric excess (>99\%) while the other two BMVOs (M446G PAMO and PAMO), in general, presented lower conversions and ee. The same trend was observed for other sulfides, as can be seen in Figure 16. Reactions with HAPMO preferentially produced the $(S)$-sulfoxide, with exception of 4-pyridine methyl sulfide and 2-furfuryl methyl sulfide. M446G PAMO (M-PAMO) and PAMO gave the opposite enantiomers when compared to HAPMO, under the same reaction conditions. Rioz-Martínez et al . (2010) also observed small amounts (less than $8 \%$ ) of sulfone in the oxidation reactions.

Among BVMO enzymes, PAMO (phenylacetone monooxygenase) is the one that shows narrow substrate specificity, with acceptance of only small aromatic ketones, sulfides, amines and boron compounds. In order to expand the substrate scope, van Beek et al. (2012) blended a sequencerelated BVMOs into PAMO. Therefore, structureinspired subdomain exchanges were performed using phenylacetone monooxygenase (PAMO) as a scaffold, introducing a novel selectivity for STMO (Steroid monooxygenase) and CHMO (cyclohexanone monooxygenase). In this study, the 
PAMO-CHMO blend acts as a mixture of both parent enzymes, giving the $(R)$-sulfoxide from thioanisole with moderate enantioselectivity $(60 \%)$. The other blends, PASTMO and PAMEMO1 improved their $(S)$-enantioselectivity in respect to the wild type STMO and with higher enantioselectivity than wild PAMO ( $16 \%$ ee to $60 \%$ ee).

Aiming the expansion of available flavoprotein monooxygenases, eight unexplored genes from Rhodococcus jostii RHA1 were cloned by Riebel et al. (2013). These genes proved to express a new subclass of class B flavoprotein monooxygenases, which were coined as Type II FMOs. Type II FMOs were evaluated in thioanisole, 4-methylthioanisole, ethyl benzyl sulfide, and benzyl phenyl sulfide oxidation. Thioanisole was converted by most of the type II FMOs achieving low to moderate yields (4-56\%) and enantiomeric excess (5-57\%) in favor of $(R)$-sulfoxide for all the FMOs used, with exception to FMO-G, which formed the $(S)$ sulfoxide in $57 \%$ ee. When a bulkier substrate was employed (such as benzyl ethyl sulfide) none of the tested monooxygenases could selectively oxidize the substrate. On the other hand, the biocatalysts FMO-E, FMO-G and FMO-F gave methyl phenyl sulfone, as an over oxidation product, instead of the aimed sulfoxide.

Dietzia sp. BVMO4 was used to catalyze the oxidation of a range of sulfides by Bisagni et al. (2014) producing the $(R)$-enantiomer. The monooxygenase showed preference for nonsubstituted aromatic sulfides, however, it could still convert substrates containing small substituent at para- (methyl, fluoro) or meta- position (chloro). The addition of one carbon atom in the substrate structure (ethyl phenyl sulfide) showed a significant increase in the enantioselectivity, achieving 99\% ee, in comparison to $50 \%$ ee for methyl phenyl sulfide, Figure 17.

As shown above, usually, enantiomerically pure sulfoxides are achieved using oxygenase-type enzymes as biocatalysts, such as the one described
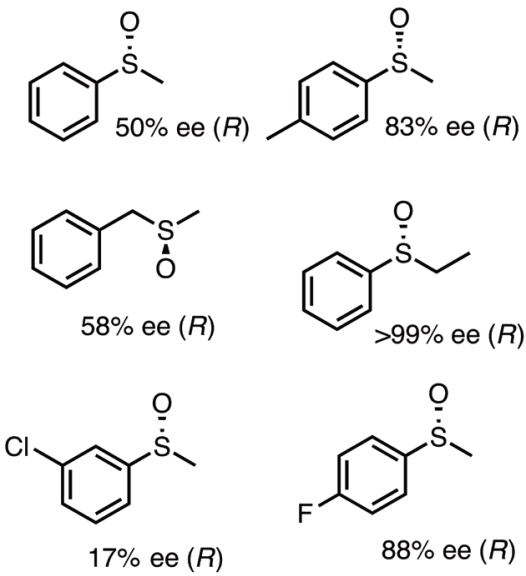

Figure 17 - Several sulfoxides prepared from oxidations with Dietzia sp.

by Brink et al. (1998, 1999, 2001). In these studies, the authors employed a vanadium bromo peroxidase (VBPO) from brown seaweed, Ascophyllum nodosum, to produce sulfoxides. Phenylsulfides containing substituent on the aromatic ring were also evaluated in this study. Activating substituent on the para-position of the aromatic ring, such as $-\mathrm{NH}_{2}$ or $-\mathrm{OCH}_{3}$, resulted in an increase in the selectivity of the sulfoxidation (from $76 \%$ ee to $89 \%$ ee for phenyl methyl sulfide as substrate). However, strong electron withdrawing groups, such as $-\mathrm{CN}$ and $-\mathrm{NO}_{2}$ have a dramatic negative effect on the selectivity and conversion. Brink et al. (2001) suggested that the aromatic sulfides bind with a relative low affinity near/in the active site of VBPO from A. nodosum, allowing the selective direct oxygen transfer from the active site to sulfide.

Evidently, different methods to produce enantiomerically enriched sulfoxides via sulfide oxidation are available, however, another method can exploit the reverse reaction, sulfoxide deoxygenation. For example, a periplasmic protein from Rhodobacter sphaeroides f.s. denitrificans (Abo et al. 1995, 1997) was used to deoxygenate racemic methyl- $p$-substituted phenyl sulfoxides. The $(S)$-enantiomer was exclusively deoxygenated, leaving the enantioenriched $(R)$-sulfoxide isomer 


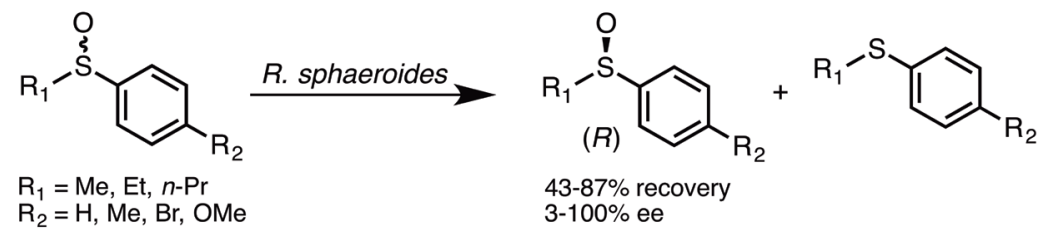

Figure 18 - Deoxygenation of racemic sulfoxide by Rhodobacter sphaeroides $f$. sp. denitrificans (Abo et al. 1997).

(3-100\% ee) in good recoveries (43-87\%), as seen in Figure 18. In this study, Abo et al. (1997) verified that it was more effective to use cells in stationary phase ( $72 \mathrm{~h}$ of culture) than in the exponential phase ( $24 \mathrm{~h}$ culture). Remarkably, in a preparative scale $(31 \mathrm{mmol})$, the authors were able to produce $(R)$-methyl-p-tolyl sulfoxide with $100 \%$ ee and $42 \%$ yield.

Hanlon et al. (1998) have also attempted the sulfoxide deoxygenation, using dimethyl sulfoxide reductase (DMSO reductase) from Rhodobacter capsulatus, Escherichia coli or Proteus vulgaris. Using whole cells, DMSO reductase from $R$. capsulatus presented a different stereoselectivity (towards $(S)$-enantiomer) when compared to DMSO reductase from other organisms. The enantioselective reduction of racemic sulfoxides with opposite stereospecificity was also performed with a pure dimethyl sulfoxide reductase. For instance, from a racemic mixture of methyl $p$-tolyl sulfoxide, $(S)$-enantiomer was enantioselectively deoxygenated and the $(R)$-enantiomer was recovered with $88 \%$ yield and $>99 \%$ ee (Hanlon et al. 1998). Other substrates were also tested, but the absolute configuration for these compounds was not determined, as shown in Figure 19.

A DMSO reductase from Citrobacter braakii provided the enantioselective deoxygenation of racemic sulfoxides (alkyl aryl sulfoxides, dialkyl sulfoxides and cyclic sulfoxides) via kinetic resolution, as shown in Figure 20 (Boyd et al. 2002). Enriched samples of alkyl aryl sulfoxides (>98\% ee), dialkyl sulfoxides ( $44 \%$ ee) and cyclic sulfoxides $(97 \%$ ee) were obtained. When intact cells of C. braakii DMSO-11 were used for the conversion of racemic 1,4-dihydrobenzo[d][1,2] dithiine 2-oxide, an excess of the $(S)$-enantiomer was obtained $(17-77 \%$ ee).

Thioanisole derivatives have been by far the most studied substrates for the oxidation of sulfides into their corresponding sulfoxides, but other substrates have also been studied, due to their environmental or pharmaceutical relevance.

Baldwin et al. (1984) studied the ring formation from $\delta$-(L- $\alpha$-aminoadipoyl)-L-cysteinylD-valine (L,L,D-ACV) into penicillin. In a previous study, $\delta$-(L- $\alpha$-aminoadipoyl)-L-cysteinylD-aminobutyrate was converted to a penam and a cepham compound via two different pathways, which had a common monocyclic $\beta$-lactam as

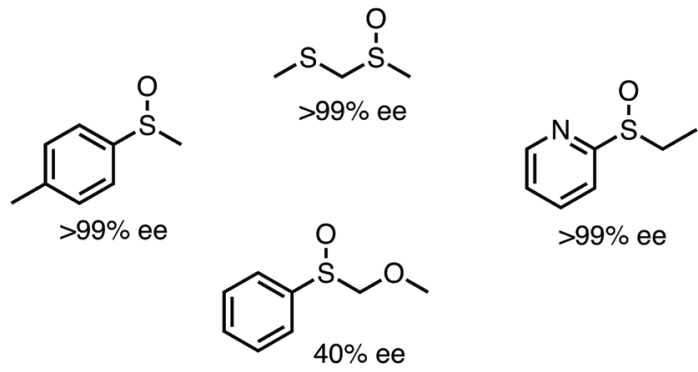

Figure 19 - Substrates used by Hanlon et al. (1998) for deoxygenation with dimethyl sulfoxide reductase.

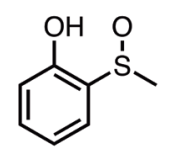

$>98 \%$ ee

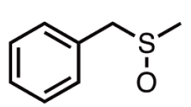

$44 \%$ ee

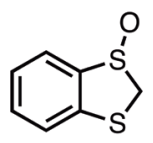

$97 \%$ ee
Figure 20 - Substrates for enantiomeric enrichment via deoxygenation using DMSO reductase from Citrobacter braakii. 


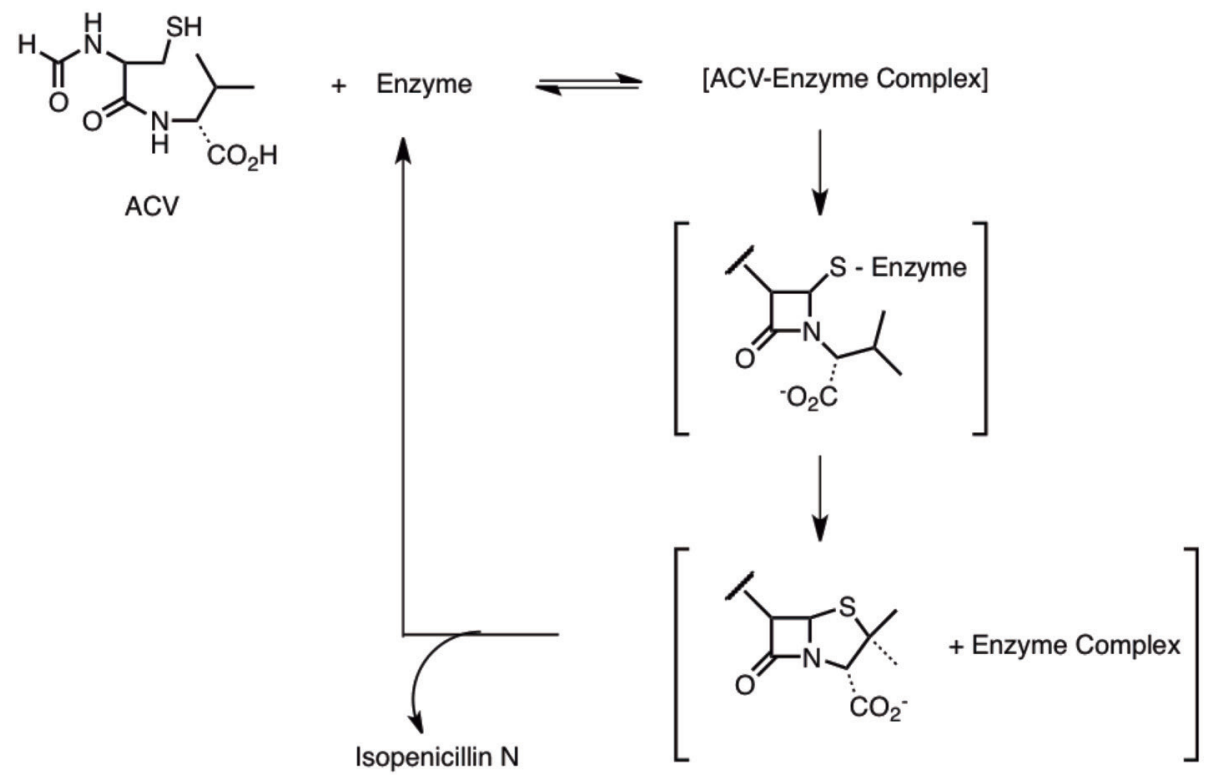

Figure 21 - Transformation of $\delta$-(L- $\alpha$-aminoadipoyl)-L-cysteinyl-D-valine into isopenicillin N.

an intermediate (Baldwin et al. 1983). Based on this work, Baldwin et al. (1984) reported that $\delta$-(L- $\alpha$-aminoadipoyl)-L-cysteinyl-D-valine transformation into isopenicillin $\mathrm{N}$ possibly involves a similar monocyclic $\beta$-lactam intermediate during the enzymatic conversion (Figure 21). These reactions were performed in a cell-free extract of isopenicillin $\mathrm{N}$-synthetase from Cephalosporium acremonium in the presence of a $\beta$-lactamase I. The competition between enzymes showed that there was discrimination at the cysteinyl 3-position, supporting the idea of an initial formation of a $\beta$-lactam prior to the thiazolidine synthesis.

Another field of interest is the use of microbes for the reduction/oxidation of sulfur containing molecules from oil extracts (Fedorak and Westlake 1983, 1984, Fedorak et al. 1988, Kropp et al. 1996). When introducing benzothiophene and 3-methylbenzothiophene in aerobic cultures, Fedorak et al. (Fedorak and Grbic-Galic 1991) were able to observe the benzothiophene-2,3dione and 3-methylbenzothiophene sulfoxide and sulfone formation. Therefore, Pseudomonas sp. strain BT1 performed the preferential oxidation at carbons 2 and 3 in benzothiophene, however, when carbon 3 was substituted by a methyl group, only the sulfur atom was oxygenated. With that selectivity in mind, Saftiet et al. (1992) and Kropp et al. (1994a) used the same strain to perform oxidations of several substituted benzothiophenes. They observed that methyl benzothiophenes with methyl groups on the thiophene ring have produced sulfoxides and sulfones in contrast to the ones containing the methyl group on the benzene ring, which yielded 2,3-diones, as can be seen in Figure 22. The only exception to this rule was 7-methylbenzothiophene, which yielded a variety of the three major metabolites.

Benzothiophene was also a matter of study by Eaton et al. (Eaton and Nitterauer 1994) with the strains Pseudomonas putida RE204 and TnS mutant derivatives. Unlike Fedorak et al. (1991), Eaton et al. (1994) have observed different pathways for this biotransformation, one starting from the oxidation of the benzene ring and the other one starting from the oxidation of the thiophene ring, both resulting in ring opening (Figure 23). 


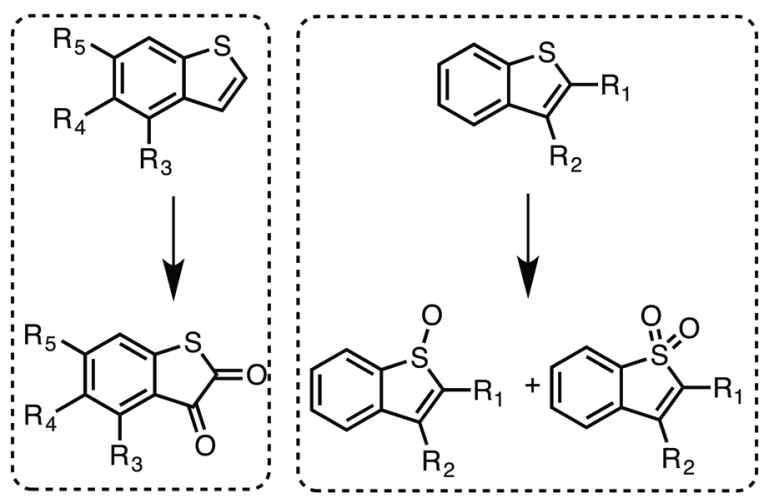

Figure 22 - Oxidation of benzothiophene derivatives by Pseudomonas sp. BT1.

This trend was also observed by Boyd et al. (1993). In their study, Boyd et al. (1996) detected cis/trans-dihydrodiol metabolites in the biotransformation with $P$. putida. Products with high-molecular weight were also observed in these reactions and identified by Kropp et al. (1994b) as condensation products, which transformed a two-ring sulfur heterocycle into a four-ring one. Benzothiophenes were likewise transformed into these high-molecular weight metabolites identified by Kropp et al. (1994b) using Sphingomonas sp. XLDN2-5 (Gai et al. 2008). The benzo[b] naphtho[1,2-d]thiophene is thought to be generated from a Diels-Alder-type reaction. Boyd et al. (1998) postulated that large-groups in the aromatic rings are responsible for the stereoselectivity of these reactions. Finn et al. (2004) performed the oxidation of $p$-bromoanisole with toluene dioxygenase, finding the product with a $\beta$-absolute configuration, which was in agreement with Boyd et al. (1996) findings.

More recently, using benzo[b]thiophene $(\mathrm{B}[\mathrm{b}] \mathrm{T})$ and methylbenzo[b]thiophene $(\mathrm{MB}[\mathrm{b}]$ T) as substrates for sulfide oxidation, Boyd et al. (2012) compared the stereochemistry of two different dioxygenases (TDO, NDO - naphthalene dioxygenase) and one monooxygenase (SMO) enzyme. In their studies, they have observed that monocyclic thiophenes when treated with $P$. putida UV4 cells (Boyd et al. 2003, Dansette et al. 2005) yielded unstable monosulfoxides and cis-diols as initial metabolites. Under acidic conditions cis-diols and trans-diols undergone dehydration reaction to yield hydroxythiophenes. Besides, a spontaneous dimerization of the monocyclic thiophene monosulfoxides also occurred, with the formation of their disproportionation products, thiophenes, sulfones and disulfoxides. The biotransformation of benzo[b]thiophenes with $P$. putida UV4 was preferential for electron-rich thiophene ring, achieving ca. $75 \%$ of the cis-hydroxylation and sulfoxidation. One of the isolated products,

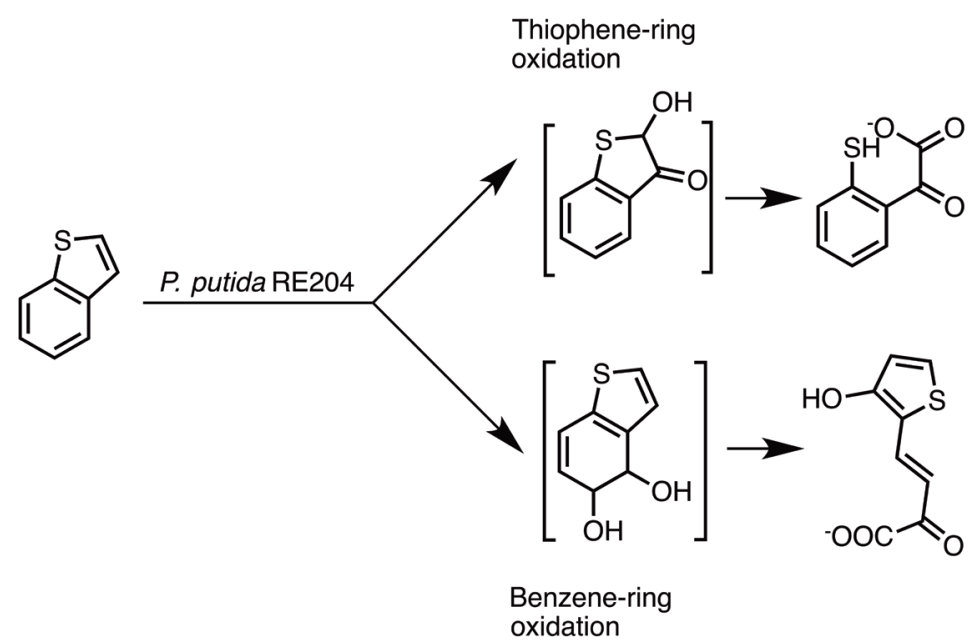

Figure 23 - Oxidation of benzothiophene with Pseudomonas putida RE204. 

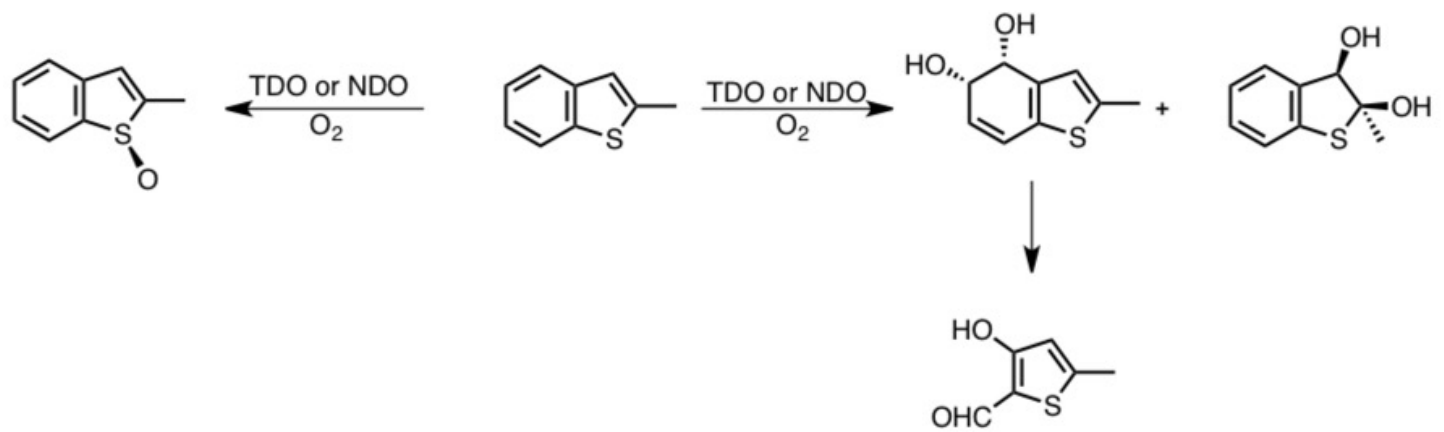

Figure 24 - Dioxygenase-catalysed oxidation of 2-MB[b]T.

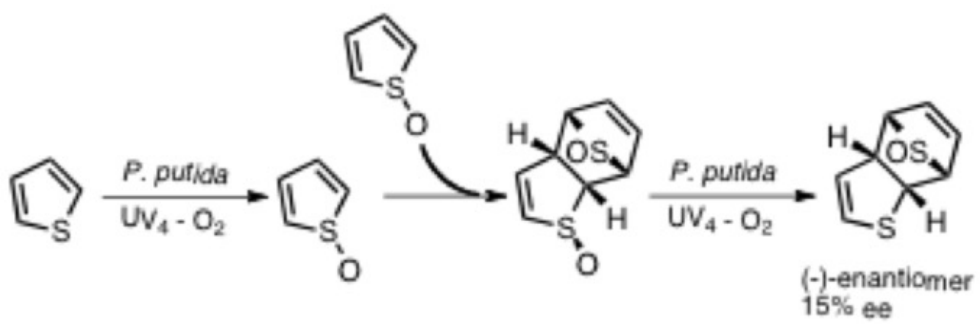

Figure 25 - Thiophene over oxygenation and formation of cycloadducts.

(-)-Benzo[b]naphtho[2,1-d]thiophene-7-oxide, was shown to be configurationally stable, since it did not spontaneously racemize at room temperature. However, this compound was produced with low enantiopurity values $(<10 \%$ ee $)$.

The effects of a methyl substituent at the benzothiophene ring was evaluated by Boyd et al. (2012), with 2-methylbenzo[b]thiophene having a preference for cis-dihydroxylation of the carbocyclic ring leading to cis-dihydrodiol in $83 \%$ yield (from reaction with TDO) and 90\% yield (from reaction with NDO, Figure 24). The cisdihydroxylation of benzene ring was possibly due to an inhibitory effect of the 2-methyl substituent in the thiophene ring preventing the oxidation of the sulfur atom or at 2,3-C $=\mathrm{C}$ bond. When the authors used NDO3 as biocatalyst, they have observed a change in regioselectivity in comparison to NDO1, with oxidation occurring exclusively at the thiophene ring to give cis-diol in $60 \%$ yield and $2-\mathrm{MB}[\mathrm{b}] \mathrm{T}$ sulfoxide in $40 \%$ yield. In the same study, when SMO (styrene monooxygenase) was used as biocatalyst, a quantitative yield of 2-MB[b]
T sulfoxide was obtained. The regioselectivities for $\mathrm{B}[\mathrm{b}] \mathrm{T}$ substrates observed for oxygenase enzymes TDO, NDO1, NDO2, NDO3 and SMO were dependent on the substituent pattern and enzyme type. The site-directed mutant strain E. coli F352V (NDO3) showed preferential oxidation (85-100\% yield) for the thiophene ring over the benzene ring, when compared to TDO and NDO1.

In comparison to the sulfide oxidation, the thiophene ring is usually slower oxidized, as evidenced by Boyd et al. (2003). Dioxygenase oxidizes an acyclic sulfur center more readily than heterocyclic sulfur. This preference arises due to a significant loss of resonance energy related to the formation of a thiophene oxide (Boyd et al. 2003). However, after the oxygenation of a thiophene and formation of disulfoxide cyclo adducts, the deoxygenation or decomposition of its disulfoxide could contribute for the isolation of enantiomerically enriched monosulfoxide in $15 \%$ ee, (-)-enantiomer, as shown in Figure 25.

Chiral thiosulfinate, were obtained by Boyd et al. (2014) from the oxidation of 1,2-disulfides using 


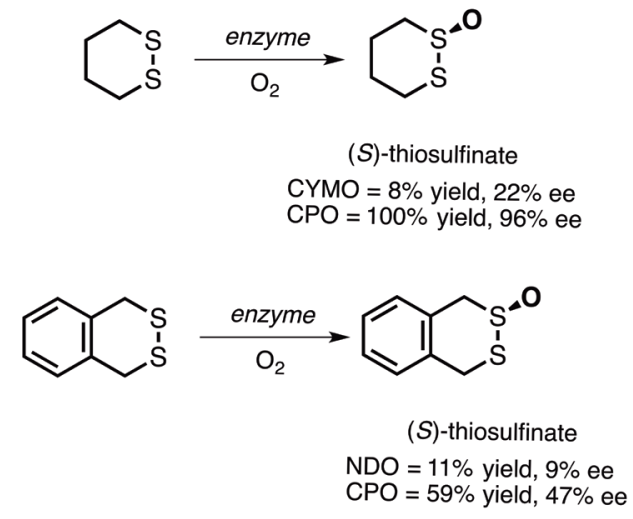

Figure 26 - Thiosulfinates obtained by sulfoxidation of 1,2-disulfides.

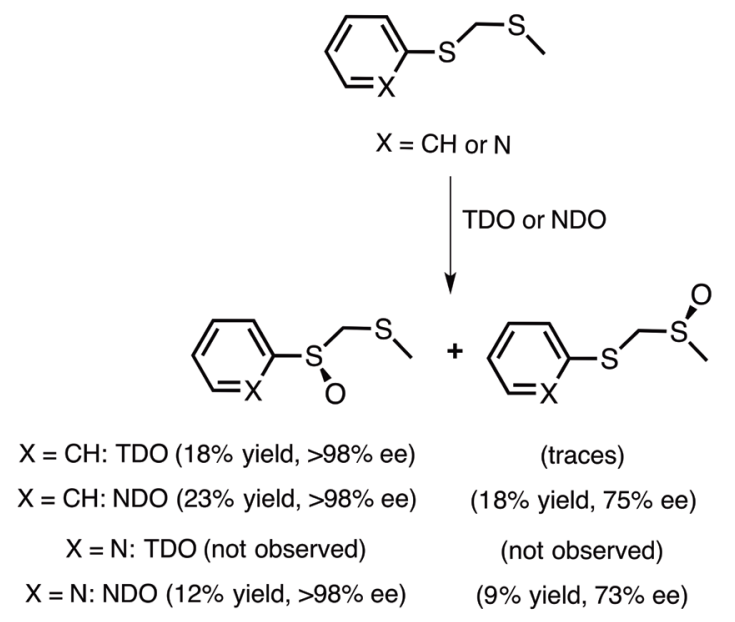

Figure 27 - Sulfoxidation of 1,3-disulfides mediated by TDO and NDO.

TDO (toluene dioxygenase), NDO (naphthalene dioxygenase), CYMO (cyclohexanone monooxygenase) and chloro peroxidase (CPO) enzymes. Thiosulfinate with $96 \%$ enantiomeric excess was obtained (100\% yield) with CPO as the biocatalyst, while the other systems resulted in lower yields (8-95\%) and enantiomeric excesses (9-52\%) (Figure 26) (Boyd et al. 2014).

For instance, Boyd et al. (2001) verified that the oxidation of acyclic 1,3-disulfides with TDO (toluene dioxygenase), NDO (naphthalene dioxygenase), gives an enantiopure $(S)$-alkyl aryl sulfoxide (ee $>98 \%$ ), whereas $(R)$ - ((methylsulfinyl) methyl)(phenyl)sulfane was obtained in a lower ee value (75\%) with NDO as biocatalyst (Figure 27).

Using methionine derivatives as substrates for CPO, Holland et al. (1999a, 2002) observed a moderate to high diastereomeric excess (12-84\%), obtaining $(R)$-sulfoxides stereochemistry. When L-methionine derivatives were used as substrates, the $(S, R)$-product showed high de (de: diastereomeric excess, 80-91\%), indicating the simplicity and high efficiency of their route to diastereomerically enriched $N$-phthaloylmethionines (Holland et al. 1999a, 2002).

The presence of organic sulfur-containing compounds in the environment can be harmful to animals and human health. Their release in the nature comes from the combustion of fossil fuels. Biodesulfurization is an interesting exploitation of the ability of certain microorganisms to remove organic sulfur compounds from fuels without compromising the calorific value (Buzanello et al. 2014).

CPO enzyme from C. fumago had been used by Ayala et al. (2000) to oxidize sulfur-containing contaminants (Seymour et al. 1997) into compounds with higher boiling points, allowing their removal from diesel fuel by a simple distillation. This process reduced from $1.27 \%$ to $0.27 \%$ the amount of sulfur, indicating possible routes for oil desulfurization processes. The immobilization of CPO on silica-based materials was performed by Montiel et al. (2007) to obtain a stable and reusable biomaterial for such desulfurization processes. The immobilized CPO was used for the oxidation of 4,6-dimethyl dibenzothiophene (Torres and Aburto 2005), showing a turnover value which is close to the one of free enzyme, a higher activity at $50^{\circ} \mathrm{C}$ and reusability up to 5 cycles, Figure 28 .

Recently, Buzanello et al. (2014) used nine different bacteria isolated from a tropical farm soil to perform degradation of dibenzothiophene (DBT). It was found that, high amount of DBT were removed after 24 hours, showing the formation 


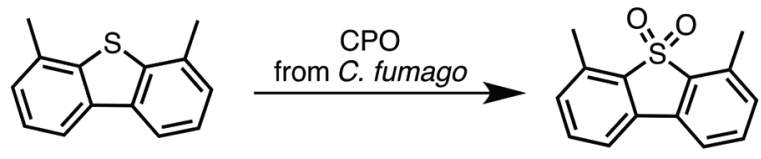

Figure 28 - Oxidation of 4,6-dimethyl dibenzothiophene by CPO immobilized on silica-based materials. (Montiel et al. 2007).

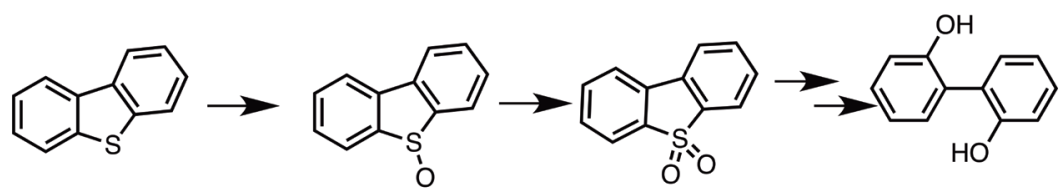

Figure 29 - Microbial desulfurization of DBT.

of 2-hydroxybiphenyl, as shown in Figure 29. By comparison to other DBT-degrading strains, Buzanello et al.observed that the highest capacity for DBT degradation was achieved with strain RR-3 from a Bacillus genus. These results indicate that desulfurization by microorganisms have great biotechnological potential for the removal of DBT from fossil fuels.

Environmental aspects of dimethylsulfide (DMS) pollution led Hayes et al. (2010) to investigate microbial degradation of DMS, which involved the study of its catabolism to $\mathrm{H}_{2} \mathrm{~S}$ via methanethiol. They highlighted the importance of using two microorganisms: Hyphomicrobium spp. and Thiorbacillus spp. due to their synergism. The $\mathrm{pH}$ control is also necessary in their system. When the reaction $\mathrm{pH}$ was decreased from 7 to 5, the specific growth rate of Hyphomicrobium spp. decreased by $85 \%$. When the culture was enriched with methanol, the specific growth rate of Hyphomicrobium spp. declined much less over the same $\mathrm{pH}$ range (leading to better DMS removal even at $\mathrm{pH}$ levels not useful to high growth rates). Through the same $\mathrm{pH}$, the specific growth rate of Thiobacillus spp. remained similar.

A study on thiocarbamate herbicides oxidation with liver enzyme systems was performed by Casida et al. (1975) in order to detect which intermediates would be produced in the mammalian metabolism.
In this study, sulfoxide is obtained as the major product while the corresponding sulfones were not detected. Mercaptans could be identified by the strong odor liberated during the biotransformation. According to the authors, this compound would be formed from the cleavage of the sulfoxides by a GSH S transferase system. This cleavage indicated that herbicides, thiocarbamate sulfoxides, would not to persist in mammals, Figure 30.

Optically active sulfoxides are very important compounds and can be used in medicinal and pharmaceutical chemistry due to their high biological activity [For a review see (Legros et al. 2005)].

Studies of selective oxidation of sulfides to sulfoxides can have a direct use in pharmaceutical compounds, such as esomeprazole, pantoprazole, ilaprazole and lansoprazole, which are used for the treatment of gastroesophageal reflux disease. Synthesis of these compounds requires the oxidation of their sulfide precursors. Babiak et al. (2011) were the first group to describe the synthesis of an enantiopure esomeprazole ( $100 \%$ ee) in the presence of whole cells of Lysinibacillus, as shown in Figure 31. With a fed-batch setup, Babiak et al. observed a continuous culture growing and esomeprazole production at a constant rate from the 9th to the 18th hour of cultivation. Strain Lysinibacillus sp. B71 could not oxidize other similar sulfides, with 

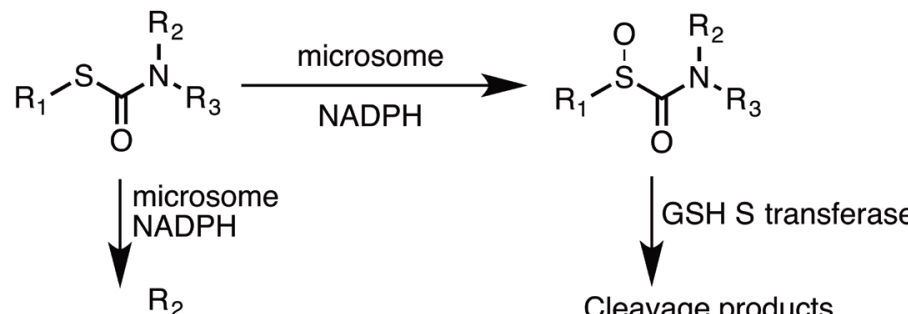

$$
\begin{aligned}
& \mathrm{R}_{1}-\prod_{\mathrm{O}}^{\mathrm{S}_{2}} \\
& \mathrm{R}_{1}=p \text {-Cl-benzyl, ethyl, } n \text {-butyl } \\
& \mathrm{R}_{2}=\text { Ethyl, } n \text {-propyl, } i \text {-propyl, } \\
& \mathrm{R}_{3}=\text { Ethyl, cyclohexyl, } n \text {-butyl, } i \text {-propyl, } n \text {-propyl }
\end{aligned}
$$

Figure 30 - Oxidation of thiocarbamate herbicides by liver enzymes.
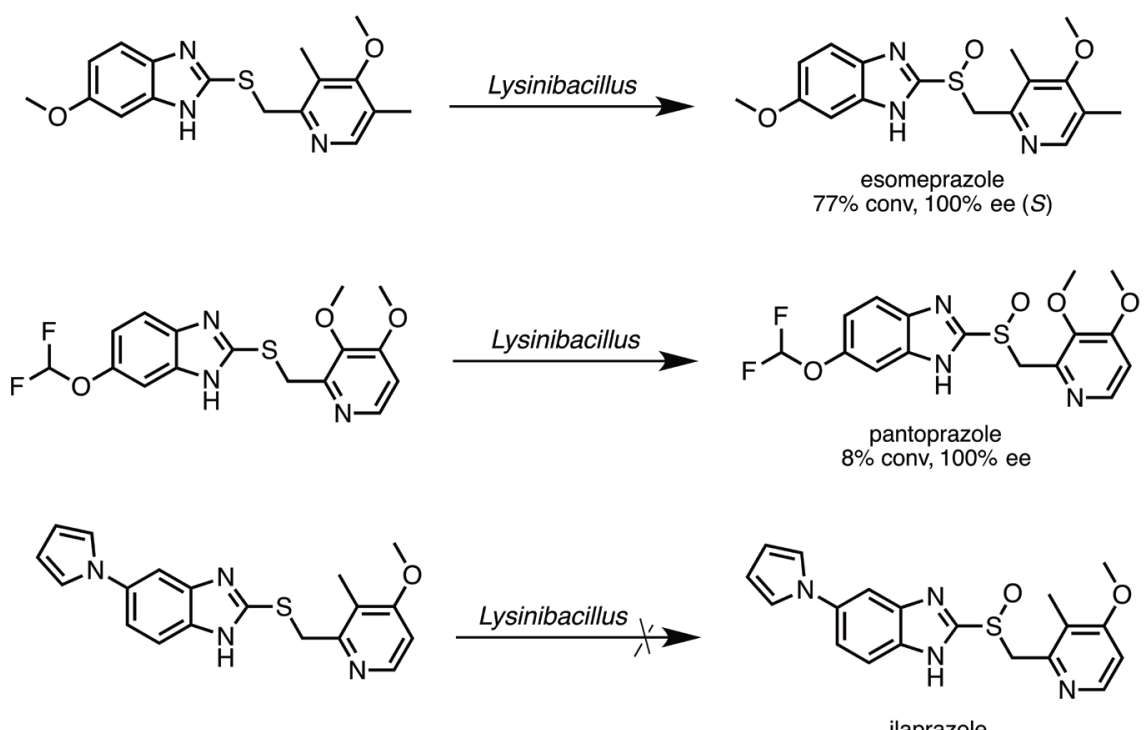<smiles>Cc1c(OC(F)(F)F)ccnc1CSc1nc2ccccc2[nH]1</smiles><smiles>C[14CH3]</smiles><smiles>Cc1c(OC(F)(F)F)ccnc1CSc1nc2ccccc2[nH]1</smiles>

Figure 31 - Esomeprazole sulfide and other related compounds used as substrates for biooxidations with Lysinibacillus sp. B71 (Babiak et al. 2011).

exception of a difluoromethoxy substituted one, which exhibited $8 \%$ conversion and $100 \%$ ee.

Olivo et al. (2005) employed Beauveria bassiana and Bacillus subtilis in a one-pot reaction to afford $(S)$-modafinil in good yield (60\% overall yield and $81 \%$ ee). Another pharmaceutical compound, sulforaphone, which is a potent inducer of phase II detoxification enzymes in mammalian metabolism, was produced in moderate yield (60\%) and high ee ( $88 \%$ in favor of $(R)$-sulfoxide) using cells of Helminthosporium NRRL 4671 (Holland et al. 1994a). 
(a)

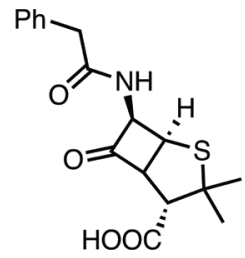

Penicillin G

or

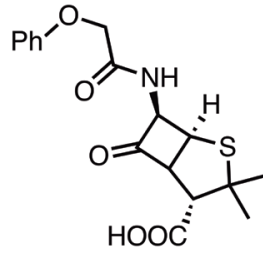

Penicillin V

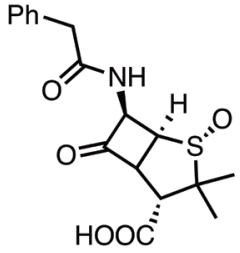

(R)-sulfoxide

or

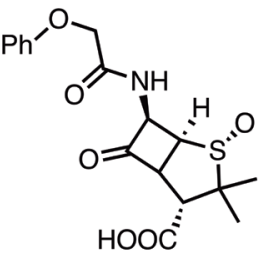

(R)-sulfoxide

(b)

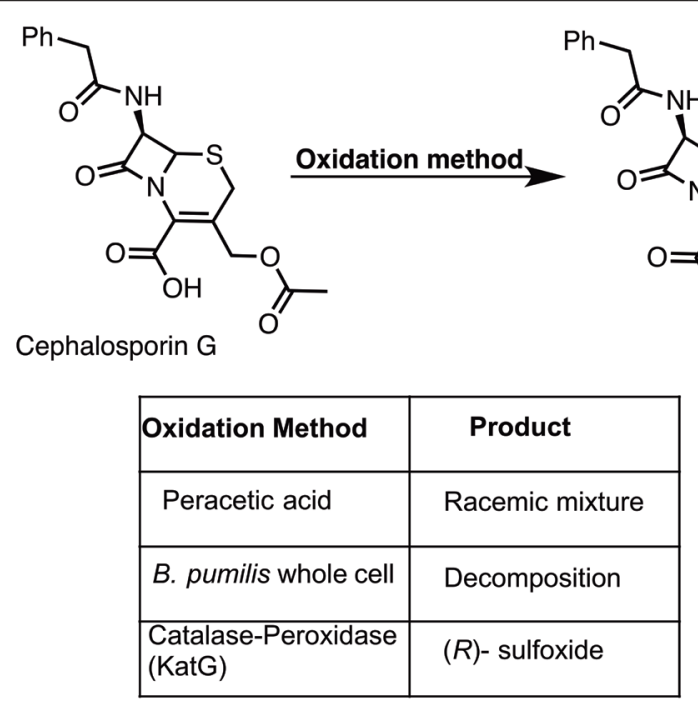

Figure 32 - Oxidation of Cephalosporin G, Penicillin G and Penicillin V.

The antibiotics Penicillin V, Penicillin G and Cephalosporin $\mathrm{G}$ were oxidized to their $(R)$-oxides by Sangar et al. (2012), as can be seen in Figure 32. Penicillin G was used as model substrate for the oxidations with $B$. pumilis. Two strains were tested, B4W and BIMT 9004. Only strain B4W gave the corresponding $(R)$-sulfoxide as exclusive product. In addition, penicillin $\mathrm{V}$ was oxidized to the $(R)$-enantiomer by $\mathrm{B} 4 \mathrm{~W}$ strain. In the case of Cephalosporin $\mathrm{G}$, the use of B. pumilis strain B4W was discouraging due to the extensive product decomposition. In view of these results, Sangar et al. (2012) decided to perform the oxidation of Cephalosporin $\mathrm{G}$ with the isolated enzyme, catalase-peroxidase (KatG), obtaining as exclusive product, the $(R)$-Cephalosporin G sulfoxide, Figure 32a.

A relevant issue that should be overcome in the synthesis of pharmaceutical compounds is the large-scale productions/reactions. Therefore, Pezzotti et al. described an oxidase/peroxidase bi-enzymatic system (Pezzotti et al. 2005) for the enantioselective oxidation of heteroaryl-methylsulfides. The main advantage of this method was the cheap commercial enzymes, allowing these reactions to proceed in large-scales. For instance, 
Cunninghamella blakesleeana was used to oxidize albendazole and three metabolites were produced (Gurram et al. 2009). These metabolites were found to be the sulfoxide, a sulfone and an $N$-methyl sulfoxide. The study of the components for the culture media showed little effect in the selectivity towards any metabolites, with exception of the addition of vitamins. Ascorbic acid, choline, colic acid, inositol, pantothenic acid and pyridoxine increased sulfoxide formation.

Engineered Baeyer-Villiger monooxygenases were used in the esomeprazole synthesis (patent described by Codexis Inc.; Bong et al. 2011). The enantiosselectivity is dependent on the amino acid residues swapped in the native enzyme. This work indicates that the enantioselectivity of a BVMO can be inverted through enzyme engineering, since both sulfoxide enantiomers can be produced. A 200fold increase in enzyme activity and almost 2-fold increase in thermal stability were also achieved (Bornscheuer et al. 2012).

\section{HYDROLASES}

Hydrolytic enzymes can also be called promiscuous enzymes, due to the broad range of reactions and substrate acceptance [For a review see: (Busto et al. 2010)]. The first example of a hydrolasetype enzyme for organo-sulfur compounds was described by Reid et al. (1967), Stein and Fahrn (1968), who used pepsin for the hydrolysis of phenyl tetrahydrofurfuryl sulfite. For this racemic compound, the hydrolysis proceeded with excellent conversion $(50 \%)$, since it is a kinetic resolution. However, when methyl phenyl sulfite was used as substrate, the reaction achieved $100 \%$ conversion, showing no enantioselectivity. The mechanism for the hydrolysis of a sulfite ester by pepsin was studied by Stein et al. (1968). The authors postulated the formation of a mixed anhydride intermediate I, as shown in Figure 33, which is attacked by water. Studies using an enzyme with a ${ }^{18} \mathrm{O}$-labeled

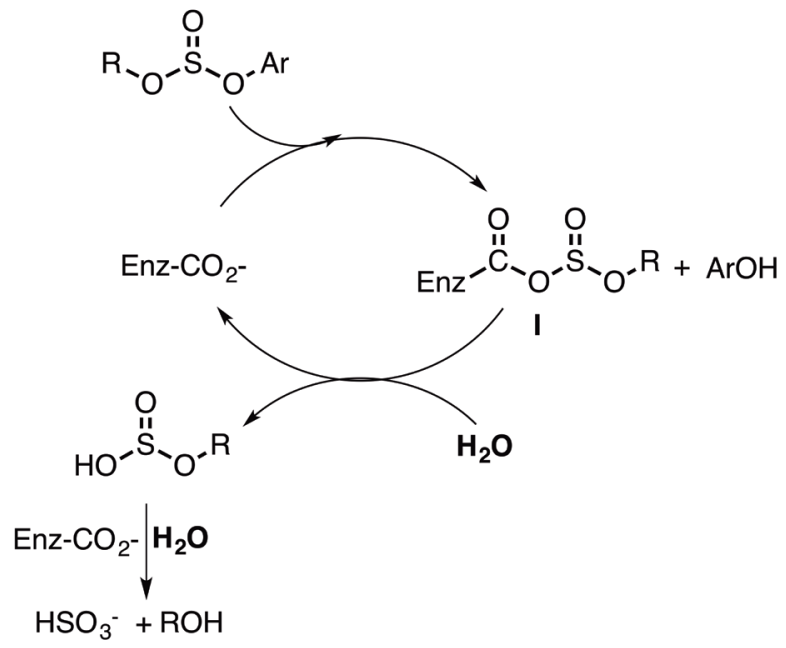

Figure 33 - Pathway for the pepsin-catalyzed hydrolysis of sulfite esters described by Stein and Fahrn (1968).

carboxyl group at the active-site were performed. Based on these studies, they could infer that it is more likely that $\mathrm{H}_{2} \mathrm{O}$ attacks the carboxyl group of the enzyme-substrate complex and thereafter, the incorporated oxygen atom into the bisulfite ion is originated from the ${ }^{18} \mathrm{O}$-labeledcarboxyl residue of the enzyme.

Pepsin was also used by May et al. $(1969,1971)$ for the hydrolysis of bis- $p$-nitrophenyl sulfite (Figure 34). This substrate is hydrolyzed $10^{3}$ times faster than other substrates. The order of $k_{\text {cat }} / \mathrm{K}_{\mathrm{M}}$ of three different substituted phenyl sulfites was found to be diphenylsulfite $<$ bis- $p$-bromophenyl sulfite $<$ bis- $p$-nitrophenyl sulfite. Since bis-p-nitrophenyl sulfite exhibited the highest $k_{\text {cat }} / \mathrm{K}_{\mathrm{M}}$ ratio $\left(1.7 \times 10^{5}\right.$ $\mathrm{M}^{-1} \mathrm{~s}^{-1}$ in comparison to $74 \mathrm{M}^{-1} \mathrm{~s}^{-1}$ ), it could be used in a study of pepsin inhibition by diphenyl sulfite. The influence of $\mathrm{pH}$ in the hydrolysis of bis- $p$ nitrophenyl sulfite by pepsin was also described by May and Kaiser (1971). They have observed the highest $k_{\text {cat }} / \mathrm{K}_{\mathrm{M}}$ ratio around $\mathrm{pH} 3\left(2.75 \mathrm{M}^{-1} \mathrm{~s}^{-1}\right)$. Comparing their results to other neutral substrates hydrolysis, they concluded that there are certain common mechanistic features to the peptidase and sulfite-esterase activity of pepsin. 
In fact, Hubbard and Stein (1971) observed that the mechanism is consistent with the ${ }^{18} \mathrm{O}$ work of Stein and Fahrn (1968), suggesting its involvement in the mechanism by forming a carboxylicsulfurous acid anhydride. Since the same kinetics are observed in a glycine buffer (Hubbard and Stein 1971), which excludes the possibility of water in the hydrolysis of sulfites. The mechanism for the hydrolysis of bis- $p$-nitrophenyl sulfite was then later proposed by May and Kaiser (1972). They also claim the possibility of an active-site carboxylate group attacks the sulfur of the sulfite ester, while another carboxyl group assists the reaction, acting as a general acid. These covalent intermediates were trapped by Nakagawa et al. (1976), supporting this theory.

Candida antarctica lipase (CAL-B) was used to catalyze carbon-sulfur bond addition to vinyl esters in organic media (Lou et al. 2008). By changing the reaction solvent, the authors were able to control the formation of an anti-Markovnikov product or a Markovnikov product. For instance, the reaction of

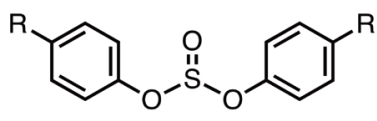

$\mathrm{R}: \mathrm{H}, \mathrm{Br}$ or $\mathrm{NO}_{2}$

Figure 34 - Substrates used in the hydrolysis reaction by pepsin. benzyl thiol with vinyl acetate in diisopropyl ether gave $83.9 \%$ of Markovnikov C-S bond addition, while in DMF, 93.1\% of the anti-Markovnikov C-S bond addition product was achieved (Figure 35). By using other polar solvents such as acetonitrile, THF, $t$-butyl alcohol and DMSO, the yields of antiMarkovnikov reaction were lower than 31\%. The authors attributed these differences in selectivity to an enzyme conformational change due to the presence of different solvents.

The addition of nucleophiles to $\alpha, \beta$-unsaturated sulfinyl derivatives using hydrolytic enzymes was performed by Madalinska et al. (2012). The benzenethiol addition to phenyl vinyl sulfoxide was observed only in the presence of enzymes, using ethanol as solvent, however, none of the products were enantiomerically enriched (Figure 36). On the other hand, $(S)$-enantioenriched product was obtained $(25 \%$ ee) with cyclic $\alpha$-sulfinylalkenylphosphonate and benzenethiol as substrates. An explanation for these results was proposed by Madalinska et al. (2012). They state that inside the "oxyanion hole" in the enzyme active site, the sulfinyl oxygen atom is bonded with hydrogen bonding. In parallel, the nucleophilicity of benzenethiol is enhanced due to the coordination to histidine. Despite the interaction to be identical as in the case of Michael addition of thiols to enones, the H-binding of the sulfinyl oxygen atom must be

(a)

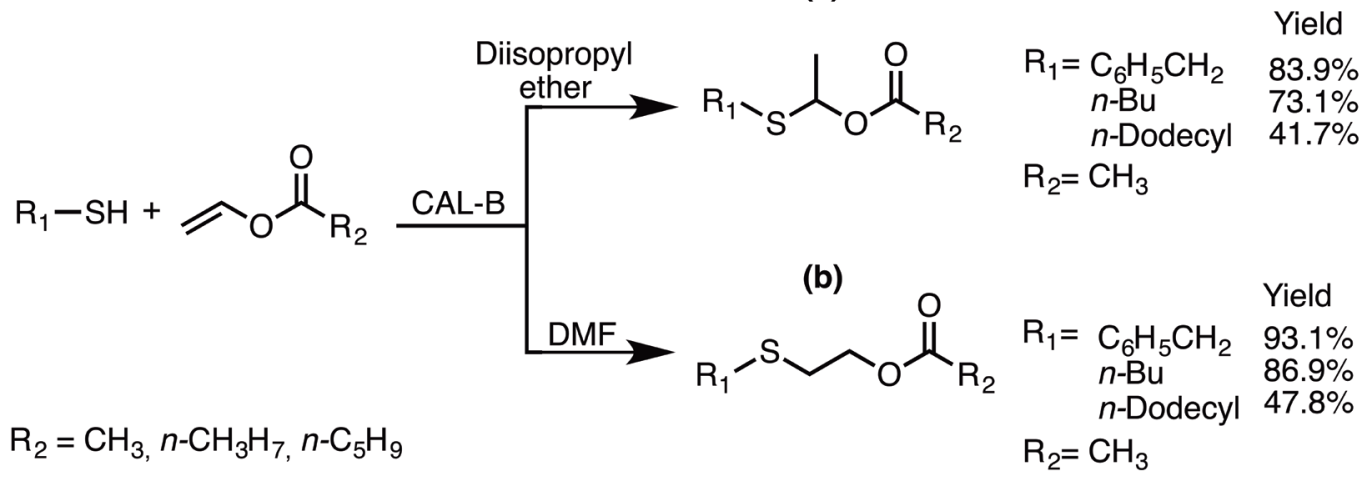

Figure 35 - Reactions of thiols with vinyl esters catalyzed by lipase, CAL-B: Markovnikov product (a) and anti-Markovnikov product (b). 


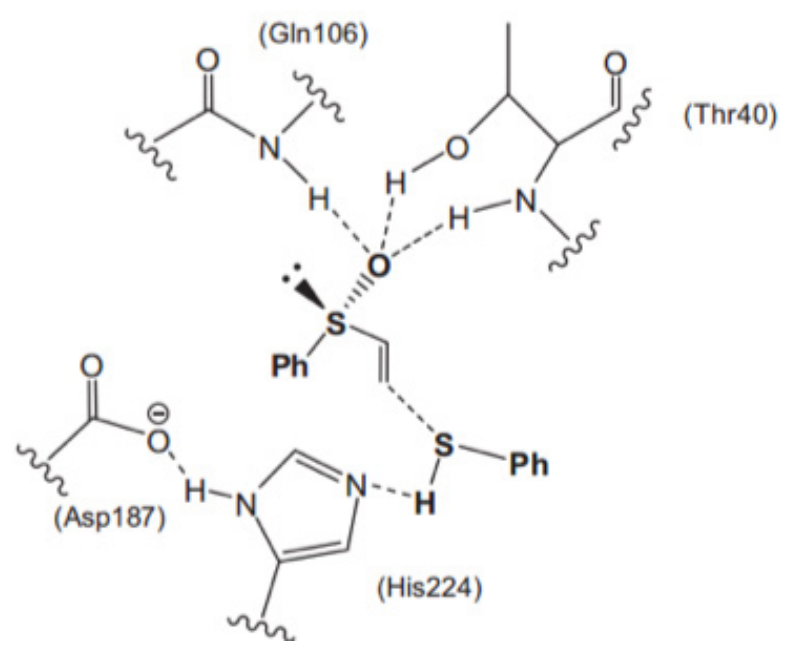

Figure 36 - Addition of nucleophiles to $\alpha, \beta$-unsaturated sulfinyl derivatives using hydrolytic enzymes. Figure adapted with permission from Elsevier (Madalinska et al. 2012).

different from that of the carbonyl oxygen atom, which results in a less efficient catalytic reaction.

Alkyl-sulfatase Pisa 1 (Schober et al. 2012) was evaluated for transformations of rac-sec-alkyl sulfate into a homochiral mixture of a sec-alcohol, as shown in Figure 37. For sulfate ester group at the (w-1)-position, the enantioselectivity was higher by increasing chain length or branching. Some of the water-miscible solvents, such as ethylene glycol, DMSO, 1,2-dimethoxyethane and methanol had a positive effect in the selectivity (ee of the product from $90 \%$ to $>99 \%$ ) with a small cost of relative activity $(\sim 10 \%)$. Synechococcus and Paracoccus spp. alkylsulfatase were used for transformation of racemic sec-alkylsulfate esters, furnishing either $(R)$ - or $(S)$-sec-alcohols. Addition of alcohols improved the ee for the $(S)$ product isomer $(22 \%$ ee), with $t$ - $\mathrm{BuOH}(>99 \%$ ee) being more effective than $\mathrm{MeOH}$ ( $85 \%$ ee), $\mathrm{EtOH}(93 \%$ ee) and $\mathrm{i}-\mathrm{PrOH}(92 \%$ ee). The authors also stated that lipophilic co-solvents yield biphasic system, which makes the enzymes to act on the interface (Gadler et al. 2009). The hydrolysis of sec-alkyl sulfate esters was also studied by Toesch et al. (2014a), who observed that Alkylsulfatase Pisa1 has its enantioselectivity significantly improved (up to $E>200$ ) by suppressing the autohydrolysis of substrates with DMSO as co-solvent. The authors also observed that the introduction of electronwithdrawing substituent in the meta position of the benzylic sec-sulfate esters had a positive effect on the selectivity, achieving the following enantioselectivity order: $\mathrm{OMe}<\mathrm{F}<\mathrm{Cl}<\mathrm{CF}_{3}$ (ee ${ }_{\mathrm{pDMSO}}$ free $/ e_{\text {pwith DMSO }}: 40 / 82<60 / 93<61 / 93<85 / 99$ ).

Toesch et al. (2014a) also performed ${ }^{18} \mathrm{O}$-labeling experiments to determine which atom would be attacked ( $\mathrm{S}$ or $\mathrm{C}$ ) and the type of reaction mechanism. If the ${ }^{-} \mathrm{OH}$ group attacks the carbon atom in a $\mathrm{S}_{\mathrm{N}} 2$-type reaction, the product would be an alcohol with opposite configuration. In case of sulfur, the product would have retention of configuration. The third option would be a $\mathrm{S}_{\mathrm{N}} 1$ type reaction with the formation of an ion on the carbon, leading to product racemization. These ${ }^{18} \mathrm{O}$ labeled experiments revealed the mechanism of autohydrolysis to proceed through a $\mathrm{S}_{\mathrm{N}}$ 2-type inversion at carbon and racemization $\left(\mathrm{S}_{\mathrm{N}} 1\right)$.

Sulfatases are also used for deracemization of alkyl sulfates [For a review see (Schober and Faber 2013, Toesch et al. 2014b)]. In this area, one can highlight the work described by Schober et al. (2011) who performed hydrolysis using unlabeled 1-octyl- and rac-2-octyl sulfate in a ${ }^{18} \mathrm{O}$-enriched buffer. This work showed the formation of 1-octanol and $(S)$-2-octanol (ee $>99 \%$ ) with full ${ }^{18} \mathrm{O}$-label incorporation. These results proved that $\mathrm{C}-\mathrm{O}$ bond is cleaved in both cases. Once the mechanism of Pisal was determined, a study of substrate scope was performed. Schober et al. (2011) described that Pisa1 can accept a broad range of substrates, including linear, branched, or cyclic sec-alkyl sulfates. The best conversions and $E$-values were obtained for straight, branched and aromatic chains sulfate esters, being resolved with excellent enantioselectivity $(E>200)$ and full conversion (50\%, as expected for kinetic resolution). A preparative scale of the chemoenzymatic 

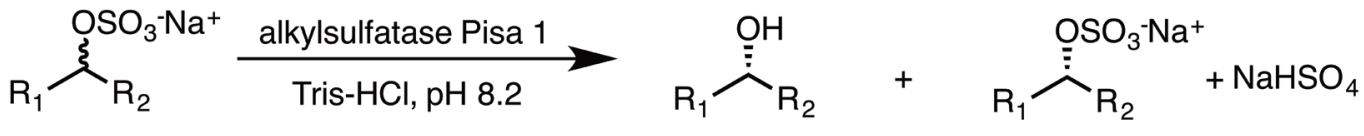

$4-57 \%$ conversion $32->99 \%$ ee

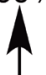

p-TosOH/t-BuOMel

$\mathrm{H}_{2} \mathrm{O}$, Dioxane

$\mathrm{R}_{1}=\mathrm{Me}, \mathrm{Et}, \mathrm{n}-\mathrm{Pr}, \mathrm{CH}=\mathrm{CH}_{2}, \mathrm{C} \equiv \mathrm{CH}$

$\mathrm{R}_{2}=\mathrm{n}-\mathrm{Pr}, \mathrm{n}-\mathrm{Bu}$, n-hexyl, n-pentyl, n-heptyl, $\mathrm{Ph},\left(\mathrm{CH}_{2}\right)_{2} \mathrm{CHMe}_{2},\left(\mathrm{CH}_{2}\right)_{2} \mathrm{CH}=\mathrm{CH}_{2}, \mathrm{CH}_{2}-\mathrm{CH}=\mathrm{CH}_{2}$, $\mathrm{CH}_{2}-\mathrm{CHMe}_{2}, 3,5-\left(\mathrm{CF}_{3}\right)_{2} \mathrm{C}_{6} \mathrm{H}_{3}, \mathrm{C} \equiv \mathrm{C}-\mathrm{Et}, \mathrm{C} \equiv \mathrm{C}-\mathrm{Me}, \mathrm{C} \equiv \mathrm{C}-\mathrm{Ph}, \mathrm{CH}_{2}-\mathrm{C} \equiv \mathrm{C}-\mathrm{Me}$

Figure 37 - Use of alkylsulfatase Pisa 1 to obtain a mixture of sec-alcohol and non-reacted sulfate ester.

deracemization protocol was shown to give $(S)$ alcohols in up to $>99 \%$ ee.

Fuchs etal.(2013) described a chemoenzymatic synthesis of $(R)$ - Lasiodiplodin methyl ether. One of the key steps, the esterification was performed using a chiral alcohol with $(S)$-configuration, which was obtained by the sulfatase-based deracemization process. Alkyl sulfatase Pisa1 could invert the $(R)$ enantiomer from a racemic mixture of an alkyl sulfate, obtaining the corresponding $(R)$ alcohol in $99 \%$ ee and $50 \%$ conversion, while leaving the $(S)$-precursor (alkyl sulfate) untouched. The total synthesis was completed through a combined ring-closing metathesis and hydrogenation of the macrocyclic $\mathrm{C}=\mathrm{C}$ bond to givethe $(R)$-lasiodiplodin methyl ether in $93 \%$ ee and anoverall yield of $44 \%$.

More recently, Schober et al. (2013) performed one-pot deracemization of secondary alcohols. Two different enzymes were evaluated, PAS (arylsulfatase from Pseudomonas aeruginosa) and Pisal in a series of sec-alkylsulfate esters. PAS could resolve substrates bearing an acetylene moiety next to the stereocenter with good to excellent enantioselectivities for the $(S)$-stereoisomer ( $E 59$ to $>200$ ). Pisal resolved the $s e c$-alkylsulfate esters bearing short-chain acetylene moiety in excellent enantioselectivity for the $R$ isomer $(E>200)$. The deracemization can be performed by hydrolysis of sulfate esters using enantiocomplementary enzymes: PAS and Pisa1.

\section{MISCELLANEOUS}

Aracemicphosphorodithioatewas enantioselectively oxidized by chloroperoxidase (CPO) from $C$. fumago by Mikolajczyk et al., resulting in a kinetic resolution process (Mikołajczyk et al. 2009). The synthesis of methyl parathion and its oxon form was performed in one-pot reaction, with CPO in combination with Lawesson's reagent, as can be seen in Figure 38. The complete kinetic resolution was achieved after 22 days, which was observed by ${ }^{31} \mathrm{P}$ NMR. By analyzing the absolute configuration, the product was the $(S)$ enantiomer in $99.6 \%$ ee, while the unreacted compound had the opposite configuration at the phosphorus $(R, 97 \%$ ee). The final step involved the Lawesson's thionation (for the (S)-oxon) and a reaction with iodoxybenzene in the presence of montmorillonite K10 as an activator (for the $(R)$ - dithiophosphate), resulting in $(S)$-dithiophosphate and the corresponding $(R)$ oxon with $99.6 \%$ ee and $94.9 \%$ ee, respectively.

More recently, Hibi et al. (2013) performed the asymmetric oxidation of sulfur-containing L-amino acids. The reaction with a $\mathrm{Fe}(\mathrm{II}) / \alpha$-ketoglutaratedependent dioxygenase produced several chiral amino acid sulfoxides, including methionine sulfoxide with $99 \%$ de $((S)$-configuration of the 


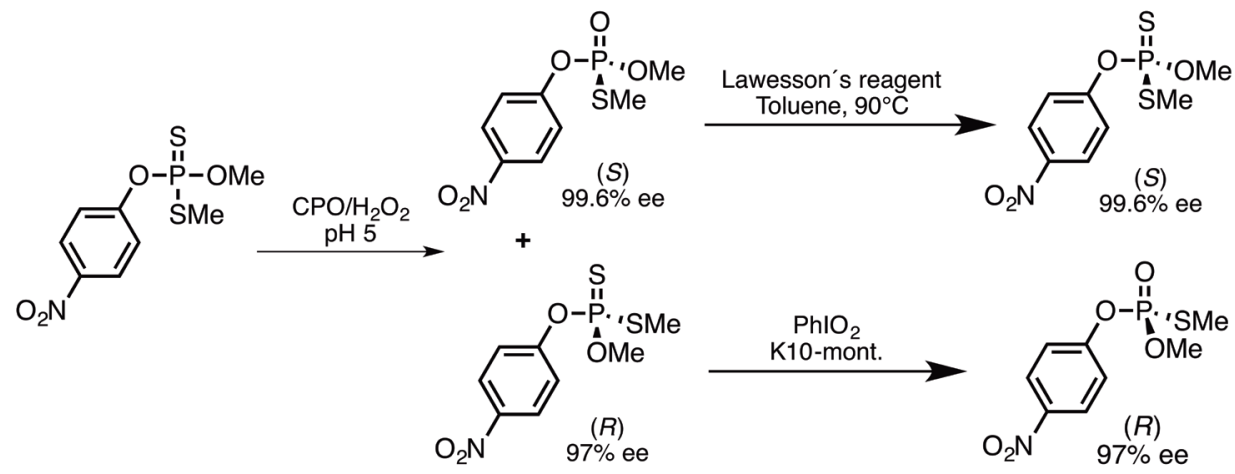

Figure 38 - Chemo-enzymatic synthesis of methyl parathion and its oxon.

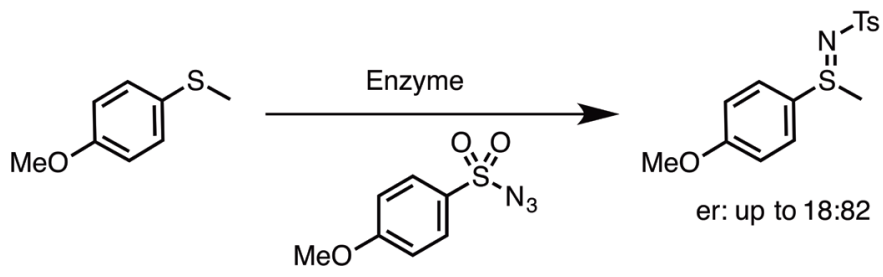

Figure 39 - Nitrogen transfer reaction using P450 enzymes.

sulfinyl group). Methionine, S-methyl-L-cysteine, S-ethyl-L-cysteine, and S-allyl-L-cysteine were fully converted (10 $\mathrm{mM}$ substrate in 16 hours), while L-methionine presented a lower conversion (67\%). The de values for the S-alkyl-L-cysteines sulfoxides were lower (83-91\%) than for the S-alkyl- L-homocysteine sulfoxides (>99\%). The lower de values were reasoned by the authors as being caused due to the relative position of the sulfur atom in the amino acid molecules. For amino acids bearing a sulfur atom at the $\delta$-position, a more stereoselective reaction than those containing the sulfur atom at $\gamma$-position was observed.

$\mathrm{P}_{450}$ enzymes were used for a nitrogen transfer reaction (Farwell et al. 2014). The product of the reaction is a sulfimide, which is also a useful building block in asymmetric synthesis. Similarly, to sulfoxidation, the electronic effect of the substrate has great influence in the reaction. The total number of turnovers (TTN) for the reaction of different sulfides with tosyl azide revealed that sulfides with electron-donating substituent on the aryl sulfide ring were better substrates for sulfimidation. For example, a substrate with a methoxy-substituent has a 300 TTN while methyl-substituent 190 TTN. However, differently from a sulfoxidation reaction, which requires a small molecule for the oxidation of a sulfide, sulfur imidation requires a large donor, such as aryl sulfonylazide, Figure 39.

\section{SELENIUM}

Selenium is a trace essential element found in at least 25 human proteins exhibiting a positive action to human health (Papp et al. 2007). In rat erythrocytes, selenium is associated with the enzyme glutathione peroxidase and possesses a cooperative effect against oxidative stress (Li et al. 2014, Sandre et al. 2006, Uğuz et al. 2009). In humans, it is associated with hemoglobin (Haratake et al. 2005, Whanger 1998) where it is carried through the body and transferred to the plasma (Haratake et al. 2008), playing its role in oxidative stress (Lettow et al. 2005). The incorporation of selenium in animals is via plant ingestion, (Papp et al. 2007) in which the inorganic selenium is uptaken and transformed into 


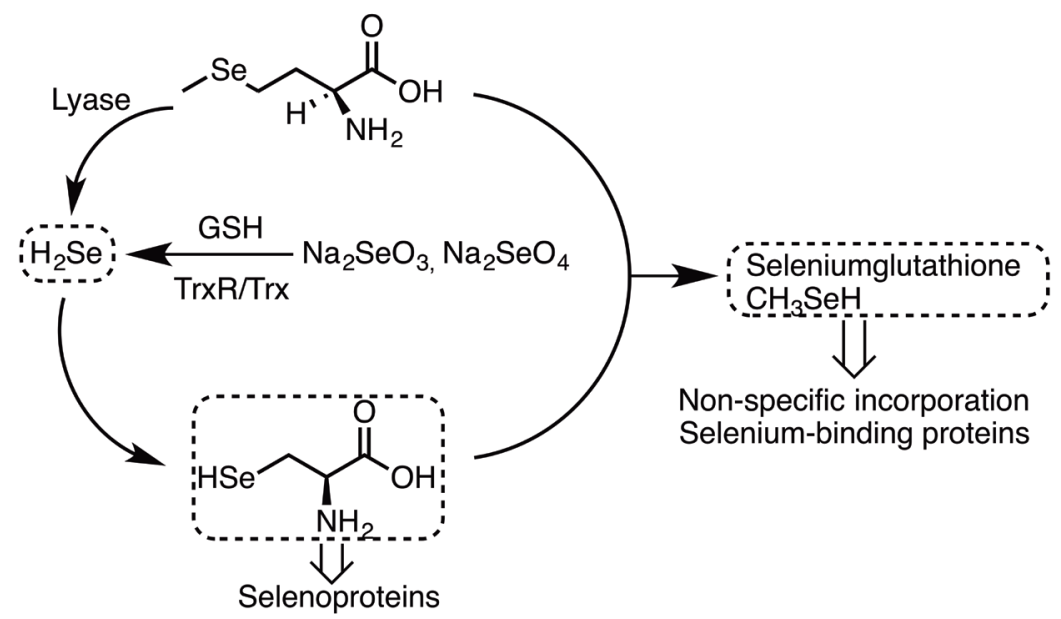

Figure 40 - Selenium metabolism pathway in animals.

organoselenium species, such as selenomethionine. The mammalian uptake and conversion is shown in Figure 40. Selenocysteine, the analogue of cysteine, is probably the most active form of selenium found in nature. However, others selenium species such as selenoglutathione and methylselenide which are found in animals also exert important factor in selenoprotein formation (Papp et al. 2007).

When selenium properties such as ion radius, redox potentials and electronegativity are compared to sulfur, one can notice their similarities and cannot indicate a direct evidence for different reactivities (Wessjohann et al. 2007). However, although their polarizabilities present some differences, the main contrast between selenium and sulfur is on their molecules $\mathrm{p} K \mathrm{a}$, for example, selenocysteine has a $5.2 \mathrm{pKa}$ while the cysteine a $\mathrm{pKa}$ of 8.3 . The $\mathrm{pKa}$ plays a major role in enhancing the activity of selenocysteine in comparison to cysteine (McGrath and Raines 2011) and it is therefore, the biggest advantage of selenium, indicating nature's interest in synthesizing Se-mutant enzymes in place of the trivial sulfur (Kuiper et al. 2003, Wessjohann et al. 2007).

Organoselenium compounds are substrates for enzymes in nature, as for example selenocysteine synthase, which catalyzes the conversion of seryl-
tRNA into selenocysteyl-tRNA (Forchhammer and Bock 1991,/EndNote> Holtmann et al. 2014). Inspired by the ability of proteins to catalyze the conversion of selenium, chemists started to explore biocatalytic reactions of organoselenium compound (Comasseto and Gariani 2009). Here is described some results with oxidoreductases for the transformation of such compounds, however with a major focus in the last seven years.

\section{OXIDOREDUCTASES}

Organoselenium compounds can also be oxygenated as evidenced for organosulfur compounds described above.

Inspired by the works on the enantioselective oxidation of sulfides and taking into account the similar chemistry of sulfur and selenium, Auret et al. (1973) studied the biotransformation of benzyl( $p$-tolyl)selane by Aspergillus niger. The authors observed the formation of 4-methylbenzeneseleninic acid as final product, which was suggested due to a dealkylating process (Figure 41). When adding selexonide in the reaction, it remained intact. Then, it can be proposed that this oxidation does not occur via initial formation of selenoxide. These observations can prove that the mechanism should undergo via a dealkylation 


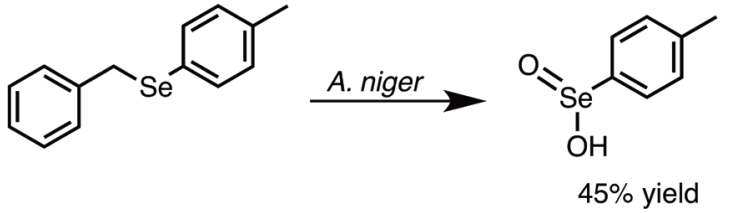

Figure 41 - Oxidation of benzyl(p-tolyl)selane with $A$. niger.

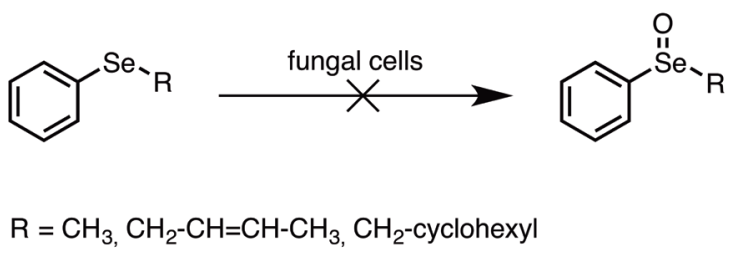

Figure 42 - Incubation of a series of phenyl selenides with Aspergillus niger, Aspergillus foetidus, Mortierella isabellina and Helminthosporium sp.

process followed by selenium oxidation to give the final product, seleninic acid.

Holland and Carter (1983) described the incubation of a series of phenyl selenides with Aspergillus niger, Aspergillus foetidus, Mortierella isabellina, and Helminthosporium sp. The selenoxide was not detected among the products after incubation with the selected fungi. It seemed that a complete degradation was occurring. A study was performed with Mortierella isabellina using a substrate ${ }^{14} \mathrm{C}$-labeled at methyl group (methyl phenyl selenide). In this study, the residual radioactivity after the process (61\% of the starting activity) when compared to the recovered selenium (98\%) obtained by quantitative analysis, had corroborated to elaborate an interesting explanation: The fraction of radioactivity at the end of the process would be consequence of the $\mathrm{Se}-{ }^{14} \mathrm{CH}_{3}$ bond cleavage, and therefore, the formation of volatile one-carbon metabolic products. In this scenario, no selenoxide would be produced (Figure 42).

Even with those previous discouraging results, the oxidation of propargylic phenyl selenide was attempted by Branchaud and Walsh (1985) and Reich et al. (1983). These research groups, independently, have employed cyclohexanone

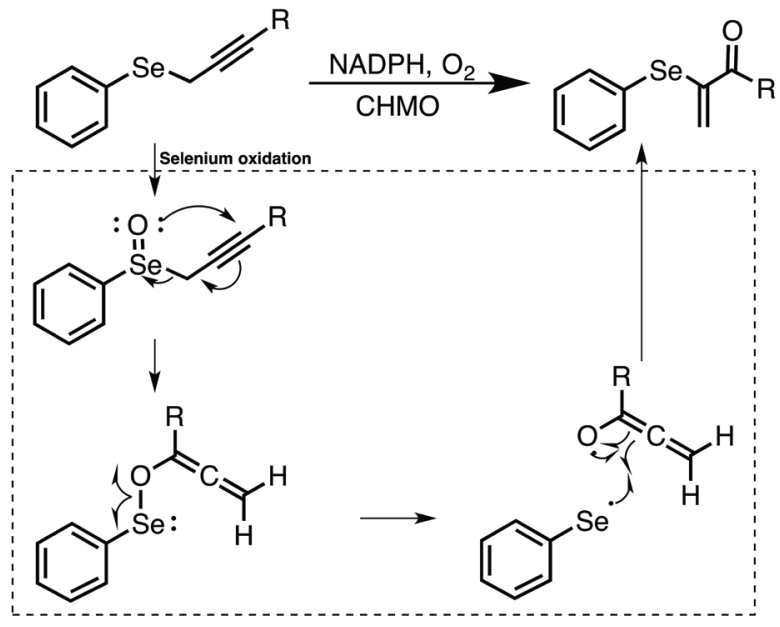

Figure 43 - $\alpha$-Phenylselenoacrolein formation using cyclohexanone oxygenase.

oxygenase which were already applied for oxidation of allyl phenyl sulfides (Branchaud and Walsh 1985, Reich et al. 1983). Branchaud and Walsh (1985) have described that CHMO could oxygenate the selenium of phenyl methyl selenide to the corresponding selenoxide with relatively high efficiency $\left(k_{\text {cat }} / \mathrm{K}_{\mathrm{M}}=2 \times 10^{5} \mathrm{M}^{-1} \mathrm{~s}^{-1}\right)$. However, Reich et al. (1983) could only briefly observe the selenoxide formation at $-80^{\circ} \mathrm{C}$, detecting a possible favored 2,3-sigmatropic rearrangement for the organoselenium compounds in comparison to the sulfur compounds. Latham et al. (1986) also studied the [2,3]-sigmatropic rearrangement and observed the $\alpha$-phenylselenoacrolein formation as a fragmentation-recombination product, as shown in Figure 43.

Ebselen, an in vitro mimetic of the catalytic activity of glutathione peroxidase had its metabolites, selenol and methylselenide, kinetically studied via oxidation with purified Flavin-containing monooxygenase (FMO1) from pig liver (Ziegler et al. 1992). The authors found out that ebselen inactivate FMOl in the absence of GSH (glutathione). Although ebselen appears to be a substrate, in the absence of GSH, it progressively inactivates the enzyme, apparently by covalent 


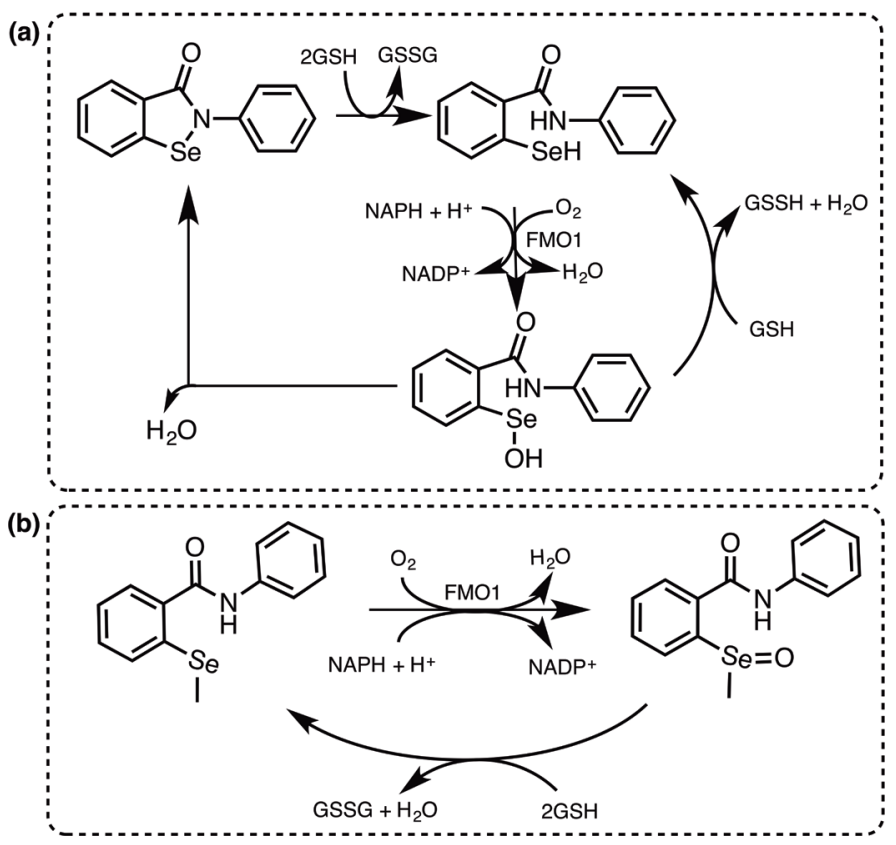

Figure 44 - Oxidation of Ebselen (a) and 2-(Methylseleno)benzanilide (b) catalyzed by FMO1 (Ziegler et al. 1992).

binding to essential enzyme thiol residues (being reduced). However, stepwise reduction of ebselen by GSH through the intermediate selenyl sulfide generates 2-selenylbenzanilide, which does not inhibit FMO1. Rapid reduction of the selenide oxide by GSH was unexpected and suggests that, unlike S-oxidation of sulfides, Se-oxidation of selenides may be a route for bioactivation. In the presence of FMOl micromolar amounts of either of these metabolites establish a catalytic cycle for the oxidation of GSH to GSSG (glutathione disulfide) by NADPH and oxygen (Figure 44).

Biomethylation of organoselenium compounds was performed by Costa et al. (2007) using whole cells of $A$. terreus (Figure 45). These reactions occurred unexpectedly during the screening of conditions for biotransformation of (RS)-1-(phenylseleno)-2propanol. The increase in cell mass promoted the formation of a methylated derivative. The proposed mechanism involves the formation of a selenoxide (Chasteen and Bentley 2003), which undergoes syn-elimination reaction to give seleninic acid.

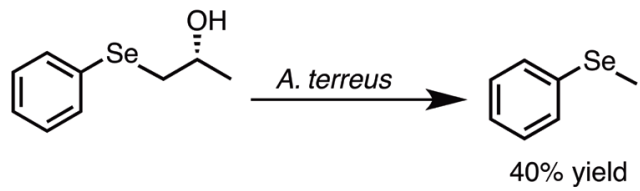

Figure 45 - Biomethylation reaction of (S)-1-(phenylseleno)2-propanol.

Hence, the intermediate can be transformed into its methylated derivative via biomethylation. These reactions involve the biooxidation of the substrate.

Andrade et al. (2011) described the oxidation of organoseleniumacetophenones to the corresponding selenoxides in high conversions (76->99\%) was achieved with phenylacetone monooxygenase (PAMO) as a biocatalyst in aqueous medium, as shown in Table V. The reactions also employed a NAD(P)H-regenerating system using glucose6-phosphate dehydrogenase from Leuconostoc mesenteroides. Substrates substituted at the orthoposition were not converted to their corresponding selenoxides. In addition, selenoxides are readily racemized in the presence of water, then, the 
TABLE V

Oxidation of organoselenium acetophenones using phenylacetone monooxygenase (PAMO) and a NAD(P) H-regenerating system.
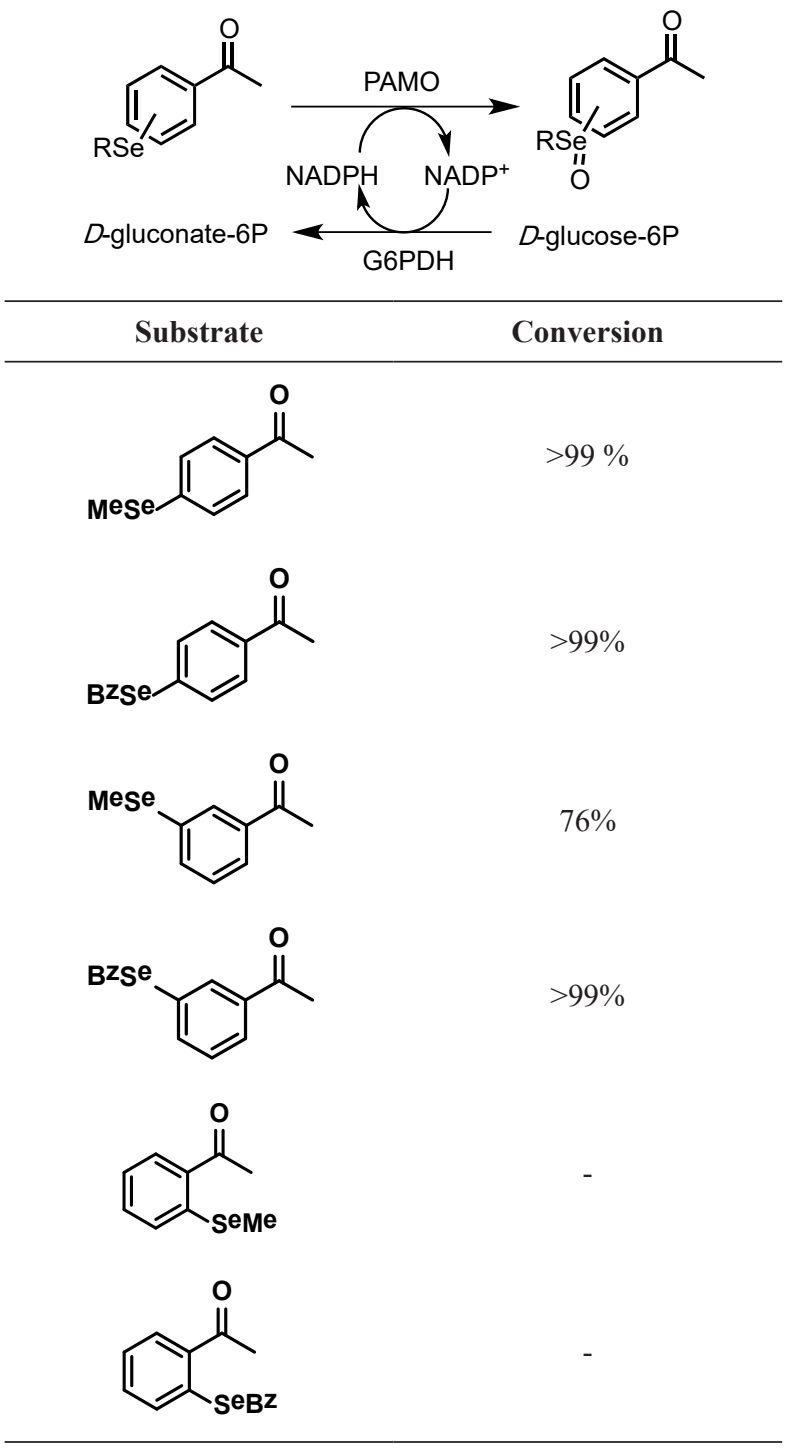

enantiomeric excesses for these compounds were not determined.

An oxidative approach for kinetic resolution of aromatic selenides was studied by Brondani et al. (2012b). The enantioselective oxidations of these organoselenium compounds were performed using Baeyer-Villiger monooxygenases including, PAMO, M446G PAMO, CHMO and HAPMO. The regeneration of the cofactor was performed by phosphite dehydrogenase (PTDH). While M446G PAMO and PAMO were able to perform the oxidation with low to high ee (9-98\%), HAPMO and CHMO did not mediate the oxidation reaction. The authors observed the preference for the oxidation of the $(R)$-Selenide, leading to selenoxide elimination (elimination of $\mathrm{RSeOH}$ ) giving the styrene derivative and leaving the $(S)$ selenide intact (Figure 46). In the same study, in order to perform the kinetic resolution of the same selenides, the authors tested oxidoreductasescontaining Aspergillus terreus and lipase (Cal-B) in the presence of oxidants. Unfortunatelly, satisfactory results were not observed in this case.

\section{BORON}

Boron is a semiconductor element with intermediate properties between metals and nonmetals. This atom has a unique chemistry which might be the most intriguing and complex after the chemistry of carbon (Bolaños et al. 2004). Besides that, boron is essential in small amounts to most

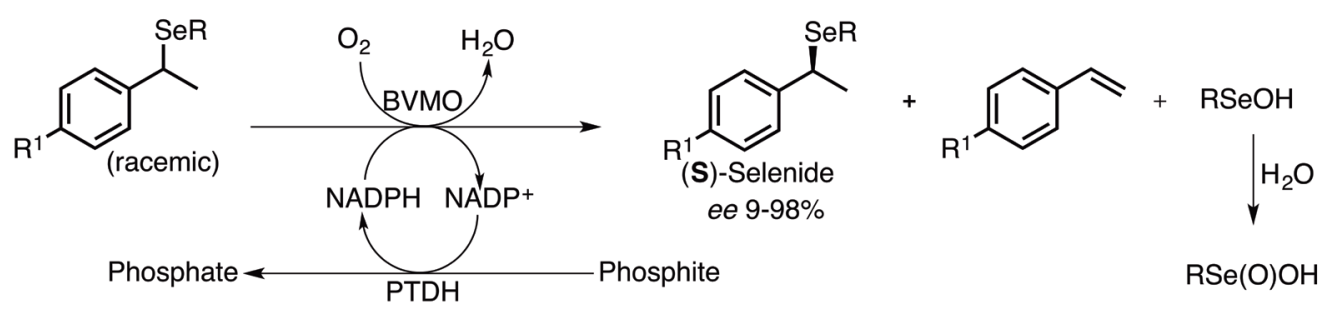

$\mathrm{R}=\mathrm{Ph}$ or $\mathrm{Bn}$

$\mathrm{R}^{1}=\mathrm{H}, \mathrm{Me}$ or $\mathrm{F}$

Figure 46 - Kinetic Resolution of aromatic selenides using BVMOs as biocatalysts. 


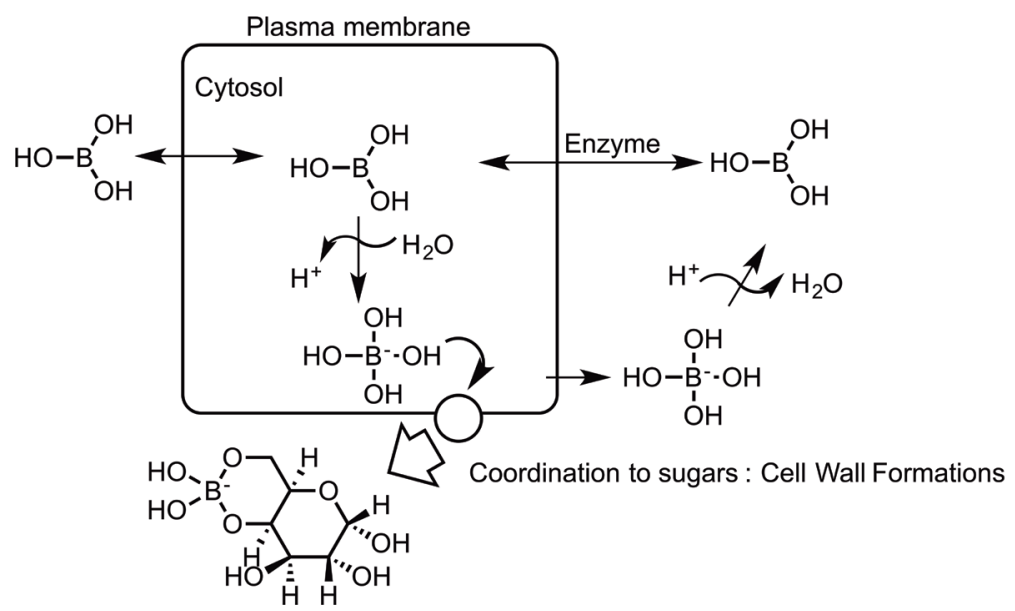

Figure 47 - Transport and absorption of borate in a cell.

types of life and its deficiency effects negatively on plant anatomy, physiology and biochemistry (Lu et al. 2014), which suggests that boron has multiple functions in organisms, especially for vascular plants, diatoms and some species of marine algal flagellates (Hunt 1994, Loomis and Durst 1992, Lovatt 1985). However, the primary role of boron remains unclear (Kaya et al. 2009). In most physiological fluids, boric acid $\mathrm{B}(\mathrm{OH})_{3}$ and small amounts of borate anion $\mathrm{B}(\mathrm{OH})_{4}^{-}$, which can readily form complexes with existing sugars or cis-hydroxyl containing groups molecules, are related to the cell wall architecture (Bolaños et al. 2004). The mechanism of boron transport in a cell is exemplified in Figure 47, where there is a passive diffusion mechanism of the boric acid and an enzymatic one, which facilitates the transport (Takano et al. 2008).

Despite the interesting chemistry and importance, there are only few reports on the biotransformation of organoboron compounds, mainly due to the possible inhibitory effects that these compounds might have on enzymes (Das et al. 2013). Although, some progress have been made using oxidoreductases, as will be evident in the discussion below.

\section{OXIDOREDUCTASES}

Cyclohexanone oxygenase, a bacterial flavoprotein monooxygenase, was used by Branchaud and Walsh (1985) for the oxidation of boronic acids, as shown in Figure 48. The oxidation of phenylboronic acid and $n$-octylboronic acid gave the corresponding alcohols (phenol and 1-octanol) (Walsh and Chen 1988). Phenylboronic acid was also oxidized to phenol by PAMO, in $11 \%$ conversion after 24 hours, (Gonzalo et al. 2005) while HAPMO (4-Hydroxyacetophenone monooxygenase from Pseudomonas fluorescens ACB) gave 24\% conversion after 48 hours (Gonzalo et al. 2006).

Baeyer-Villiger Monooxygenases (BVMO) were also used by Brondani et al. (2011) for the selective oxidation of organoboron compounds. Initially, five boron-containing acetophenones were employed to verify which enzyme would have high chemoselectivity (ketone versus boron oxidation), as shown in Figure 49. Full conversion to corresponding phenols was observed with PAMO as biocatalyst, but the Baeyer-Villiger oxidation was only achieved with 4-substituted compounds. The mutant M446G PAMO showed a similar behavior, but with less efficiency in Baeyer-Villiger oxidation, resulting in a mixture of compounds. HAPMO-catalyzed oxidations 


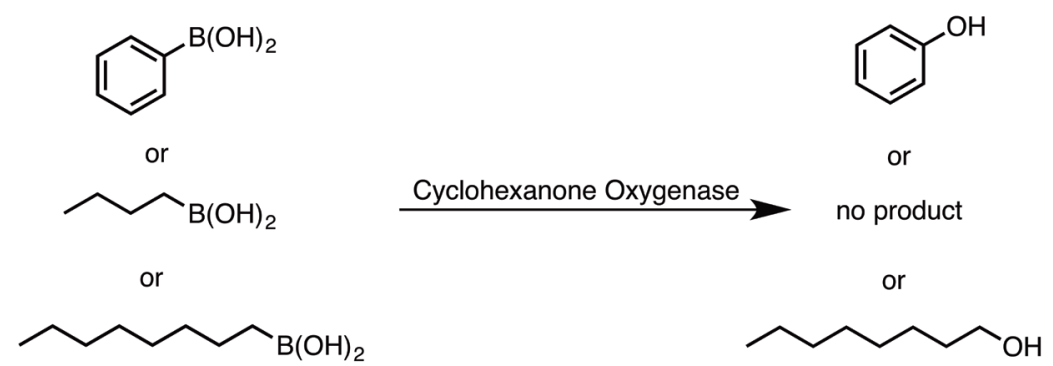

Figure 48 - Oxidation of boronic acids by cyclohexanone oxygenase.
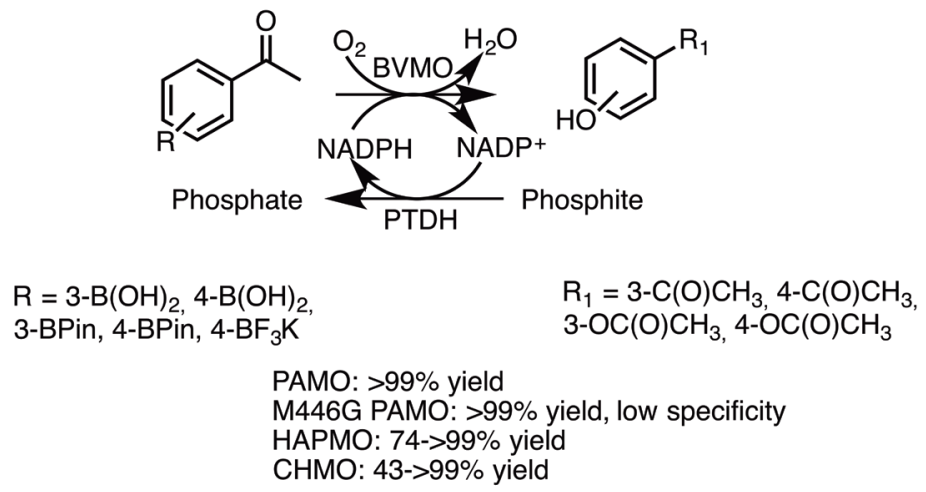

Figure 49 - Oxidation of boron-containing acetophenones by BaeyerVilliger Monooxygenases.

occurred both at boron and at ketone moieties, while CHMO presented high chemoselectivity for boron oxidation, but with low activity.

In the same work, other substrates were evaluated, such as vinyl boron compounds and chiral boron compounds. The exclusive boron oxidation was observed when the substrate was accepted by the enzymes (substrates with an aromatic moiety). These results led them to study the oxidation of chiral boron compounds with PAMO enzyme, obtaining the $(S)$-borane oxidation to the corresponding $(S)$-alcohol and recovery of the $(R)$-borane $(E=23)$, as shown in Figure 50.

BVMOs (PAMO and M446G PAMO) were also exploited for oxidative kinetic resolutions of chiral organoboron compounds by Brondani et al. (2012a). As can be seen in Figure 51, the aromatic compounds were converted in moderate yields $(49-52 \%)$ and moderate to high ee for $(S)$-alcohol (50-91\%), with the exception of the $p$-fluorinated

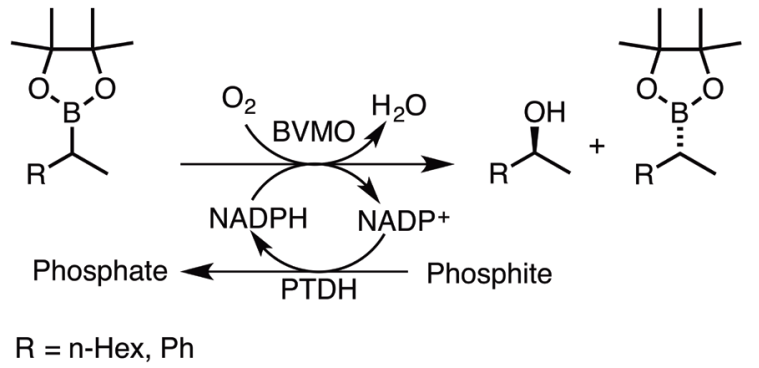

Figure 50 - Oxidation of chiral boranes to alcohols by BVMO.

compound, did not react. The b-borylated carboxylic esters also did not serve as good substrates for the BVMOs, while the cyclopropyl boronic esters were oxidized, but with no enantioselectivity.

\section{PHOSPHORUS}

Phosphorus is a bio-essential element found in DNA, cell membranes and bones (Tacke et al. 1998). It is available as inorganic phosphorus in the soil, which can be taken up by plants. The 

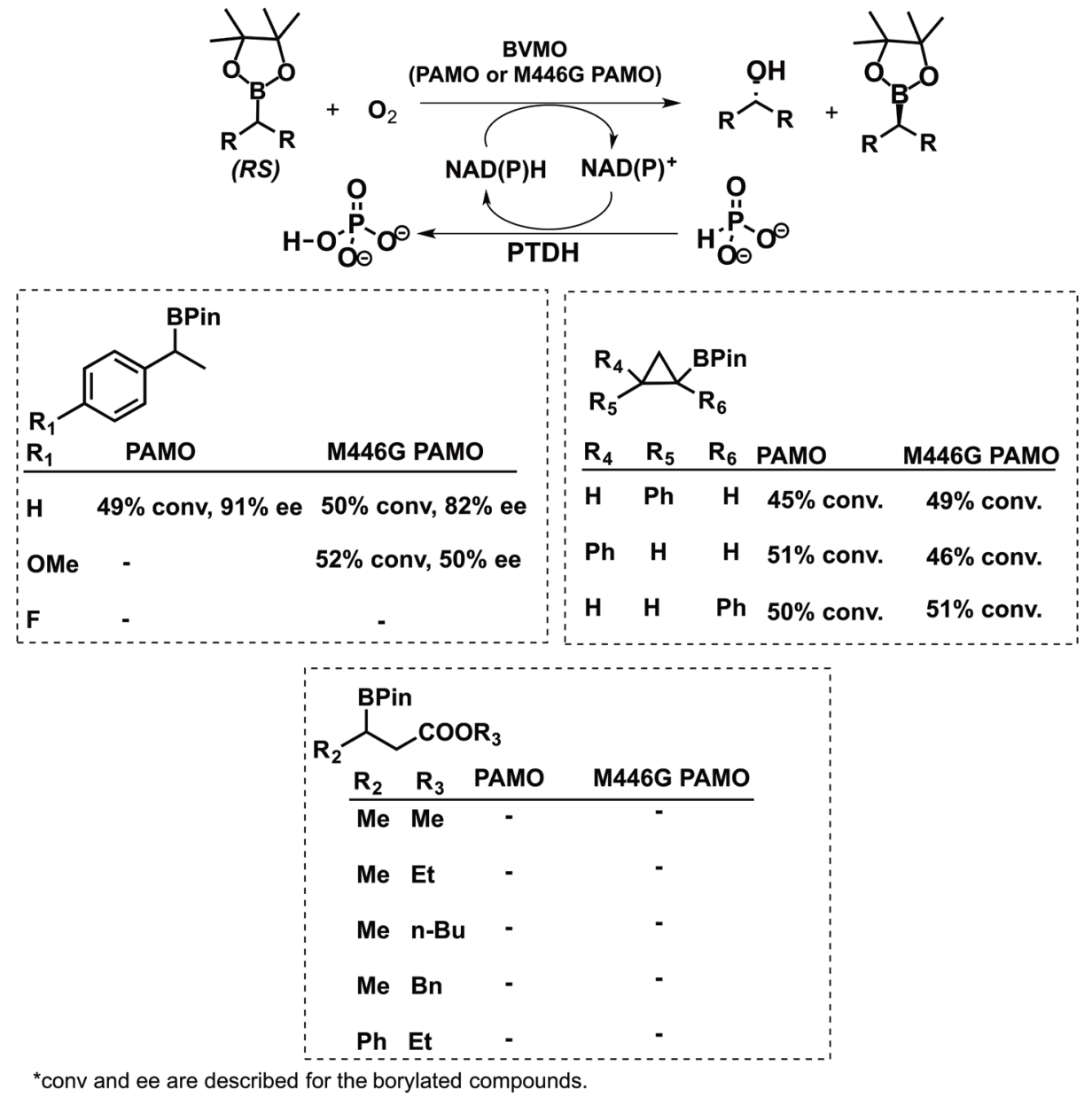

Figure 51 - Reactions of several organoboron compounds with BVMOs.

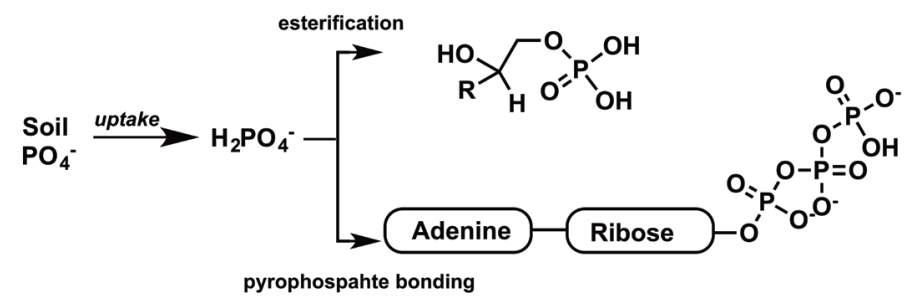

Figure 52 - Phosphorus uptake and its metabolic pathway.

major forms of inorganic phosphorus can be found as orthophosphate or pyrophosphate, (Maathuis 2009) while organic phosphorus (phosphate ester) is synthesized through the esterification by pyrophosphate bonds (e.g., in ATP), as can be seen in Figure 52.

Organic compounds containing phosphorus, especially organophosphonates, are important building blocks in organic synthesis. Moreover, organophosphorus compounds possess high biological activity, and can be used in agriculture as pesticides and as plant growth regulators. Some organophosphorus compounds are also employed as antibiotics, enzyme inhibitors, antiviral and anticancer drugs (Albrecht 2010). There are recent reviews considering different aspects of 
organophosphorus biotransformation (Matsuda 2007, Kolodiazhnyi 2012, Kolodiazhnyi et al. 2014, Żymańczyk-Duda and Klimek-Ochab 2012).

\section{OXIDOREDUCTASES}

Bialaphos is a very interesting and rare case of natural organophosphorus compound in which a phosphorus atom is directly attached to carbon (C-P bond). Bialaphosis an antibiotic named $\gamma$-(hydroxymethylphosphinyl)-L- $\alpha$-aminobutyrylL-alanyl-L-alanine (Figure 53). This antibiotic was first isolated from Streptomyces viridochromogenes strains (Baye et al. 1972) and Seto et al. (1982, $1983 \mathrm{a}, \mathrm{b})$ studied its biosynthesis, observing the formation of phosphinic acid derivatives at an early stage of the biosynthesis, which indicated the reduction of the phosphorus. The phosphate reduction precedes the C-P bond formation and results in the formation of a phosphinoenolpyruvic acid, which therefore rearrange to other metabolites (Seto et al. 1982, 1983a, b). The mechanism of the phosphate reduction involves the Pyrococcus horikoshii protease (Zhan et al. 2011) as proposed by the authors (Metcalf and Donk 2009).

Other organophosphorus compounds can be found in different natural products and used in medicine and agriculture (Seto and Kuzuyama 1999). The biosynthesis of these compounds and other relevant studies are described elsewhere (Allen and Wang 2014, Cicchillo et al. 2009, Ju et al. 2014, Kim et al. 2012, Nair and van der Donk 2011, Wu et al. 2014).

\section{HYDROLASES}

An organophophorus insecticide, Crotoxyphos was hydrolyzed by a partially purified and isolated enzyme from clay loam, (Getzin and Satyanarayana 1979) Figure 54. The authors also observed that this enzyme can be found in soil as an extracelluar entity.

Bialaphos, the natural product used in oxidoreductase-type enzyme studies, was also a matter of study for hydrolase-like enzymes. In this case, Natchev et al. (1988b) described the use of a

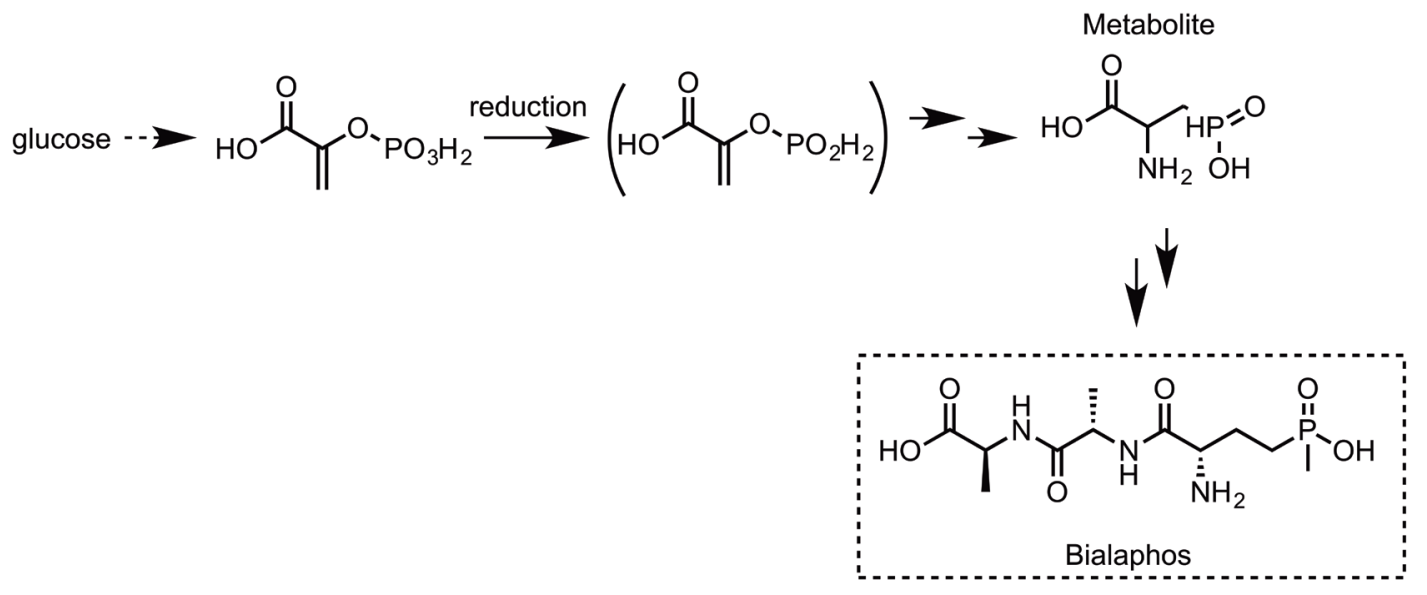

Figure 53 - Bialaphos biosynthesis.

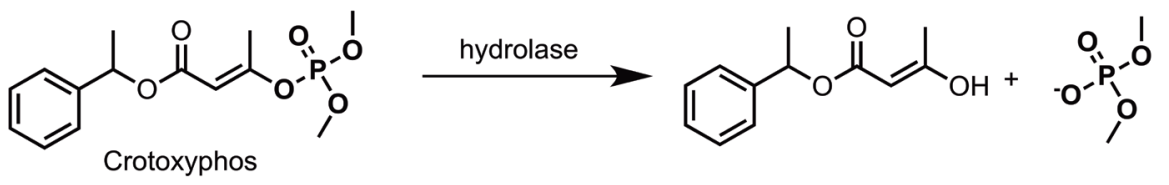

Figure 54 - Crotoxyphos degradation by hydrolases. 
phosphodiesterase I (Natchev 1988a) to hydrolyze a P-ester bond from L-phosphinothricin.

The biodegradation mechanisms of organophosphorus compounds were reviewed by Jokanovic (2001), while the depletion of pesticides by microsomes was studied by Jauregui et al. (2003). It is evident that in the detoxification of organophosphorus compounds, hydrolase-type enzymes are involved. Therefore, hydrolysis reactions such as the one describing isomers of $O$-hexyl $O$-2,5-dichlorophenyl phosphoramidate was studied by Monroy-Noyola and Sogorb (2007). All serum species, hen, rat and rabbit, were able to hydrolyze this substrate. In this report, the authors concluded that the toxic effects are dependent on the isomer that survives the hydrolysis and, in this case, $(S)$-enantiomer is the fastest one to be hydrolyzed.

\section{SILICON}

Silicon is the second most abundant element in the Earth's crust, losing in abundance only to oxygen. By comparison, carbon is not even between the ten most abundant elements in this category. Although free forms of silicon do not exist in nature, the element can be found in minerals such as silica and metallic silicates. Organosilicon compounds (C-Si bond) do not exist in nature and, therefore, all known forms of silicon-containing organic compounds are synthetic (Patai and Rappoport 1989).

Organic synthesis of silicon compounds is under continuous development. Among the most popular reactions involving organosilicon compounds, it is possible to highlight their use as protecting groups, (Crouch 2013, Kocienski 2005) in Peterson olefination, (Peterson 1968) in hydrosilylation of alkenes and alkynes, (Itami et al. 2002, Molander and Retsch 1995, Sabourault et al. 2002) in Brook rearrangement, (Brook 1974, Moser 2001) in Tamao-Kumada-Fleming oxidations

(Fleming et al. 1984, Tamao et al. 1983a, b) and in Hiyama-Denmark type palladium-catalyzed crosscouplings. (Frampton and Zelisko 2009, Gordillo et al. 2013, Tacke et al. 1983)

Some contributions regarding biocatalysis of organosilicon compounds have been published, using mainly hydrolases as biocatalysts, with few applications of enzymes from other classes.

\section{HYDROLASES}

Although the first biocatalyzed reactions of organosilicon compounds have been achieved by using oxidoreductases, a broadening scope was accomplished by using hydrolases as biocatalysts.

In biotransformations involving hydrolases, the reactions are focused in siloxane bond formations and transetherifications/transesterification of silyl ethers.

Investigations about the ability of hydrolases to perform siloxane bond formation started by condensation reaction of a silanol and combined hydrolysis-condensation reactions of silyl ether, Figure 55 (Bassindale et al. 2003).

After a screening of hydrolases and solvents for condensation reaction, best result for $\mathrm{Si}-\mathrm{O}-\mathrm{Si}$ bond formation from trimethylsilanol was achieved by using trypsin as biocatalyst and Tris- $\mathrm{HCl}$ buffer, Figure 55a. In the reaction without enzyme only traces of siloxane were formed.

(a)

2

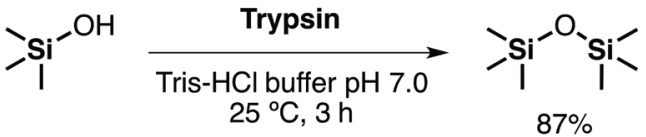

(b)

2

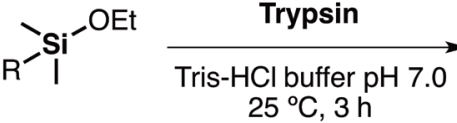

Figure 55 - Trypsin-catalyzed siloxane bond formation. 
2

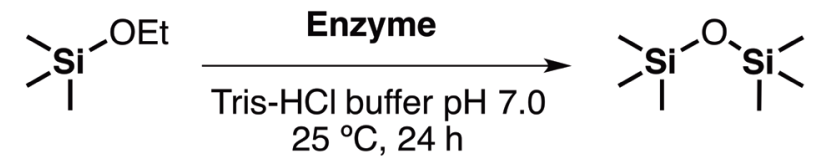

Figure 56 - Enzyme-catalyzed siloxane bond formation.
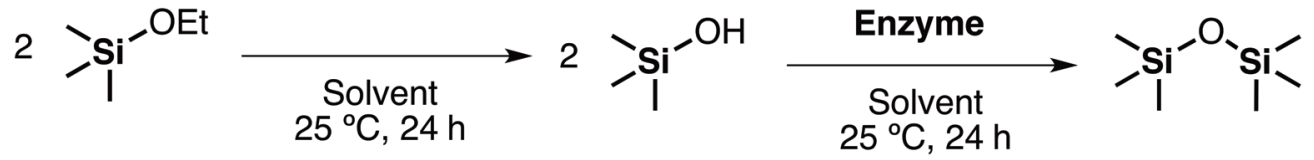

Figure 57 - Screening of enzymes for siloxane bond formation in aqueous or organic solvent media.

Interestingly, for silyl ethers, siloxane bond formation by combined hydrolysiscondensation reactions is only possible when trimethylethoxysilane (Figure 55b, R $=\mathrm{Me}$ ) was used. For phenyldimethylethoxysilane (Figure 55b, $\mathrm{R}=\mathrm{Ph}$ ), corresponding siloxane was obtained in only $2 \%$ yield and phenyldimethylsilanol was the major product ( $98 \%$ yield). These results indicate that trypsin active site presents selectivity towards condensation reaction.

Later on, a work by Maraite et al. questioned whether hydrolysis of trimethylethoxysilane has been promoted by enzymatic catalysis or by the aqueous medium (Maraite et al. 2009). Performing reactions in similar conditions as desribed by Brandstadt et al. (2003), they have found evidences that the hydrolysis of silyl ether was not being accomplished by a trypsin-catalyzed reaction, but by the buffered medium instead. In this work, other silyl ethers were used as substrates in enzymatic hydrolysis experiments, but there was no evidence of enzymatic activity in hydrolyzing such substrates.

Abbate et al. (2010) suggested that differences in substrate and enzyme concentrations and even different analytical methods could possibly explain those controversial results. In this behalf, they carried out an extensive study using biocatalytic conditions to break $\mathrm{Si}-\mathrm{O}$ bonds in trimethylethoxysilane, and then make a siloxane bond, Figure 56 (Abbate et al. 2010).
In $24 \mathrm{~h}$ reactions, although control experiments (reactions without enzyme) have been shown that the hydrolysis in fact is promoted by the buffered medium - and then enzymatic hydrolysis could not be differentiated from chemical hydrolysis in reactions with the presence of an enzyme source the authors were able to prove significant siloxane bond formation is only possible in enzymecontaining reactions. New enzymes were found to catalyze $\mathrm{Si}-\mathrm{O}-\mathrm{Si}$ bond formations, such as Rhizopus oryzae lipase (ROL) and four different phytase enzymes. A large screening of enzymes was performed for reactions in both aqueous and tert-butanol media, Figure 57.

Over 90 enzymes were tested and six enzymes were found to catalyze siloxane bond formation in aqueous solvent (Tris-HCl buffer $\mathrm{pH}$ 7.0) in yields above 20\%: Aspergillus ficuum phytase (56.7\%), Aspergillus niger phytase (31.4\%), chicken egg white lysozyme (23.6\%), porcine gastric mucosa pepsin (22.7\%), Rhizopus oryzae lipase (ROL) $(61.9 \%)$ and two types of bovine pancreatic trypsin (79.3 and 98\%). Reactions in terc-butanol seemed to proceed in a slow way when compared to those in buffer, and the yields were always lower than reactions in aqueous medium. In this work, a mechanism for hydrolase-catalyzed silanol condensation to produce siloxane was proposed, Figure 58.

A possible mechanism involving serinehistidine-aspartic acid triad was proposed. In this 


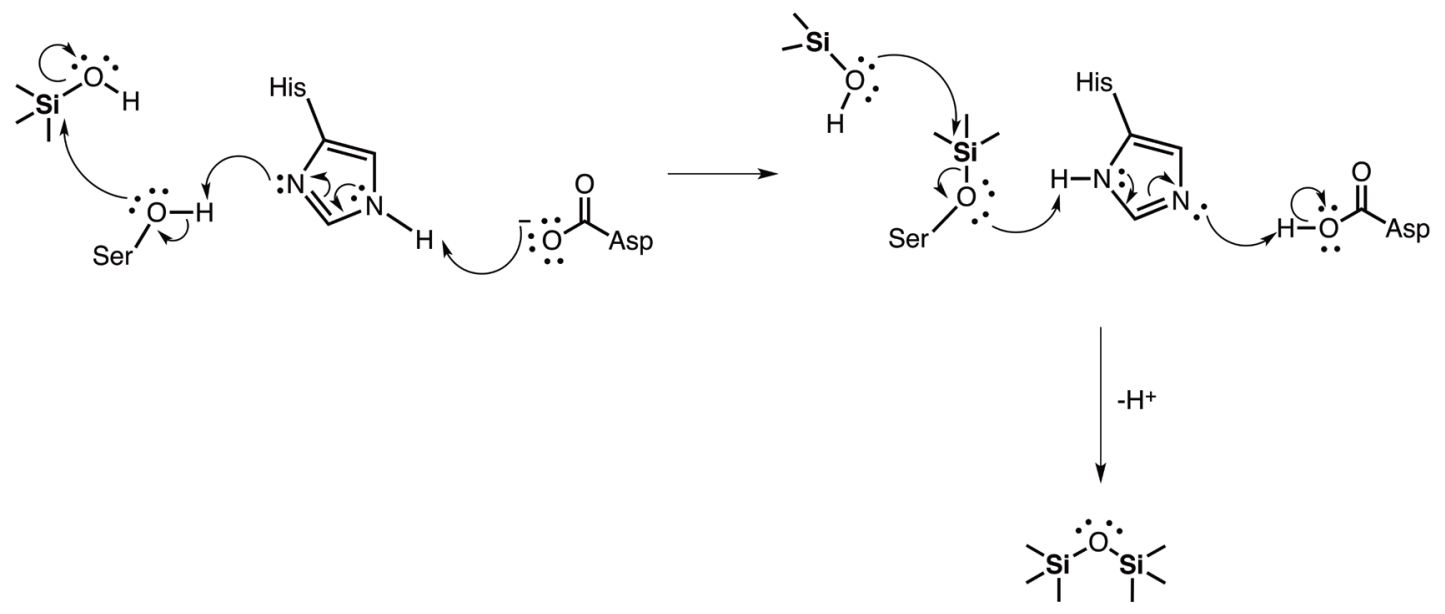

Figure 58 - A proposed mechanism for hydrolase-catalyzed silanol condensation.

(a)

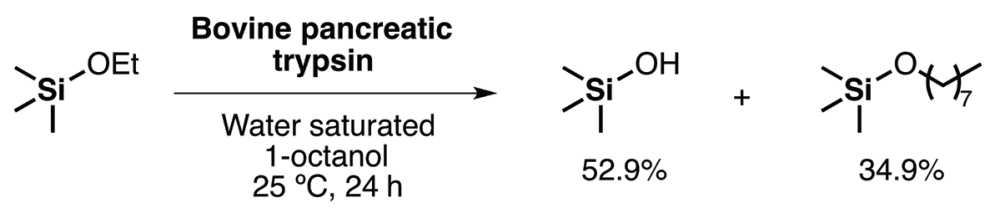

(b)

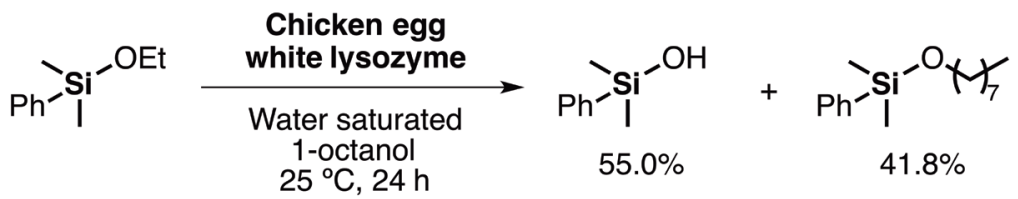

Figure 59 - Enzyme-catalyzed transetherification and/or alcohol-silanol condensation.

proposal, serine residue attacks silicon atom of silanol, producing a silylated serine that reacts with another silanol molecule to form siloxane.

All these previous contributions were important to develop a strategy to perform enzymatic transetherifications and/or alcoholsilanol condensations, Figure 59 (Abbate et al. 2013).

After a screening of enzymes, bovine pancreatic trypsin (BPT) and chicken egg white lysozyme (CEWL) were found to be the best biocatalysts to convert trimethylethoxysilane and phenyldimethylethoxysilane, respectively, into their silyl ethers analogues. Reaction of trimethylethoxysilane (Figure 59a) catalyzed by BPT afforded trimethylsilanol in $52.9 \%$ yield and trimethyloctoxysilane in $34.9 \%$ yield. For phenyldimethylethoxysilane, the reaction catalyzed by CEWL (Figure 59b) produced phenyldimethylsilanol in $55.0 \%$ and phenyldimethyloctoxysilane in $41.8 \%$. Interestingly, by using tert-butanol instead 1-octanol did not afford tert-butoxy silyl ethers. However, authors did not prove in unambiguous way, whether reaction was occurring by transetherification, alcohol-silanol condensation or both pathways.

Silyl ethers were used by Therisod as substrates for lipase-catalyzed transesterification/ 


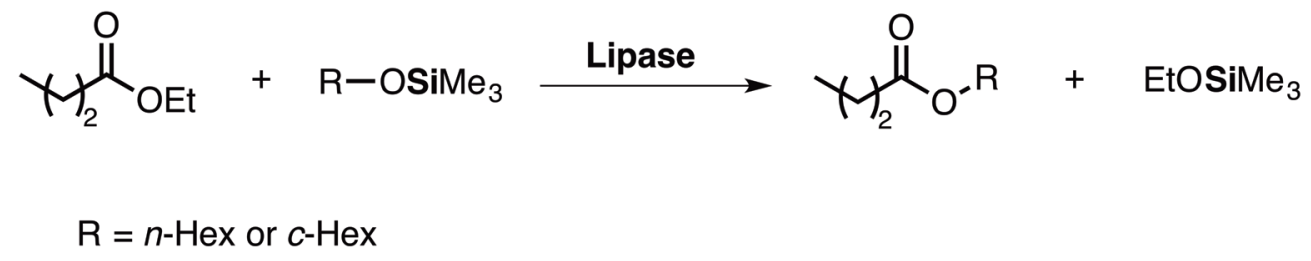

Figure 60 - Lipase-catalyzed transesterification/transetherification reactions.

transetherification reactions, Figure 60 (Therisod 1989).

For reaction in which $\mathrm{R}=n$-Hexyl, enzyme PPL led to the best results and initial rate reaction was $4.7 \mathrm{mmol} \mathrm{L}^{-1} \mathrm{~h}^{-1}$. When $\mathrm{R}=c$-Hex and enzyme CVL were used, a initial rate reaction was $0.7 \mathrm{mmol}$ $\mathrm{L}^{-1} \mathrm{~h}^{-1}$. Due to the low rate reaction, and comparing with free alcohol transesterification, authors concluded that silicon compounds probably were not suitable substrates to this type of transformation.

\section{CONCLUSIONS}

All examples described in this review certainly demonstrate that biocatalysis is a powerful tool to obtain a vast range of heteroatom-containing compounds. Some of these examples even include classes of compounds that are known to be enzymatic inhibitors, such as organoboron and organoselenium, evidencing the broadness of substrates that enzymes can act as biocatalyst.

From all the molecules discussed herein, organosulfur molecules were the mostly studied so far, using biotransformations for almost 70 years. A good example is observed in this class of compounds, since even if essentially the focus of organosulfur biotransformation rounded about the oxidation of a sulfide to its sulfoxide, other reactions, such as reductions were also performed using different microorganisms and enzymes and the same trend can be observed for the other heteroatom-containing molecules.

The studies on biotransformation of heteroatom-containing molecules have an important contribution to the knowledge of enzyme mechanisms and even enzyme active sites. Considerable contributions have been performed using specially oxidoreductases for the transformation of heteroatom in hetero-organic molecules. In fact, this indicates that there are still several open areas of study with heteroatomconatining molecules, due to the almost unlimited number of enzymes found in nature.

\section{ACKNOWLEDGMENTS}

The authors are grateful to the Conselho Nacional de Desenvolvimento Científico e Tecnológico $(\mathrm{CNPq})$ and the Fundação de Amparo à Pesquisa do Estado de São Paulo (FAPESP) for financial support (FAPESP).

\section{REFERENCES}

ABBATE V, BASSINDALE AR, BRANDSTADT, KF, LAWSON R AND TAYLOR PG. 2010. Enzyme mediated silicon-oxygen bond formation; the use of Rhizopus oryzae lipase, lysozyme and phytase under mild conditions. Dalton Trans 39: 9361-9368.

ABBATE V, BRANDSTADT KF, TAYLOR PG AND BASSINDALE AR. 2013. Enzyme-Catalyzed Transetherification of Alkoxysilanes. Catalysts 3: 27-35.

ABO M, OKUBO A AND YAMAZAKI S. 1997. Preparative asymmetric deoxygenation of alkyl aryl sulfoxides by Rhodobacter sphaeroides f.sp. denitrificans. Tetrahedron: Asymm 8(3): 345-348.

ABO M, TACHIBANA M, OKUBO A AND YAMAZAKI S. 1995. Enantioselective Deoxygenation of Alkyl Aryl Sulfoxides by DMSO Reductase from Rhodobacter sphaeroides f.s. denitrificans. Bioorgan Med Chem 3(2): 109-112.

ABUSHANAB E, REED D, SUZUKI F AND SIH CJ. 1978. Stereospecific microbial oxidation of thioethers to sulfoxides. Application to the synthesis of R-Mevalonolactone. Tetrahedron Lett 19(37): 3415-3418. 
ADAM W, HECKEL F, SAHA-MÖLLER CR, TAUPP M, MEYER JM AND SCHREIER P. 2005. Opposite Enantioselectivities of Two Phenotypically and Genotypically Similar Strains of Pseudomonas frederiksbergensis in Bacterial Whole-Cell Sulfoxidation. Appl Environ Microb 71(4):2199-2202.

ADAM W, HECKEL F, SAHA-MÖLLER CR, TAUPP M AND SCHREIER P. 2004. A highly enantioselective biocatalytic sulfoxidation by the topsoil bacterium Pseudomonas frederiksbergensis. Tetrahedron: Asymm 15: 983-985.

ALBRECHT Ł, ALBRECHT A, KRAWCZYK H AND JØRGENSEN K. 2010. Organocatalytic Asymmetric Synthesis of Organophosphorus Compounds. Chem Eur J 16: 28-48.

ALLEN KD AND WANG SC. 2014. Spectroscopic characterization and mechanistic investigation of P-methyl transfer by a radical SAM enzyme from the marine bacterium Shewanella denitrificans OS217. Biochim Biophys Acta 1844: 2135-2144.

ALPHAND V AND WOHLGEMUTH R. 2010. Applications of Baeyer-Villiger Monooxygenases in Organic Synthesis. Curr Org Chem 14: 1928-1965.

ALWEDI E, ZAKHAROV LN AND BLAKEMORE PR. 2014. Chain Extension of Boronic Esters with Lithiooxiranes Generated by Sulfoxide-Metal Exchange Stereocontrolled Access to $2^{\circ} / 2^{\circ}, 2^{\circ} / 3^{\circ}$, and $3^{\circ} / 3^{\circ}$ Vicinal Diols and Related Compounds. Eur J Org Chem 30: 66436648.

ANDRADE LH, PEDROZO EC, LEITE HG AND BRONDANI PB. 2011. Oxidation of organoselenium compounds. A study of chemoselectivity of phenylacetone monooxygenase. J Mol Catal B: Enzym 73: 63-66.

ANOBOM CD, PINHEIRO AS, DE-ANDRADE RA, AGUIEIRAS EC, ANDRADE GC, MOURA MV, ALMEIDA RV AND FREIRE DM. 2014. From Structure to Catalysis: Recent Developments in the Biotechnological Applications of Lipases. BioMed Res Int 2014: 684506.

APPLEGATE GA AND BERKOWITZ DB. 2015. Exploiting Enzymatic Dynamic ReductiveKinetic Resolution (DYRKR) in Stereocontrolled Synthesis. Adv Synth Catal 357: 1619-1632.

AURET BJ, BOYD DR, BREEN F, GREENE RME AND ROBINSON PM. 1981. Stereoselective Enzyme-catalysed Oxidation-Reduction Reactions of Thioacetals-Thioacetal Sulphoxides by Fungi. J Chem Soc Perkin Trans 1(3): 930933.

AURET BJ, BOYD DR AND HENBEST HB. 1966. A Range of Stereoselectivity in the Microbiological Oxidation of Thioethers to Sulphoxide. Chem Commun 3: 66-67.

AURET BJ, BOYD DR, HENBEST HB AND ROSS S. 1968. Stereoselectivity in the Oxidation of Thioethers to Sulphoxides Presence of Aspergillus niger. J Chem Soc C: $2371-2374$.
AURET BJ, BOYD DR, HENBEST HB AND WATSON CG. 1973. Monooxygenase-Catalysed Metabolism of Thioethers and Selenoethers by Fungi. Phytochemistry 12: 2609-2611.

AURET BJ, BOYD DR, HENBEST HB, WATSON CG, BALENOVIĆ K, POLAK V, JOHANIDES V AND DIVJAK S. 1974. Species-Strain dependence of Stereoselectivity in Microbial Oxidation of thioethers. Phytochemistry 13(1): 65-68.

AYALA M, ROBLEDO NR, LOPEZ-MUNGUIA A AND VAZQUEZ-DUHALT R. 2000. Substrate Specificity and Ionization Potential in Chloroperoxidase-Catalyzed Oxidation of Diesel FueL. Environ Sci Technol 34: 28042809.

BABIAK P, KYSLÍKOVÁ E, STĚPÁNEK V, VALEŠOVÁ R, PALYZOVÁ A, MAREŠOVÁ H, HÁJÍČEK J AND KYSLÍK P. 2011. Whole-cell oxidation of omeprazole sulfide to enantiopure esomeprazole with Lysinibacillus sp. B71. Bioresource Technol 102: 7621-7626.

BALDWIN JE AND ABRAHAM E. 1988. The Biosynthesis of Penicillins and Cephalosporins. Nat Prod Rep 5: 129145.

BALDWIN JE, ABRAHAM EP, ADLINGTON RM, CHAKRAVARTI B, DEROME AE, MURPHY JA, FIELD LD, GREEN NB, TING HH AND USHER JJ. 1983. Penicillin biosynthesis. Dual pathways from a modified substrate. J Chem Soc Chem Commun, p. 1317-1319.

BALDWIN JE, ADLINGTON RM, MORONEY SE, FIELD LD AND TING HH. 1984. Stepwise Ring Closure in Penicillin Biosynthesis. Initial b-Lactam Formation. J Chem Soc Chem Commun, p. 984-986.

BASSINDALE AR, BRANDSTADT KF, LANE TH AND TAYLOR PG. 2003. Enzyme-catalysed siloxane bond formation. J Inorg Biochem 96: 401-406.

BAYER E, GUGEL KH, HÄGELE K, HAGENMAIER H, JESSIPOW S, KÖNIG WA AND ZÄHNER H. 1972. Stoffwechselprodukte von Mikroorganismen. 98. Mitteilung. Phosphinothricin und PhosphinothricylAlanyl-Alanin. Helv Chim Acta 55(1): 224-239.

BEECHER J, RICHARDSON P AND WILLETTS A. 1994. Baeyer-Villiger Monooxygenase-dependent biotransformations: stereospecific heteroatom oxidations by camphor-grown Pseudomonas putida to produce chiral sulfoxides. Biotechnol Lett 16(9): 909-912.

BENOIT E, BURONFOSSE T, MORONI P, DELATOUR P AND RIVIERE JL. 1993. Stereoselective S-oxygenation of an aryl-trifluoromethyl sulfoxide to the corresponding sulfone by rat liver cytochromes P450. Biochem Pharmacol 46(12): 2337-2341.

BERGBREITER DE AND MOMONGAN M. 1992. Asymmetric synthesis of organometallic reagents using enzymatic methods. Appl Biochem Biotech 32: 55-72. 
BISAGNI S, SUMMERS B, KARA S, HATTI-KAUL R, GROGAN G, MAMO G AND HOLLMANN F. 2014. Exploring the substrate specificity and enantioselectivity of a Baeyer-Villiger monooxygenase from Dietzia sp. D5: oxidation of sulfides and aldehydes. Top Catal 57: 366375.

BOERIU CG, FRISSEN AE, BOER E, VAN KEKEM K, VAN ZOELEN DJ AND EGGEN IF. 2010. Optimized enzymatic synthesis of C-terminal peptide amides using subtilisin A from Bacillus licheniformis. J Mol Catal B: Enzym 66: 33-42.

BOLAÑOS L, LUKASZEWSKI K, BONILLA I AND BLEVINS D. 2004. Why boron? Plant Physiol Bioch 42: 907-912.

BONG YK, CLAY MD, COLLIER SJ, MIJTS B, VOGEL M, ZHANG X, ZHU J, NAZOR J, SMITH D AND SONG S. 2011. Synthesis of prazole compounds. WO 2011071982 A2.

BORNSCHEUER UT, HUISMAN GW, KAZLAUSKAS RJ, LUTZ S, MOORE JC AND ROBINS K. 2012. Engineering the third wave of biocatalysis. Nature 485: 185.

BOYD DR ET AL. 2001. Dioxygenase-catalysed mono-, diand tri-oxygenation of dialkyl sulfides and thioacetals: chemoenzymatic synthesis of enantiopure cis-diol sulfoxides. J Chem Soc Perkin Trans 1: 3288-3296.

BOYD DR ET AL. 2002. Enzyme-catalysed oxygenation and deoxygenation routes to chiral thiosulfinates. Chem Commun 14: 1452-1453.

BOYD DR ET AL. 2012. Bacterial dioxygenase- and monooxygenase-catalysed sulfoxidation of benzo[b] thiophenes. Org Biomol Chem 10: 782-790.

BOYD DR, SHARMA ND, BOYLE R, MCMURRAY BT, EVANS TA, MALONE JF, DALTON H, CHIMA J AND SHELDRAKE GN. 1993. Biotransformation of Unsaturated Heterocyclic Rings by Pseudomonas putida to Yield cis-Diols. J Chem Soc Chem Commun, p. 49-51.

BOYD DR, SHARMA ND, BRANNIGAN IN, HAUGHEY SA, MALONE JF, CLARKE DA AND DALTON H. 1996. Dioxygenase-catalysed formation of cis/trans-dihydrodiol metabolites of mono and bi-cyclic heteroarenes. Chem Commun, p. 2361-2362.

BOYD DR, SHARMA ND, GUNARATNE N, HAUGHEY SA, KENNEDY MA, MALONE JF, ALLEN CC AND DALTON H. 2003. Dioxygenase-catalysed oxidation of monosubstituted thiophenes: sulfoxidation versus dihydrodiol formation. Org Biomol Chem 1: 984-994.

BOYD DR, SHARMA ND, HAUGHEY SA, KENNEDY MA, MCMURRAY BT, SHELDRAKE GN, ALLEN CCR, DALTON H AND SPROULE K. 1998. Toluene and naphthalene dioxygenase-catalysed sulfoxidation of alkyl aryl sulfides. J Chem Soc Perkin Trans 1: 1929-1934.

BOYD DR, SHARMA ND, SHEPHERD SD, ALLENMARK SG AND ALLEN CCR. 2014. Enzyme-catalysed oxidation of 1,2-disulfides to yield chiral thiosulfinate, sulfoxide and cis-dihydrodiol metabolites. RSC Adv 4: 27607-27619.

BRANCHAUD BP AND WALSH CT. 1985. Functional group diversity in enzymic oxygenation reactions catalyzed by bacterial flavin-containing cyclohexanone oxygenase. J Am Chem Soc 107(7): 2153-2161.

BRINK HB, TUYNMAN A, DEKKER HL, HEMRIKA W, IZUMI Y, OSHIRO T, SCHOEMAKER HE AND WEVER R. 1998. Enantioselective sulfoxidation catalyzed by vanadium haloperoxidases. Inorg Chem 37: 6780-6784.

BRINK HBT, HOLLAND HL, SCHOEMAKER HE, VAN LINGEN H AND WEVER R. 1999. Probing the scope of the sulfoxidation activity of vanadium bromoperoxidase from Ascophyllum nodosum. Tetrahedron: Asymm 10: 4563-4572.

BRINK HBT, SCHOEMAKER HE AND WEVER R. 2001. Sulfoxidation mechanism of vanadium bromoperoxidase from Ascophyllum nodosum. Evidence for direct oxygen transfer catalysis. Eur J Biochem 268: 132-138.

BRODERICK JB, DUFFUS BR, DUSCHENE KS AND SHEPARD EM. 2014. Radical S-adenosylmethionine enzymes. Chem Rev 114(8): 4229-4317.

BRONDANI PB, DUDEK HM, REIS JS, FRAAIJE MW AND ANDRADE LH. 2012a. Exploiting the enantioselectivity of Baeyer-Villiger monooxygenases via boron oxidation. Tetrahedron: Asymm 23: 703-708.

BRONDANI PB, GONZALO G, FRAAIJE MW AND ANDRADE LH. 2011. Selective oxidations of organoboron compounds catalyzed by Baeyer-Villiger monooxygenases. Adv Synth Catal 353: 2169-2173.

BRONDANI PB, GUILMOTO NMAF, DUDEK HM, FRAAIJE MW AND ANDRADE LH. 2012 b. Chemoenzymatic approaches to obtain chiral-centered selenium compounds. Tetrahedron 68(51): 10431-10436.

BROOK AG. 1974. Molecular rearrangements of organosilicon compounds. Acc Chem Res 7: 77-84.

BUSTO E, GOTOR-FERNÁNDEZ V AND GOTOR V. 2010. Hydrolases: catalytically promiscuous enzymes for nonconventional reactions in organic synthesis. Chem Soc Rev 39: 4504-4523.

BUZANELLO EB, REZENDE RP, SOUSA FM, DE LIMA SILVA MARQUES E AND LOGUERCIO LL. 2014. A novel Bacillus pumilus-related strain from tropical landfarm soil is capable of rapid dibenzothiophene degradation and biodesulfurization. BMC Microbiology 14: 257-266.

BZHEZOVSKII VM, IL'CHENKO NN, CHURA MB, GORB LG AND YAGUPOL'SKII LM. 2005. An ab initio Quantum-Chemical Study of C6H5S(O)CH3 and C6H5S(O)CF3. Russ J Gen Chem 75(1): 86- 93.

BZHEZOVSKY VM, IL'CHENKO NN, KAPUSTIN EG, CHURA MB, YAGUPOLSKII LM, GORB LG AND LESZCZYNSKI J. 2004. A Nonempirical Quantum- 
Chemical Study and Natural Bond Orbital Analysis of C6H5XCY3 Species (X $=\mathrm{SO}$ or $\mathrm{SO} 2, \mathrm{Y}=\mathrm{H}$ or F). Struct Chem 15(5): 527-538.

CASIDA JE ET AL. 1975. Sulfoxidation of Thiocarbamirte Herbicides and Metabolism of Thiocarbamate Sulfoxides in Living Mice and Liver Enzyme Systems'. Pestic Biochem Phys 5: 1-11.

CHANG SW AND SHAW JF. 2009. Biocatalysis for the production of carbohydrate esters. New Biotechnol 26(34): 109-116.

CHASTEEN TG AND BENTLEY R. 2003. Biomethylation of selenium and tellurium: microorganisms and plants. Chem Rev 103(1): 1-25.

CHEN G, KAYSER MM, MIHOVILOVIC MD, MRSTIK ME, MARTINEZ CA AND STEWART JD. 1999. Asymmetric oxidations at sulfur catalyzed by engineered strains that overexpress cyclohexanone monooxygenase. New J Chem 23: 827-832.

CHEN Y, ZHUO J, ZHENG D, TIAN S AND LI Z. 2014. Stereoselective oxidation of sulfides to optically active sulfoxides with resting cells of Pseudomonas monteilii CCTCC M2013683. J Mol Catal B: Enzym 106: 100-104.

CICCHILLO RM, ZHANG H, BLODGETT JA, WHITTECK JT, LI G, NAIR SK, VAN DER DONK WA AND METCALF WW. 2009. An unusual carbon-carbon bond cleavage reaction during phosphinothricin biosynthesis. Nature 459: 871-875.

COLONNA S. 1994. Stereocontrolled organic synthesis, In: Trost B (Ed), Blackwell: London, 435 p.

COLONNA S, GAGGERO N, CARREA G AND PASTA P. 1997. A new enzymatic enantioselective synthesis of dialkyl sulfoxides catalysed by monooxygenases. Chem Commun, p. 439-440.

COLONNA S, GAGGERO N, PASTA P AND OTTOLINA G. 1996. Enantioselective oxidation of sulfides to sulfoxides catalysed by bacterial cyclohexanone monooxygenases. Chem Commun, p. 2303-2307.

COMASSETO JV AND GARIANI RA. 2009. Biotransformations on organic selenides and tellurides: synthetic applications. Tetrahedron 65: 8447-8459.

CROUCH RD. 2013. Recent advances in silyl protection of alcohols. Synthetic Commun 43: 2265-2297.

DA COSTA CE, COMASSETO JV, CRUSIUS IHS, ANDRADE LH AND PORTO ALM. 2007. Biotransformation of b-hydroxyphenyl selenides, diphenyldiselenide and benzeneseleninic acid by whole cells of Aspergillus terreus. J Mol Catal B: Enzym 45: 135-139.

DAMBORSKY J AND BREZOVSKY J. 2014. Computational tools for designing and engineering enzymes. Curr Opin Chem Biol 19: 8-16.

DANSETTE PM, BERTHO G AND MANSUY D. 2005. First evidence that cytochrome P450 may catalyze both
S-oxidation and epoxidation of thiophene derivatives. Biochem Biophys Res Commun 338: 450-455.

DAS BC ET AL. 2013. Boron chemicals in diagnosis and therapeutics. Future Med Chem 5(6): 653-676.

DEASY RE AND MAGUIRE AR. 2014. Baker's-Yeastmediated reduction of sulfur-containing compounds. Eur J Org Chem 18: 3737-3756.

DEMETRIUS L. 1998. Role of enzyme-substrate flexibility in catalytic activity: an evolutionary perspective. J Theor Biol 194: 175-194.

EATONRW AND NITTERAUER JD. 1994. Biotransformation of benzothiophene by isopropylbenzene degrading bacteria. J Bacteriol 176(13): 3992-4002.

ELLIS RJ. 1953. Cysteine biosynthesis in beet discs. Phytochemistry 2: 129-136.

FALOONA I. 2009. Sulfur processing in the marine atmospheric boundary layer: A review and critical assessment of modeling uncertainties. Atmos Environ 43: 2841-2854.

FANG JM, LIN CH, BRADSHAW CW AND WONG CH. 1995. Enzymes in organic synthesis: oxidoreductions. J Chem Soc Perkin Trans 1: 967-978.

FARWELL CC, MCINTOSH JA, HYSTER TK, WANG ZJ AND ARNOLD FH. 2014. Enantioselective imidation of sulfides via enzyme-catalyzed intermolecular nitrogen atom transfer. J Am Chem Soc 136: 8766-8771.

FEDORAK PM AND GRBIC-GALIC D. 1991. Aerobic microbial cometabolism of benzothiophene and 3-methylbenzothiophene. Appl Environ Microb 57(4): 932-940.

FEDORAK PM, PAYZANT JD, MONTGOMERY DS AND WESTLAKE DW. 1988. Microbial degradation of n-alkyl tetrahydrothiophenes found in petroleum. Appl Environ Microbiol 54: 1243-1248.

FEDORAK PM AND WESTLAKE DWS. 1983. Microbial degradation of organic sulfur compounds in Prudhoe Bay crude oil. Can J Microbiol 29: 291-296.

FEDORAK PM AND WESTLAKE DWS. 1984. Degradation of sulfur heterocycles in prudhoe bay crude oil by soil enrichments. Water Air Soil Pollut 21: 255-230.

FERNÁNDEZ I AND KHIAR N. 2003. Recent developments in the synthesis and utilization of chiral sulfoxides. Chem Rev 103: 3651-3705.

FESKO K AND GRUBER-KHADJAWI M. 2013. Biocatalytic methods for C-C bond formation. ChemCatChem 5(6): 1248-1272.

FINN KJ, CANKA $\check{R}$ P, JONES TRB AND HUDLICKY T. 2004. Enzymatic oxidation of thioanisoles: isolation and absolute configuration of metabolites. Tetrahedron: Asymm 15: 2833-2836.

FLEMING I, HENNING R AND PLAUT H. 1984. The phenyldimethylsilyl group as a masked form of the hydroxy group. J Chem Soc Chem Commun, p. 29-31. 
FORCHHAMMER K AND BOCK A. 1991. Selenocysteine synthase from Escherichia coli: analysis of the reaction sequence. J Biol Chem 266(10): 6324-6328.

FRAMPTON MB AND ZELISKO PM. 2009. Organosilicon biotechnology. Silicon 1: 147-163.

FUCHS M, TOESCH M, SCHOBER M, WUENSCH C AND FABER K. 2013. Chemoenzymatic asymmetric total synthesis of $(R)$-lasiodiplodin methylether through a sulfatase-based deracemization process. Eur J Org Chem: 356-361.

GADLER P, REITER TC, HOELSCH K, WEUSTERBOTZ D AND FABER K. 2009. Enantiocomplementary inverting sec-alkylsulfatase activity in cyano- and thiobacteria Synechococcus and Paracoccus spp.: selectivity enhancement by medium engineering. Tetrahedron: Asymm 20: 115-118.

GAI Z, YU B, WANG X, DENG Z AND XU P. 2008. Microbial transformation of benzothiophenes, with carbazole as the auxiliary substrate, by Sphingomonas sp. strain XLDN2-5. Microbiology 154: 3804-3812.

GAO WW, ZHANGA FX, ZHANG GX AND ZHOU CH. 2015. Key factors affecting the activity and stability of enzymes in ionic liquids and novel applications in biocatalysis. Biochem Eng J 99: 67-84.

GETZIN LW AND SATYANARAYANA T. 1979. Isolation of an enzyme from soil that degrades the organophosphorus insecticide, crotoxyphos. Arch Environm Contam Toxicol 8: 661-672.

GNEDENKOT BB AND RYABOV AD. 1994. Biodegradation of soluble redox polymers. 1. (0.017Ferrocene)amylose. Anal Chem 66: 2240-2244.

GONZALO G, PAZMIÑO DET, OTTOLINA G, FRAAIJE MW AND CARREA G. 2005. Oxidations catalyzed by phenylacetone monooxygenase from Thermobifida fusca. Tetrahedron: Asymm 16: 3077-3083.

GONZALO G, PAZMIÑO DET, OTTOLINA G, FRAAIJE MW AND CARREA G. 2006. 4-Hydroxyacetophenone monooxygenase from Pseudomonas fluorescens ACB as an oxidative biocatalyst in the synthesis of optically active sulfoxides. Tetrahedron: Asymm 17: 130-135.

GORDILLO A, ORTUÑO MA, LÓPEZ-MARDOMINGO C, LLEDÓS A, UJAQUE G AND DE JESÚS E. 2013. Mechanistic studies on the Pd-catalyzed vinylation of aryl halides with vinylalkoxysilanes in water: the effect of the solvent and NAOH promoter. J Am Chem Soc 135: 1374913763.

GOSWAMI P, CHINNADAYYALA SS, CHAKRABORTY M, KUMAR AK AND KAKOTI A. 2013. An overview on alcohol oxidases and their potential applications. Appl Microbiol Biotechnol 97: 4259-4275.

GOTOR V. 1999. Non-conventional hydrolase chemistry: amide and carbamate bond formation catalyzed by lipases. Bioorgan Med Chem 7(10): 2189-2197.
GUAN Z, LI LY AND HE YH. 2015. Hydrolase-catalyzed asymmetric carbon-carbon bond formation in organic synthesis. RSC Adv 5: 16801-16814.

GURRAM SP, KOLLU NR, SIVADEVUNI G AND SOLIPURAM MR. 2009. Biotransformation of albendazole by Cunninghamella blakesleeana: influence of incubation time, media, vitamins and solvents. Iran J Biotechnol 7(4): 205-215.

HANLON SP, GRAHAM DL, HOGAN PJ, HOLT RA, REEVE CD, SHAW AL AND MCEWAN AG. 1998. Asymmetric reduction of racemic sulfoxides by dimethyl sulfoxide reductases from Rhodobacter capsulatus, Escherichia coli and Proteus species. Microbiology 144: 2247-2253.

HARATAKE M, FUJIMOTO K, HIRAKAWA R, ONO M AND NAKAYAMA M. 2008. Hemoglobin-mediated selenium export from red blood cells. J Biol Inorg Chem 13: 471-479.

HARATAKE M, FUJIMOTO K, ONO M AND NAKAYAMA M. 2005. Selenium binding to human hemoglobin via selenotrisulfide. Biochim Biophys Acta 1723(1-3): 215220.

HAYES AC, LISS SN AND ALLEN DG. 2010. Growth kinetics of Hyphomicrobium and Thiobacillus spp. in mixed cultures degrading dimethyl sulfide and methanol. Appl Environ Microbiol 76(16): 5423-5431.

HERWALD S, LIU AY, ZHU BE, SEA KW, LOPEZ KM, SAZINSKY MH AND CRANE EJ 3RD. 2013. Structure and substrate specificity of the pyrococcal coenzyme a disulfide reductase/polysulfide reductase (coadr/ psr): implications for $\mathrm{s}(0)$-based respiration and sulfurdependent antioxidant system in Pyrococcus. Biochemistry 52(16): 2764-2773.

HIBI M, KAWASHIMA T, YAJIMA H, SMIRNOV SV, KODERA T, SUGIYAMA M, SHIMIZU S, YOKOZEKI K AND OGAWA J. 2013. Enzymatic synthesis of chiral amino acid sulfoxides by Fe(II)/a-ketoglutarate-dependent dioxygenase. Tetrahedron: Asymm 24: 990-994.

HICKS LM, CAHOON RE, BONNER ER, RIVARD RS, SHEFFIELD J AND JEZ JM. 2007. Thiol-based regulation of redox-active glutamatecysteine ligase from Arabidopsis thaliana. Plant Cell 19: 2653-2661.

HÖHNE M AND BORNSCHEUER UT. 2009. Biocatalytic routes to optically active amines. ChemCatChem 1: 42-51.

HOLLAND HL. 1988. Chiral sulfoxidation by biotransformation of organic sulfides. Chem Rev 88: 473485.

HOLLAND HL. 1992. Organic synthesis with oxidative enzymes. New York: Wiley-VCH Verlag GmbH, New York, USA.

HOLLAND HL. 2001. Biotransformation of organic sulfides. Nat Prod Rep 18: 171-181. 
HOLLAND HL, ALLEN LJ, CHERNISHENKO MJ, DIEZ M, KOHL A, OZOG J AND GU JX. 1997a. Side chain oxidation of aromatic compounds by fungi. 7. A rationale for sulfoxidation, benzylic hydroxylation, andolefin oxidation by Mortierella isabellina. J Mol Catal B: Enzym 3: $311-324$

HOLLAND HL, ANDREANA PR AND BROWN FM. 1999a. Biocatalytic and chemical routes to all the stereoisomers of methionine and ethionine sulfoxides. Tetrahedron: Asymm 10: 2833-2843.

HOLLAND HL, BROWN FM, LAKSHMAIAH G, LARSEN BG AND PATEL M. 1997b. Biotransformation of organic sulfides - VII. A predictive model for sulfoxidation by Helminthosporium species NRRL 4671. Tetrahedron: Asymm 8(5): 683-697.

HOLLAND HL, BROWN FM AND LARSEN BG. 1994a. Preparation of $(R)$-sulforaphane by biotransformation using Helminthosporium species NRRL 4671. Tetrahedron: Asymm 5(7): 1129-1130.

HOLLAND HL, BROWN FM AND LARSEN BG. 1994b. Biotransformation of organic sulfides-IV. Formation of chiral benzyl alkyl and phenyl alkyl sulfoxides by Helminthosporium species NRRL 4671. Bioorgan Med Chem 2(7): 647-652.

HOLLAND HL, BROWN FM, LOZADA D, MAYNE B, SZERMINSKI WR AND VAN VLIET AJ. 2002. Chloroperoxidase-catalyzed oxidation of methionine derivatives. Can J Chem 80: 633-639.

HOLLAND HL AND CARTER IM. 1983. An investigation of the biotransformation of organic selenides by fungi. Bioorg Chem 12: 1-7.

HOLLAND HL, TURNER CD, ANDREANA PR AND NGUYEN D. 1999b. Biotransformation of organic sulfides. Part 12. Conversion of heterocyclic sulfides to chiral sulfoxides by Helminthosporium sp. NRRL 4671 and Mortierella isabellina ATCC 42613. Can J Chem 77: 463-471.

HOLMLUND CE, SAX KJ, NIELSEN BE, HARTMAN RE, EVANS JÚNIOR RH AND BLANK RH. 1962. Stereospecific oxidation of a methylthio steroid to the sulfoxide by Calonectria decora. J Org Chem 27: 14681470.

HOLTMANN D, FRAAIJE MW, ARENDS IWCE, OPPERMAN DJ AND HOLLMANN F. 2014. The taming of oxygen: biocatalytic oxyfunctionalisations. Chem Commun 50: 13180-13200.

HOWELL JAS ET AL. 1996. Enzymatic generation of planar chirality in the (arene) $\mathrm{Cr}(\mathrm{CO}) 3$ series: Experimental results and modelling studies. Tetrahedron: Asymm 7: 95104.

HUANG WH, WILCOX RE AND DAVIS PJ. 2002. Comparative molecular field analysis (CoMFA) for sulfoxidation reactions in Mortierella isabellina ATCC
42613 and Helminthosporium sp. NRRL 4671. J Mol Model 8: 8-23.

HUBBARD CD AND STEIN TP. 1971. The pepsin catalysed hydrolysis of bis-P-nitrophenyl sulfite. Biochem Biophys Res Commun 45: 293-296.

HUNT CD. 1994. The biochemical effects of physiologic amounts of dietary boron in animal nutrition models. Environ Health Perspect 102: 35-43.

ITAMI K, MITSUDO K, NISHINO A AND YOSHIDA J. 2002. Metal-catalyzed hydrosilylation of alkenes and alkynes using dimethyl(pyridyl)silane. J Org Chem 67: 2645-2652.

JAUREGUI J, VALDERRAMA B, ALBORES A AND VAZQUEZ-DUHALT R. 2003. Microsomal transformation of organophosphorus pesticides by white rot fungi. Biodegradation 14: 397-406.

JOKANOVIC M. 2001. Biotransformation of organophosphorus compounds. Toxicology 166: 139-160.

JU KS, DOROGHAZI JR AND METCALF WW. 2014. Genomics-enabled discovery of phosphonate natural products and their biosynthetic pathways. J Ind Microbiol Biotechnol 41: 345-356.

KADNIKOVA EN AND KOSTIC NM. 2003. Effects of the environment on microperoxidase-11 and on its catalytic activity in oxidation of organic sulfides to sulfoxides. J Org Chem 68: 2600-2608.

KAGAN HB. 2009. Asymmetric synthesis of chiral sulfoxides, In: Toru $\mathrm{T}$ and Bolm C (Eds), Organosulfur chemistry in asymmetric synthesis. Weinheim, Germany: Wiley-VCH Verlag GmbH \& Co. KGaA.

KAYA A, KARAKAYA HC, FOMENKO DE, GLADYSHEV VN AND KOC A. 2009. Identification of a novel system for boron transport: Atr1 is a main boron exporter in yeast. Mol Cell Biol 29: 3665-3674.

KESSLER D. 2006. Enzymatic activation of sulfur for incorporation into biomolecules in prokaryotes. FEMS Microbiol Rev 30: 825-840.

KIEŁBASIŃSKI P. 2011. Biocatalysis in organosulfur chemistry. Phosphorus Sulfur 186: 1104-1118.

KIM SY, JU KS, METCALF WW, EVANS BS, KUZUYAMAT AND VAN DER DONK WA. 2012. Different biosynthetic pathways to fosfomycin in Pseudomonas syringae and Streptomyces species. Antimicrob Agents Chemother 58: 4175-4183.

KOCIENSKI PJ. 2005. Protecting Groups. Stuttgart: Georg Thieme Verlag.

KOHLS H, STEFFEN-MUNSBERG F AND HÖHNE M. 2014. Recent achievements in developing the biocatalytic toolbox for chiral amine synthesis. Curr Opin Chem Biol 19: 180-192.

KOLODIAZHNYI OI. 2012. Recent developments in the asymmetric synthesis of P-chiral phosphorus compounds. Tetrahedron: Asymm 23: 1-46. 
KOLODIAZHNYI OI, KUKHAR VP AND KOLODIAZHNA AO. 2014. Asymmetric catalysis as a method for the synthesis of chiral organophosphorus compounds. Tetrahedron: Asymm 25: 865-922.

KONC J, LEŠNIK S AND JANEŽIČ D. 2015. Modeling enzyme-ligand binding in drug discovery. J Cheminform 7: 48-56.

KONIETZNY U AND GREIGNER R. 2002. Molecular and catalytic properties of phytate-degrading enzymes (phytases). Int J Food Sci Tech 37: 791-812.

KRISHNA SH. 2002. Developments and trends in enzyme catalysis in nonconventional media. Biotechnol Adv 20: 239-267.

KROPP KG, GONCALVES JA, ANDERSSON JT AND FEDORAK PM. 1994a. Bacterial transformations of benzothiophene and methylbenzothiophenes. Environ Sci Technol 28: 1348-1356.

KROPP KG, GONCALVES JA, ANDERSSON JT AND FEDORAK PM. 1994b. Microbially Mediated Formation of Benzonaphthothiophenes from Benzo[b]thiophenes. Appl Environ Microb 60: 3624-3631.

KROPP KG, SAFTIĆ S, ANDERSSON JT AND FEDORAK PM. 1996. Transformations of six isomers of dimethylbenzothiophene by three Pseudomonas strains. Biodegradation 7: 203-221.

KUIPER GG, KLOOTWIJK W AND VISSER TJ. 2003. Substitution of cysteine for selenocysteine in the catalytic center of type III iodothyronine deiodinase reduces catalytic efficiency and alters substrate preference. Endocrinology 144: 2505-2513.

LATHAM JR JA, BRANCHAUD BP, CHEN YCJ AND WALSH C. 1986. Allylic and propargylic phenyl selenide oxygenation by cyclohexanone oxygenase: $[2,3]$-sigmatropic rearrangement of the enzyme-generated selenoxide. J Chem Soc Chem Commun, p. 528-530.

LEGROS J, DEHLI JR AND BOLM C. 2005. Applications of catalytic asymmetric sulfide oxidations to the syntheses of biologically active sulfoxides. Adv Synth Catal 347: 19-31.

LEISCH H, MORLEY K AND LAU PC. 2011. BaeyerVilliger monooxygenases: more than just green chemistry. Chem Rev 111: 4165-4222.

LIEDERER BM AND BORCHARDT RT. 2006. Enzymes involved in the bioconversion ofester-based prodrugs. J Pharm Sci 95: 1177-1195.

LILLIG CH AND BERNDT C. 2013. Glutaredoxins in thiol/ disulfide exchange. Antioxid Redox Signal 18: 1654-1665.

LINDBÄCK E, DAWAIGHER S AND WÄRNMARK K. 2014. Substrate-selective catalysis. Chem Eur J 20: 1343213482.

LIU H, LI X, QIN F AND HUANG K. 2014. Selenium suppresses oxidative-stress-enhanced vascular smooth muscle cell calcification by inhibiting the activation of the
PI3K/AKT and ERK signaling pathways and endoplasmic reticulum stress. J Biol Inorg Chem 19: 375-388.

LOOMIS WD AND DURST RW. 1992. Chemistry and biology of boron. Biofactors 3: 229-239.

LOU FW, LIU BK, WU Q, LV DS AND LIN XF. 2008. Candida antarctica lipase B (CAL-B)-catalyzed carbonsulfur bond addition and controllable selectivity in organic media. Adv Synth Catal 350: 1959-1962.

LOVATT CJ. 1985. Evolution of Xylem Resulted in Requirement for Boron in the Apical Meristems of Vascular Plants. New Phytol 99: 509-522.

LU YB, YANG LT, LI Y, XU J, LIAO TT, CHEN YB AND CHEN LS. 2014. Effects of boron deficiency on major metabolites, key enzymes and gas exchange in leaves and roots of Citrus sinensis seedlings. Tree Physiol 34: 608618.

MAATHUIS FJ. 2009. Physiological functions of mineral macronutrients. Curr Opin Plant Biol 12: 250-258.

MADALINSKA L, KWIATKOWSKA M, CIERPIAŁ T AND KIEŁBASIŃSKI P. 2012. Investigations on enzyme catalytic promiscuity: The first attempts at a hydrolytic enzyme-promoted conjugate addition of nucleophiles to a,b-unsaturated sulfinyl acceptors. J Mol Catal B: Enzym 81: 25-30.

MARAITE A, ANSORGE-SCHUMACHERA MB, GANCHEGUI B, LEITNER W AND GROGAN G. 2009. On the biocatalytic cleavage of silicon-oxygen bonds: A substrate structural approach to investigating the cleavage of protecting group silyl ethers by serine-triad hydrolases. J Mol Catal B: Enzym 56: 24-48.

MASCOTTI ML, ORDENAA, BISOGNOFR, DE GONZALO G AND KURINA-SANZ M. 2012. Aspergillus genus as a source of new catalysts for sulfide oxidation. J Mol Catal B: Enzym 82: 32-36.

MATSUDA T. 2007. Future directions in biocatalysis. Amsterdam: Elsevier, 364 p.

MATSUDA T. 2013. Recent progress in biocatalysis using supercritical carbon dioxide. J Biosci Bioeng 115: 233241.

MATSUI T, DEKISHIMA Y AND UEDA M. 2014. Biotechnological production of chiral organic sulfoxides: current state and perspectives. Appl Microbiol Biotechnol 98: 7699-7706.

MAY SW AND KAISER ET. 1969. The pepsin-catalyzed hydrolysis of bis-p-nitrophenyl sulfite and its inhibition by diphenyl sulfite at pH 2. J Am Chem Soc 91: 6491-6495.

MAY SW AND KAISER ET. 1971. The $\mathrm{pH}$ dependence of the pepsin-catalyzed hydrolysis of bis-p-nitrophenyl sulfite. J Am Chem Soc 93: 5567-5572.

MAY SW AND KAISER ET. 1972. On the mechanism of the pepsin-catalyzed hydrolysis of sulfite ester. Biochemistry 11: 592-600. 
MCGRATH NAAND RAINES RT. 2011. Chemoselectivity in chemical biology: acyl transfer reactions with sulfur and selenium. Accounts Chem Res 44: 752-761.

METCALF WW AND VAN DER DONK WA. 2009. Biosynthesis of phosphonic and phosphinic acid natural products. Annu Rev Biochem 78: 65-94.

MIKOŁAJCZYK M, ŁUCZAK J, KIEŁBASIŃSKI P AND COLONNA S. 2009. Biocatalytic oxidation of thiophosphoryl compounds: a new chemo-enzymatic approach to enantiomeric insecticidal thionophosphates and their oxons. Tetrahedron: Asymm 20: 1947-1951.

MOLANDER GA AND RETSCH WH. 1995. Selective hydrosilylation of alkynes catalyzed by an organoyttrium complex. Organometallics 14: 4570-4575.

MONROY-NOYOLA A, SOGORB MA AND VILANOVA E. 2007. Stereospecific hydrolysis of a phosphoramidate as a model to understand the role of biotransformation in the neurotoxicity of chiral organophosphorus compounds. Toxicol Lett 170: 157-164.

MONTANARI F. 1965. Configurational assignment to aryl-alkyl-sulfoxides based on asymmetric synthesis. Tetrahedron Lett 38: 3367-3371.

MONTIEL C, TERRÉS E, DOMÍNGUEZ JM AND ABURTO J. 2007. Immobilization of chloroperoxidase on silicabased materials for 4,6-dimethyl dibenzothiophene oxidation. J Mol Catal B: Enzym 48: 90-98.

MOSER WH. 2001. The Brook rearrangement in tandem bond formation strategies. Tetrahedron 57: 2065-2084.

NAIR SK AND VAN DER DONK WA. 2011. Structure and mechanism of enzymes involved in biosynthesis and breakdown of the phosphonates fosfomycin, dehydrophos, and phosphinothricin. Arch Biochem Biophys 505: 13-21.

NAKAGAWA Y, KING SUN LH AND KAISER ET. 1976. Detection of covalent intermediates by nucleophile trapping in the hydrolysis of phenyl tetrahydrofurfuryl sulfite catalyzed by pepsin. J Am Chem Soc 98: 16161617.

NATCHEV IA. 1988a. Organophosphorus analogues and derivatives of the natural $\mathrm{D}$-amino carboxylic acids and peptides. I . enzymatic synthesis of D-, DL- and L-phosphinothricin and their cyclic analogues. Bull Chem Soc Jpn 61: 3699-3704.

NATCHEV IA. 1988b. Organophosphorus analogues and derivatives of the natural 1-amino carboxylic acids and peptides II. synthesis, enzyme-substrate interactions of "bialaphos" (sf-1293) and its cyclic and phosphinic amide type analogues. Bull Chem Soc Jpn 61: 3705-3709.

NIKODINOVIC-RUNIC J, COULOMBEL L, FRANCUSKI D, SHARMA ND, BOYD DR, FERRALL RM AND O'CONNOR KE. 2013. The oxidation of alkylaryl sulfides and benzo[b]thiophenes by Escherichia coli cells expressing wild-type and engineered styrene monooxygenase from Pseudomonas putida CA-3. Appl Microbiol Biotechnol 97: 4849-4858.

O'MAHONY GE, KELLY P, LAWRENCE SE AND MAGUIRE AR. 2011. Synthesis of enantioenriched sulfoxides. ARKIVOC i: 1-100.

OAE S AND OKUYAMA T. 1992. Organic sulfur chemistry: Biochemical aspects. Florida: CRC Press.

OHTA H, OKAMOTO Y AND TSUCHIHASHI GI. 1985. Microbial oxidation of alkyl aryl sulfides to the corresponding optically active sulfoxides. Agric Biol Chem 49: 671-676.

OLIVO HF, OSORIO-LOZADA A AND PEEPLES TL. 2005. Microbial oxidation/amidation of benzhydrylsulfanyl acetic acid. Synthesis of (+)-modafinil. Tetrahedron: Asymm 16: 3507-3511.

OTTOLINA G AND CARREA G. 2002. Rationalization of enzyme enantioselectivity by active-site cubic-space models. Can J Chem 80: 559-564.

OTTOLINA G, PASTA P, CARREA G, COLONNA S, DALLAVALLE S AND HOLLAND HL. 1995. A predictive active site model for the cyclohexanone monooxygenase catalyzed oxidation of sulfides to chiral sulfoxides. Tetrahedron: Asymm 6: 1375-1386.

OTTOLINA G, PASTA P, VARLEY D AND HOLLAND HL. 1996. Active site model of cyclohexanone monooxygenase. 3 . The case of benzyl sulfides bearing polar groups. Tetrahedron: Asymm 7: 3427-3430.

PAPENBROCK J, GURETZKI S AND HENNE M. 2011. Latest news about the sulfurtransferase protein family of higher plants. Amino Acids 41: 43-57.

PAPP LV, LU J, HOLMGREN A AND KHANNA KK. 2007. From selenium to selenoproteins: synthesis, identity, and their role in human health. Antioxid Redox Sign 7: 775806.

PASTA P, CARREA G, HOLLAND HL AND DALLAVALLE S. 1995. Synthesis of chiral benzyl alkyl sulfoxides by cyclohexanone monooxygenase from Acinetobacter NCIB 9871. Tetrahedron: Asymm 6: 933-936.

PATAI S AND RAPPOPORT Z. 1989. The chemistry of organic silicon compounds. New York: Wiley.

PAZMIÑO DET, WINKLER M, GLIEDER A AND FRAAIJE MW. 2010. Monooxygenases as biocatalysts: Classification, mechanistic aspects and biotechnological applications. J Biotechnol 146: 9-24.

PELLISSIER H. 2006. Use of chiral sulfoxides in asymmetric synthesis. Tetrahedron 62: 5559-5601.

PETERSON DJ. 1968. Carbonyl olefination reaction using silyl-substituted organometallic compounds. J Org Chem 33: 780-784.

PEZZOTTI F, OKRASA K AND THERISOD M. 2005. Bienzymatic synthesis of chiral heteroaryl-methylsulfoxides. Tetrahedron: Asymm 16: 2681-2683. 
PINEDO-RIVILLA C, ALEU J AND COLLADO IG. 2007. Enantiomeric oxidation of organic sulfides by the filamentous fungi Botrytis cinerea, Eutypa lata and Trichoderma viride. J Mol Catal B: Enzym 49: 18-23.

PRABHULKAR S, TIAN H, WANG X, ZHU JJ AND LI CZ. 2012. Engineered proteins: Redox properties and their applications. Antioxid Redox Sign 17: 1796-1822.

RAMADHAN SH, MATSUI T, NAKANO K AND MINAMI H. 2013. High cell density cultivation of Pseudomonas putida strain HKT554 and its application for optically active sulfoxide production. Appl Microbiol Biotechnol 97: 1903-1907.

REED AE AND VON RAGUE SCHLEYER P. 1990. Chemical bonding in hypervalent molecules. The dominance of ionic bonding and negative hyperconjugation over d-orbital participation. J Am Chem Soc 112: 1434-1445.

REETZ MT, DALIGAULT F, BRUNNER B, HINRICHS H AND DEEGE A. 2004. Directed evolution of cyclohexanone monooxygenases: enantioselective biocatalysts for the oxidation of prochiral thioethers. Angew Chem Int Ed 43: 4078-4081.

REICH H, YELM KE AND WOLLOWITZ S. 1983. Kinetics, thermodynamics and stereochemistry of the allyl sulfoxidesulfenate and selenoxide-selenenate [2,3] sigmatropic rearrangements. J Am Chem Soc 105: 2503-2504.

REID TW, STEIN TP AND FAHRNEY D. 1967. The pepsincatalyzed hydrolysis of sulfite esters. ii. resolution of alkyl phenyl sulfites. J Am Chem Soc 89: 7125-7126.

RIEBEL A, DE GONZALO G AND FRAAIJE MW. 2013. Expanding the biocatalytic toolbox of flavoprotein monooxygenases from Rhodococcus jostii RHA1. J Mol Catal B: Enzym 88: 20-25.

RIGBY JH AND SUGATHAPALA P. 1996. Lipase-mediated resolution and higher-order cycloaddition of substituted tricarbonyl ( $\eta 6$-cycloheptatriene)chromium $(0)$ complexes. Tetrahedron Lett 37: 5293-5296.

RIOZ-MARTÍNEZ A, DE GONZALO G, TORRES PAZMIÑO DE AND FRAAIJE MW. 2010. Enzymatic synthesis of novel chiral sulfoxides employing baeyervilliger monooxygenases. Eur J Org Chem 33: 6409-6416.

RIOZ-MARTÍNEZ A, KOPACZ M, DE GONZALO G, TORRES PAZMIÑO DE, GOTOR V AND FRAAIJE MW. 2011. Exploring the biocatalytic scope of a bacterial flavin-containing monooxygenase. Org Biomol Chem 9: $1337-1341$.

RYABOV AD, FIRSOVA YN, GORAL VN, RYABOVA ES, SHEVELKOVA AN, TROITSKAYA LL, DEMESCHIK TV AND SOKOLOV VI. 1998. Enantioselectivity in enzyme-catalyzed electron transfer to and from planar chiral organometallic compounds. Chem Eur J 5: 806-813.

SABOURAULT N, MIGNANI G, WAGNER A AND MIOSKOWSKI C. 2002. Platinum Oxide (PtO2): A Potent Hydrosilylation Catalyst. Org Lett 4: 2117-2119.
SAFTIET S AND FEDORAK PM. 1992. Diones, sulfoxides, and sulfones from the aerobic cometabolism of methylbenzothiophenes by Pseudomonas strain BT1. Environ Sci Technol 26: 1759-1764.

SANDRE C, AGAY D, DUCROS V, FAURE H, CRUZ C, ALONSO A, CHANCERELLE Y AND ROUSSEL AM. 2006. Kinetic changes of oxidative stress and selenium status in plasma and tissues following burn injury in selenium-deficient and selenium-supplemented rats. J Trauma 60: 627-634.

SANGAR S, PAL M, MOON LS AND JOLLY RS. 2012. A catalase-peroxidase for oxidation of b-lactams to their (R)-sulfoxides. Bioresource Technol 115: 102-110.

SCHOBER M AND FABER K. 2013. Inverting hydrolases and their use in enantioconvergent biotransformations. Trends Biotechnol 31: 468-478.

SCHOBER M, GADLER P, KNAUS T, KAYER H, BIRNERGRÜNBERGER R, GÜLLY C, MACHEROUX P, WAGNE U AND FABER K. 2011. A Stereoselective Inverting sec-Alkylsulfatase for the Deracemization of sec-Alcohols. Org Lett 13: 4296-4299.

SCHOBER M, KNAUS T, TOESCH M, MACHEROUX P, WAGNER U AND FABER K. 2012. The substrate spectrum of the inverting sec-alkylsulfatase pisal. Adv Synth Catal 354: 1737-1742.

SCHOBER M, TOESCH M, KNAUS T, STROHMEIER GA, VAN LOO B, FUCHS M, HOLLFELDER F, MACHEROUX P AND FABER K. 2013. One-pot deracemization of sec-alcohols: enantioconvergentenzymatic hydrolysis of alkyl sulfates using stereocomplementary sulfatases. Angew Chem Int Ed 52: 3277-3279.

SCHOEMAKER HE, MINK D AND WUBBOLTS MG. 2003. Dispelling the myths-biocatalysis in industrial synthesis. Science 299: 1694-1697.

SCHUT GJ, BRIDGER SL AND ADAMS MWW. 2007. Insights into the metabolism of elemental sulfur by the hyperthermophilic archaeon Pyrococcus furiosus: Characterization of a coenzyme a dependent $\mathrm{NAD}(\mathrm{P}) \mathrm{H}$ sulfur oxidoreductase. J Bacteriol 189: 4431-4441.

SELLMANN D AND SUTTER J. 1996. Challenges of biocatalysts: Modeling the reactivity of nitrogenases and other metal-sulfur oxidoreductases, In: Stiefel EI and Matsumoto K (Eds), Transition Metal Sulfur Chemistry. American Chemical Society, USA, p. 101-116.

SERVI S. 1999. Phospholipases as Synthetic Catalysts, Biocatalysis - From discovery to application, In: Fessner WD et al. (Eds), Springer Berlin Heidelberg, p. 127-158.

SETO H, IMAI S, TSURUOKA T, OGAWA H, SATOH A, SASAKI T AND OTAKE N. 1983b. Studies on the biosynthesis of bialaphos (SF-1293). Part 3. Production of phosphinic acid derivatives. MP-103, MP-104 and MP105, by a blocked mutant of Streptomyces Hycroscopicus 
SF-1293 and Their roles in the biosynthesis of bialaphos. Biochem Biophys Res Commun 111: 1008-1014.

SETO H, IMAI S, TSURUOKA T, SATOH A, KOJIMA M, INOUYE S, SASAKI T AND OTAKE N. 1982. Studies on the biosynthesis of bialaphos (SF-1293). 1. Incorporation of C-13-labeled and H-2-labeled precursors into bialaphos. J Antibiot 35: 1719-1721.

SETO H AND KUZUYAMA T. 1999. Bioactive natural products with carbon-phosphorus bonds and their biosynthesis. Nat Prod Rep 16: 589-596.

SETO H, SASAKI T, IMAI S, TSURUOKA T, OGAWA H, SATOH A, INOUYE S, NIIDA T AND OTAKE N. 1983a. Studies on the biosynthesis of bialaphos (sf-1293). 2. Isolation of the 1st natural-products with a C-P-H bond and their involvement in the C-P-C Bond Formation. J Antibiot 36: 96-98.

SEYMOUR DT, VERBEEK AG, HRUDEY SE AND FEDORAK PM. 1997. Acute toxicity and aqueous solubility of some condensed thiophenes and their microbial metabolites. Environ Toxicol Chem 16: 658665.

SHAINSKY J, BERNATH-LEVIN K, ISASCHAR-OVDAT S, GLASER F AND FISHMAN A. 2013. Protein engineering of nitrobenzene dioxygenase for enantioselective synthesis of chiral sulfoxides. Protein Eng Des Sel 26: 335-345.

SOMERS WAC, STIGTER ECA, VAN HARTINGSVELDT W AND VAN DER LUGT JP. 1999. Enantioselective oxidation of secondary alcohols at a quinohaemoprotein alcohol dehydrogenase electrode. Appl Biochem Biotech 75: 151-162.

STEIN TP AND FAHRN D. 1968. The pepsin-catalysed hydrolysis of sulphite esters. oxygen- 18 studies providing direct evidence for involvement of a carboxyl group in sulphite esterase activity. Chem Commun: 555-556.

TACKE R, KOSUB U, WAGNER SA, BERTERMANN R, SCHWARZ S, MERGET S AND GÜNTHER K. 1998. Enzymatic Transformation and liquid-chromatographic separation as methods for the preparation of the $(R)$ - and $(S)$-enantiomers of the centrochiral hydridogermanes $p$-XC6H4(H) Ge(CH2OAc) $\mathrm{CH} 2 \mathrm{OH}(\mathrm{X}=\mathrm{H}, \mathrm{F})$. Organometallics 17: 1687-1699.

TACKE R, LINOH H, STUMPF B, ABRAHAM WR, KIESLICH K AND ERNST L. 1983. Mikrobiologische Umwandlung von Silicium-Verbindungen: Enantioselektive Reduktion von Acetessigsäure(trimethylsilylalkyl)estern und deren Carba-Analoga. Z Naturforsch 38: 616-620.

TAKANO J, MIWA K AND FUJIWARA T. 2008. Boron transport mechanisms: collaboration of channels and transporters. Trends Plant Sci 13: 1360-1385.

TAMAO K, ISHIDA N AND KUMADA M. $1983 \mathrm{a}$. (Diisopropoxymethylsilyl)methyl Grignard reagent: a new, practically useful nucleophilic hydroxymethylating agent. J Org Chem 48: 2120-2122.

TAMAO K, ISHIDA N, TANAKA T AND KUMADA M. 1983b. Silafunctional compounds in organic synthesis. Part 20. Hydrogen peroxide oxidation of the siliconcarbon bond in organoalkoxysilanes. Organometallics 2: 1694-1696.

TANG J, BRACKENRIDGE I, ROBERTS SM, BEECHER J AND WILLETTS AJ. 1995. Bakers' yeast oxidation of methyl para-tolylsulfide: Synthesis of a chiral intermediate in the preparation of the mevinic acid-type hypocholestemic agents. Tetrahedron 51: 13217-13238.

THERISOD M. 1989. Organometallic substrates of enzymes: Lipase catalysed transesterifications in organic solvents via O-stannyl ethers. J Organomet Chem 361: C8-C10.

TOESCH M, SCHOBER M, BREINBAUER R AND FABER K. 2014a. Stereochemistry and mechanism of enzymatic and nonenzymatic hydrolysis of benzylic sec-sulfate esters. Eur J Org Chem 18: 3930-3934.

TOESCH M, SCHOBER M AND FABER K. 2014b. Microbial alkyl- and aryl-sulfatases: mechanism, occurrence, screening and stereoselectivities. Appl Microbiol Biotechnol 98: 1485-1496.

TORRES E AND ABURTO J. 2005. Chloroperoxidasecatalyzed oxidation of 4,6-dimethyldibenzothiophene as dimer complexes: Evidence for kinetic cooperativity. Arch Biochem Biophys 437: 224-232.

UĞUZ AC, NAZIROĞLU M, ESPINO J, BEJARANO I, GONZÁLEZ D, RODRÍGUEZ AB AND PARIENTE JA. 2009. Selenium modulates oxidative stress-induced cell apoptosis in human myeloid hl-60 cells through regulation of calcium release and caspase- 3 and -9 activities. J Membrane Biol 232: 15-23.

VAN BEEK HL, DE GONZALO G AND FRAAIJE MW. 2012. Blending Baeyer-Villiger monooxygenases: using a robust BVMO as a scaffold for creating chimeric enzymes with novel catalytic properties. Chem Commun 48: 32883290.

VAN LETTOW M, WEST CE, VAN DER MEER JW, WIERINGA FT AND SEMBA RD. 2005. Low plasma selenium concentrations, high plasma human immunodeficiency virus load and high interleukin-6 concentrations are risk factors associated with anemia in adults presenting with pulmonary tuberculosis in Zomba district, Malawi. Eur J Clin Nutr 59: 526-532.

WALLACE S AND BALSKUS EP. 2014. Opportunities for merging chemical and biological synthesis. Curr Opin Biotech 30: 1-8.

WALSH CT AND JACK CHEN YC. 1988. Enzymic BaeyerVilliger oxidations by flavin-dependent monooxygenases. Angew Chem Int Ed 27: 333-343.

WESSJOHANN LA, SCHNEIDER A, ABBAS M AND BRANDT W. 2007. Selenium in chemistry and 
biochemistry in comparison to sulfur. Biol Chem 388 : 997-1006.

WHANGER PD. 1998. Metabolism of Selenium in Humans. J Trace Elem Exp Med 11: 227-240.

WOJACZYNSKA E AND WOJACZYNSK J. 2010. Enantioselective synthesis of sulfoxides: 2000-2009. Chem Rev 110:4303-4356.

WRIGHT LD AND CRESSON EL. 1954. Biotin 1-sulfoxide I: The occurence of a previously unrecognized form of biotin in Certain Fermentation Sources. J Am Chem Soc 76: 4156-4160.

WRIGHT LD, CRESSON EL, VALIANT J, WOLF DE AND FOLKERS K. 1954a. Biotin Z-Sulfoxide. III. The Characterization of Biotin I-Sulfoxide from a Microbiological Source. J Am Chem Soc 76: 4163-4166.

WRIGHT LD, CRESSON EL, VALIANT J, WOLF DE AND FOLKERS K. 1954b. Biotin 1-sulfoxide. II: The isolation of a crystalline factor with biotin activity from Aspergillus niger culture filtrates. J Am Chem Soc 76: 4160-4163.

WU G, YUAN M, WEI L, ZHANG Y, YONGJUN L, ZHANG L AND LIU Z. 2014. Characterization of a novel coldadapted phosphinothricin $N$-acetyltransferase from the marine bacterium Rhodococcus sp. strain YM12. J Mol Catal B: Enzym 104: 23-28.

ZHAI XH, MA YH, LAI DY, ZHOU S AND CHEN ZM. 2013. Development of a whole-cell biocatalyst with NADPH regeneration system for biosulfoxidation. J Ind Microbiol Biotechnol 40: 797-803.
ZHAN D, HAN W AND FENG Y. 2011. Experimental and computational studies indicate the mutation of Glu12 to increase the thermostability of oligomeric protease from Pyrococcus horikoshii. J Mol Model 17: 1241-1249.

ZHANG JD, LI AT, YANG Y AND XU JH. 2010. Sequence analysis and heterologous expression of a new cytochrome P450 monooxygenase from Rhodococcus $\mathrm{sp}$. for asymmetric sulfoxidation. Appl Microbiol Biotechnol 85: 615-624.

ZHANG JD, LI AT, YU HL, IMANAKA T AND XU JH. 2011. Synthesis of optically pure S-sulfoxide by Escherichia coli transformant cells coexpressing the P450 monooxygenase and glucose dehydrogenase genes. J Ind Microbiol Biotechnol 38: 633-641.

ZHANG Y AND WEINER JH. 2014. A simple semiquantitative in vivo method using $\mathrm{H} 2 \mathrm{~S}$ detection to monitor sulfide metabolizing enzymes. Biotechniques 57: 208-210.

ZIEGLER DM, GRAF P, POULSEN LL, STAHL W AND SIES H. 1992. NADPH-dependent oxidation of reduced ebselen, 2-selenylbenzanilide, and of 2-(methylseleno) benzanilide catalyzed by pig liver flavin-containing monooxygenase. Chem Res Toxicol 5: 163-166.

ŻYMAŃCZYK-DUDA E AND KLIMEK-OCHAB M. 2012. Stereoselective biotransformations as an effective tool for the synthesis of chiral compounds with P-C bond - Scope and limitations of the methods. Curr Org Chem 16: 14081422 . 